\title{
Bioactive Limonoids and Triterpenoids from the Fruits of Melia azedarach
}

Min Song, ${ }^{\dagger}, \S$ Jian Zhang, $,{ }^{\ddagger}{ }^{\text {G Ging Chan }},{ }^{\dagger}$ Ying Hou,${ }^{\dagger}$ Xiu-ping Chen, ${ }^{\dagger}$ Xiao-Qi Zhang,,${ }^{\ddagger}$ WenCai Ye, ${ }^{\dagger}$ and Qing-Wen Zhang*, $\dagger$

$\dagger$ State Key Laboratory of Quality Research in Chinese Medicine, Institute of Chinese Medical Sciences, University of Macau, Macao SAR

$\ddagger$ Guangdong Provincial Engineering Research Center for Modernization of TCM, College of Pharmacy, Jinan University, Guangzhou 510632, China; 
Table S1. X-ray crystallographic data for Meliazedarine A (1)

Table S2. X-ray crystallographic data for Meliazedarine B (2)

Figure S1. X-ray ORETEP drawings of 1 and 2

Figure S2. ${ }^{13} \mathrm{C}$ NMR spectra of 1-3, 10 and 11

Figure S3. Experimental ECD spectra of 1, 3-8 in $\mathrm{MeOH}$

Figure S4. ${ }^{1} \mathrm{H}$ NMR spectrum of Meliazedarine A (1) in DMSO- $d_{6}$

Figure S5. ${ }^{13} \mathrm{C}$ NMR spectrum of Meliazedarine A (1) in DMSO- $d_{6}$

Figure S6. HSQC spectrum of Meliazedarine A (1) in DMSO- $d_{6}$

Figure S7. HMBC spectrum of Meliazedarine A (1) in DMSO- $d_{6}$

Figure S8. ${ }^{1} \mathrm{H}-{ }^{1} \mathrm{H}$ COSY spectrum of Meliazedarine A (1) in DMSO- $d_{6}$

Figure S9. ROESY spectrum of Meliazedarine A (1) in DMSO- $d_{6}$

Figure S10. (+)-HRESIMS spectrum of Meliazedarine A (1)

Figure S11. IR spectrum of Meliazedarine A (1)

Figure S12. UV spectrum of Meliazedarine A (1) in $\mathrm{CHCl}_{3}$

Figure S13. ${ }^{1} \mathrm{H}$ NMR spectrum of Meliazedarine B (2) in DMSO- $d_{6}$

Figure S14. ${ }^{13} \mathrm{C}$ NMR spectrum of Meliazedarine B (2) in DMSO- $d_{6}$

Figure S15. HSQC spectrum of Meliazedarine B (2) in DMSO- $d_{6}$

Figure S16. HMBC spectrum of Meliazedarine B (2) in DMSO- $d_{6}$ 
Figure S17. ${ }^{1} \mathrm{H}-{ }^{1} \mathrm{H}$ COSY spectrum of Meliazedarine B (2) in DMSO- $d_{6}$

Figure S18. ROESY spectrum of Meliazedarine B (2) in DMSO- $d_{6}$

Figure S19. (+)-HRESIMS spectrum of Meliazedarine B (2)

Figure S20. IR spectrum of Meliazedarine B (2)

Figure S21. UV spectrum of Meliazedarine $\mathrm{B}$ (2) in $\mathrm{CHCl}_{3}$

Figure S22. ${ }^{1} \mathrm{H}$ NMR spectrum of Meliazedarine C (3) in DMSO- $d_{6}$

Figure S23. ${ }^{13} \mathrm{C}$ NMR spectrum of Meliazedarine C (3) in DMSO- $d_{6}$

Figure S24. HSQC spectrum of Meliazedarine C (3) in DMSO- $d_{6}$

Figure S25. HMBC spectrum of Meliazedarine C (3) in DMSO- $d_{6}$

Figure S26. ${ }^{1} \mathrm{H}-{ }^{1} \mathrm{H}$ COSY spectrum of Meliazedarine C (3) in DMSO- $d_{6}$

Figure S27. ROESY spectrum of Meliazedarine C (3) in $\mathrm{CDCl}_{3}$

Figure S28. (+)-HRESIMS spectrum of Meliazedarine C (3)

Figure S29. IR spectrum of Meliazedarine C (3)

Figure S30. UV spectrum of Meliazedarine $\mathrm{C}(3)$ in $\mathrm{CHCl}_{3}$

Figure S31. ${ }^{1} \mathrm{H}$ NMR spectrum of Meliazedarine D (4) in DMSO- $d_{6}$

Figure S32. ${ }^{13} \mathrm{C}$ NMR spectrum of Meliazedarine D (4) in DMSO- $d_{6}$

Figure S33. HSQC spectrum of Meliazedarine D (4) in DMSO- $d_{6}$ 
Figure S34. HMBC spectrum of Meliazedarine D (4) in DMSO- $d_{6}$

Figure S35. ${ }^{1} \mathrm{H}-{ }^{1} \mathrm{H}$ COSY spectrum of Meliazedarine D (4) in DMSO- $d_{6}$

Figure S36. ROESY spectrum of Meliazedarine D (4) in DMSO- $d_{6}$

Figure S37. (+)-HRESIMS spectrum of Meliazedarine D (4)

Figure S38. IR spectrum of Meliazedarine D (4)

Figure S39. UV spectrum of Meliazedarine D (4) in $\mathrm{CHCl}_{3}$

Figure S40. ${ }^{1} \mathrm{H}$ NMR spectrum of Meliazedarine E (5) in DMSO- $d_{6}$

Figure S41. ${ }^{13} \mathrm{C}$ NMR spectrum of Meliazedarine E (5) in DMSO- $d_{6}$

Figure S42. HSQC spectrum of Meliazedarine E (5) in DMSO- $d_{6}$

Figure S43. HMBC spectrum of Meliazedarine E (5) in DMSO- $d_{6}$

Figure S44. ${ }^{1} \mathrm{H}-{ }^{1} \mathrm{H}$ COSY spectrum of Meliazedarine E (5) in DMSO- $d_{6}$

Figure S45. ROESY spectrum of Meliazedarine E (5) in DMSO- $d_{6}$

Figure S46. (+)-HRESIMS spectrum of Meliazedarine E (5)

Figure S47. IR spectrum of Meliazedarine E (5)

Figure S48. UV spectrum of Meliazedarine E (5) in $\mathrm{CHCl}_{3}$

Figure S49. ${ }^{1} \mathrm{H}$ NMR spectrum of Meliazedarine F (6) in DMSO- $d_{6}$

Figure S50. ${ }^{13} \mathrm{C}$ NMR spectrum of Meliazedarine F (6) in DMSO- $d_{6}$ 
Figure S51. HSQC spectrum of Meliazedarine F (6) in DMSO- $d_{6}$

Figure S52. HMBC spectrum of Meliazedarine F (6) in DMSO- $d_{6}$

Figure S53. ${ }^{1} \mathrm{H}-{ }^{1} \mathrm{H}$ COSY spectrum of Meliazedarine F (6) in DMSO- $d_{6}$

Figure S54. ROESY spectrum of Meliazedarine F (6) in DMSO- $d_{6}$

Figure S55. (+)-HRESIMS spectrum of Meliazedarine F (6)

Figure S56. IR spectrum of Meliazedarine F (6)

Figure S57. UV spectrum of Meliazedarine $\mathrm{F}(\mathbf{6})$ in $\mathrm{CHCl}_{3}$

Figure S58. ${ }^{1} \mathrm{H}$ NMR spectrum of Meliazedarine G (7) in DMSO- $d_{6}$

Figure S59. ${ }^{13} \mathrm{C}$ NMR spectrum of Meliazedarine G (7) in DMSO- $d_{6}$

Figure S60. HSQC spectrum of Meliazedarine G (7) in DMSO- $d_{6}$

Figure S61. HMBC spectrum of Meliazedarine G (7) in DMSO- $d_{6}$

Figure S62. ${ }^{1} \mathrm{H}-{ }^{1} \mathrm{H}$ COSY spectrum of Meliazedarine G (7) in DMSO- $d_{6}$

Figure S63. ROESY spectrum of Meliazedarine G (7) in DMSO- $d_{6}$

Figure S64. (+)-HRESIMS spectrum of Meliazedarine G (7)

Figure S65. IR spectrum of Meliazedarine G (7)

Figure S66. UV spectrum of Meliazedarine $\mathrm{G}$ (7) in $\mathrm{CHCl}_{3}$

Figure S67. ${ }^{1} \mathrm{H}$ NMR spectrum of Meliazedarine $\mathrm{H}(\mathbf{8})$ in DMSO- $d_{6}$ 
Figure S68. ${ }^{13} \mathrm{C}$ NMR spectrum of Meliazedarine H (8) in DMSO- $d_{6}$

Figure S69. HSQC spectrum of Meliazedarine H (8) in DMSO- $d_{6}$

Figure S70. HMBC spectrum of Meliazedarine H (8) in DMSO- $d_{6}$

Figure S71. ${ }^{1} \mathrm{H}-{ }^{1} \mathrm{H}$ COSY spectrum of Meliazedarine $\mathrm{H}(\mathbf{8})$ in DMSO- $d_{6}$

Figure S72. ROESY spectrum of Meliazedarine H (8) in DMSO- $d_{6}$

Figure S73. (+)-HRESIMS spectrum of Meliazedarine H (8)

Figure S74. IR spectrum of Meliazedarine H (8)

Figure S75. UV spectrum of Meliazedarine $\mathrm{H}(\mathbf{8})$ in $\mathrm{CHCl}_{3}$

Figure S76. ${ }^{1} \mathrm{H}$ NMR spectrum of Meliazedarine I (9) in DMSO- $d_{6}$

Figure S77. ${ }^{13} \mathrm{C}$ NMR spectrum of Meliazedarine I (9) in DMSO- $d_{6}$

Figure S78. HSQC spectrum of Meliazedarine I (9) in DMSO- $d_{6}$

Figure S79. HMBC spectrum of Meliazedarine I (9) in DMSO- $d_{6}$

Figure S80. ${ }^{1} \mathrm{H}-{ }^{1} \mathrm{H}$ COSY spectrum of Meliazedarine I (9) in DMSO- $d_{6}$

Figure S81. ROESY spectrum of Meliazedarine I (9) in DMSO- $d_{6}$

Figure S82. (+)-HRESIMS spectrum of Meliazedarine I (9)

Figure S83. IR spectrum of Meliazedarine I (9)

Figure S84. UV spectrum of Meliazedarine I (9) in $\mathrm{CHCl}_{3}$ 
Table S1. X-ray crystallographic data for Meliazedarine A (1)

\begin{tabular}{|c|c|}
\hline Identification code & Meliazedarine A \\
\hline Empirical formula & $\mathrm{C}_{37} \mathrm{H}_{50} \mathrm{O}_{11}$ \\
\hline Formula weight & 670.77 \\
\hline Temperature/K & $100.00(10)$ \\
\hline Crystal system & orthorhombic \\
\hline Space group & $\mathrm{P} 2{ }_{1} 2_{1} 2_{1}$ \\
\hline $\mathrm{a} / \AA ̊$ & $9.15490(10)$ \\
\hline $\mathrm{b} / \AA$ & $17.17110(10)$ \\
\hline $\mathrm{c} / \AA$ & $21.80800(10)$ \\
\hline$\alpha /^{\circ}$ & 90 \\
\hline$\beta /^{\circ}$ & 90 \\
\hline$\gamma /{ }^{\circ}$ & 90 \\
\hline Volume $/ \AA^{3}$ & $3428.21(5)$ \\
\hline Z & 4 \\
\hline$\rho_{\text {calc }} \mathrm{g} / \mathrm{cm}^{3}$ & 1.300 \\
\hline$\mu / \mathrm{mm}^{-1}$ & 0.782 \\
\hline $\mathrm{F}(000)$ & 1440.0 \\
\hline Crystal size $/ \mathrm{mm}^{3}$ & $0.15 \times 0.13 \times 0.12$ \\
\hline Radiation & $\mathrm{CuK} \alpha(\lambda=1.54184)$ \\
\hline \multicolumn{2}{|c|}{$2 \Theta$ range for data collection $/{ }^{\circ} 6.552$ to 147.202} \\
\hline Index ranges & $\begin{array}{l}-11 \leq \mathrm{h} \leq 9,-21 \leq \mathrm{k} \leq 21,-27 \leq 1 \\
\leq 27\end{array}$ \\
\hline Reflections collected & 39305 \\
\hline Independent reflections & $\begin{array}{l}6817\left[\mathrm{R}_{\text {int }}=0.0268, \mathrm{R}_{\text {sigma }}=\right. \\
0.0158]\end{array}$ \\
\hline Data/restraints/parameters & $6817 / 0 / 444$ \\
\hline Goodness-of-fit on $\mathrm{F}^{2}$ & 1.050 \\
\hline Final $\mathrm{R}$ indexes $[\mathrm{I}>=2 \sigma(\mathrm{I})]$ & $\mathrm{R}_{1}=0.0314, \mathrm{wR}_{2}=0.0820$ \\
\hline Final $R$ indexes [all data] & $\mathrm{R}_{1}=0.0319, \mathrm{wR}_{2}=0.0826$ \\
\hline \multicolumn{2}{|c|}{ Largest diff. peak/hole / e $\AA^{-3} 0.31 /-0.24$} \\
\hline Flack parameter & $0.01(3)$ \\
\hline
\end{tabular}


Table S2. X-ray crystallographic data for Meliazedarine B (2)

\begin{tabular}{|c|c|}
\hline Identification code & Meliazedarine B \\
\hline Empirical formula & $\mathrm{C}_{39} \mathrm{H}_{50} \mathrm{O}_{12}$ \\
\hline Formula weight & 710.79 \\
\hline Temperature/K & $100.00(10)$ \\
\hline Crystal system & orthorhombic \\
\hline Space group & $\mathrm{P} 2{ }_{1} 2_{1}{ }_{1}$ \\
\hline $\mathrm{a} / \AA$ & $13.75700(10)$ \\
\hline $\mathrm{b} / \AA$ & $15.59590(10)$ \\
\hline $\mathrm{c} / \AA ̊$ & $16.8013(2)$ \\
\hline$\alpha /^{\circ}$ & 90 \\
\hline$\beta /{ }^{\circ}$ & 90 \\
\hline$\gamma /{ }^{\circ}$ & 90 \\
\hline Volume $/ \AA^{3}$ & $3604.77(6)$ \\
\hline $\mathrm{Z}$ & 4 \\
\hline$\rho_{\text {calc }} \mathrm{g} / \mathrm{cm}^{3}$ & 1.310 \\
\hline$\mu / \mathrm{mm}^{-1}$ & 0.797 \\
\hline $\mathrm{F}(000)$ & 1520.0 \\
\hline Crystal size $/ \mathrm{mm}^{3}$ & $0.12 \times 0.11 \times 0.09$ \\
\hline Radiation & $\mathrm{CuK} \alpha(\lambda=1.54184)$ \\
\hline \multicolumn{2}{|c|}{$2 \Theta$ range for data collection $/{ }^{\circ} 7.734$ to 147.532} \\
\hline Index ranges & $-17 \leq \mathrm{h} \leq 17,-19 \leq \mathrm{k} \leq 15,-20 \leq 1 \leq 20$ \\
\hline Reflections collected & 40758 \\
\hline Independent reflections & $7211\left[\mathrm{R}_{\mathrm{int}}=0.0349, \mathrm{R}_{\text {sigma }}=0.0209\right]$ \\
\hline Data/restraints/parameters & $7211 / 0 / 472$ \\
\hline Goodness-of-fit on $\mathrm{F}^{2}$ & 1.052 \\
\hline Final $\mathrm{R}$ indexes $[\mathrm{I}>=2 \sigma(\mathrm{I})]$ & $\mathrm{R}_{1}=0.0327, \mathrm{wR}_{2}=0.0910$ \\
\hline Final $\mathrm{R}$ indexes [all data] & $\mathrm{R}_{1}=0.0347, \mathrm{wR}_{2}=0.0925$ \\
\hline \multicolumn{2}{|c|}{ Largest diff. peak/hole / e $\AA^{-3} 0.18 /-0.38$} \\
\hline Flack parameter & $0.00(5)$ \\
\hline
\end{tabular}




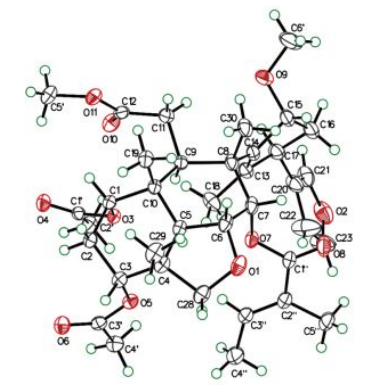

1

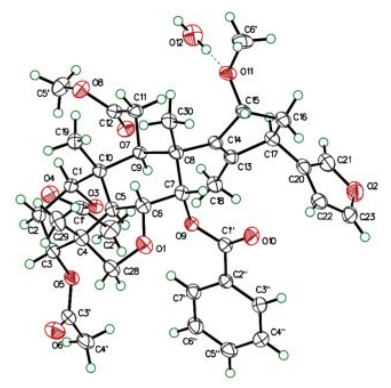

2

Figure S1 X-ray ORETEP drawings of 1 and $\mathbf{2}$

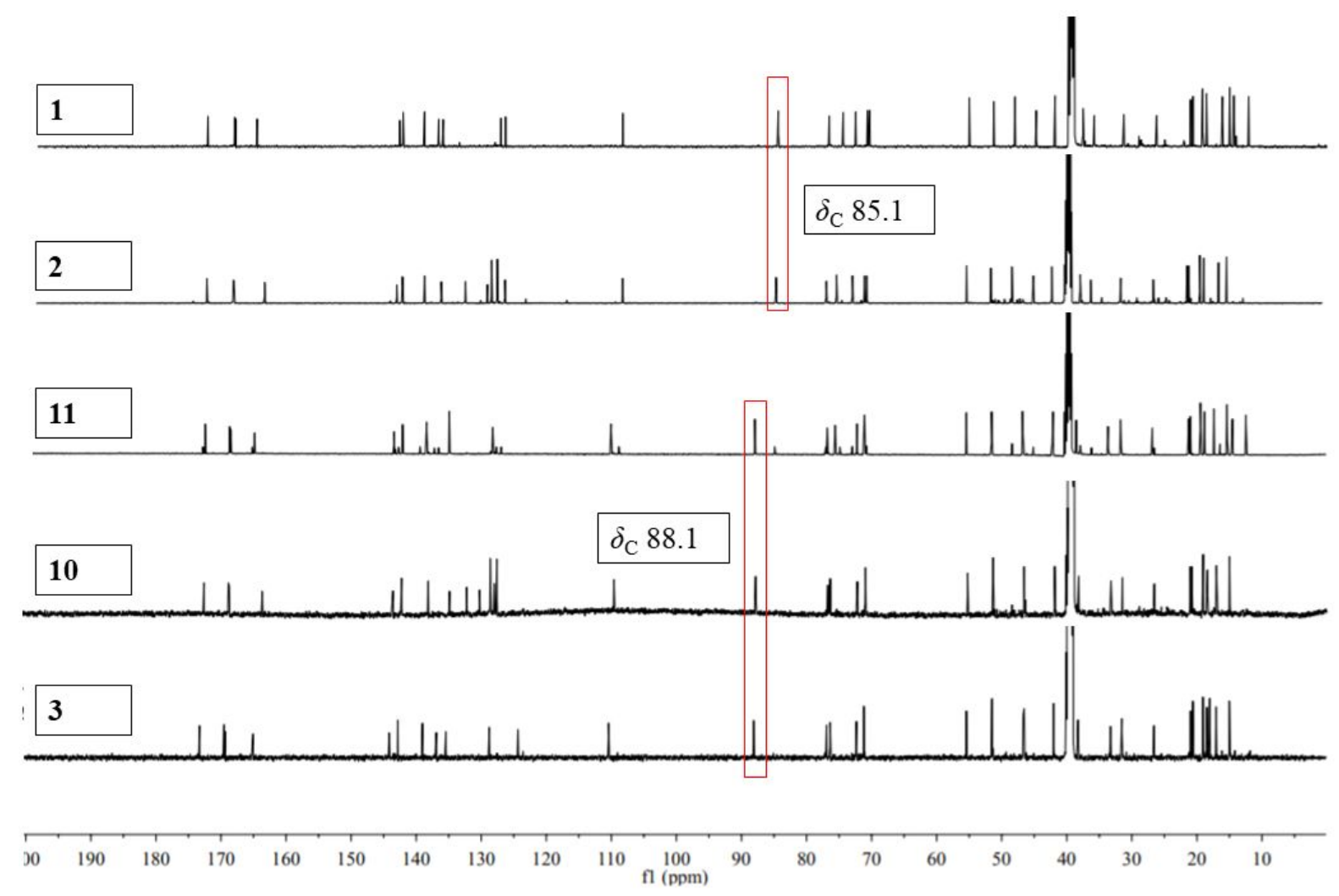

Figure S2. ${ }^{13} \mathrm{C}$ NMR spectra of 1-3, 10 and 11
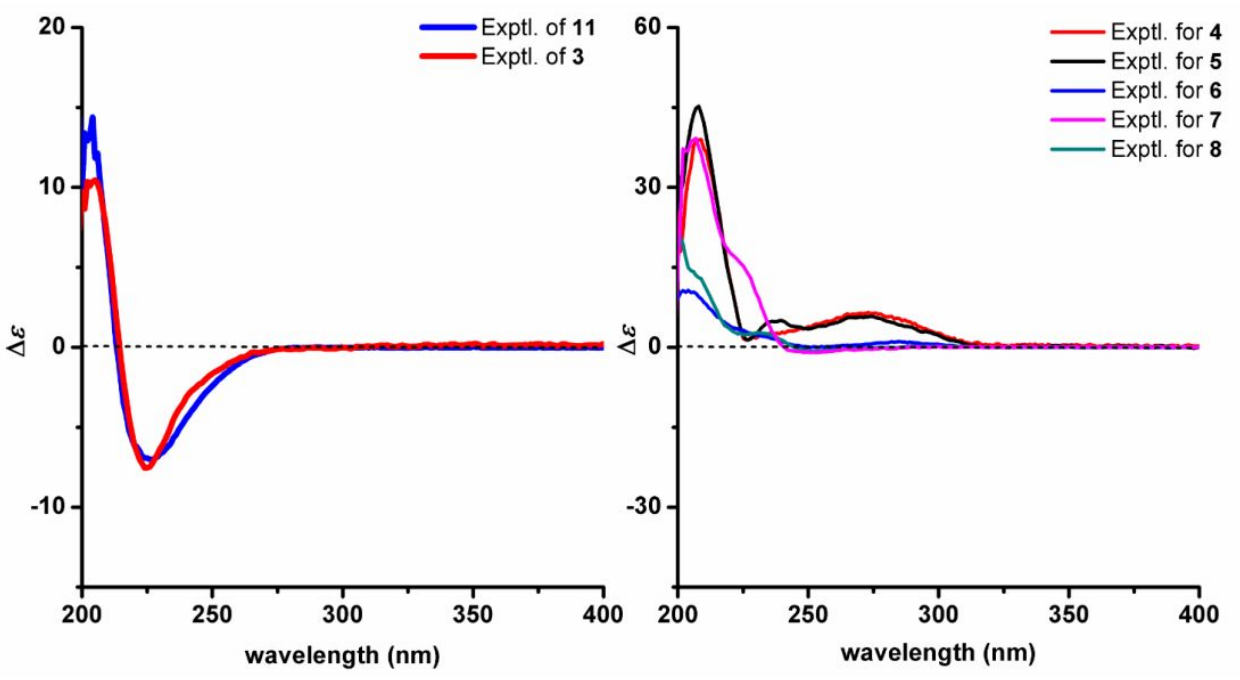

Figure S3. Experimental ECD spectra of 1, 3-8 in $\mathrm{MeOH}$ 


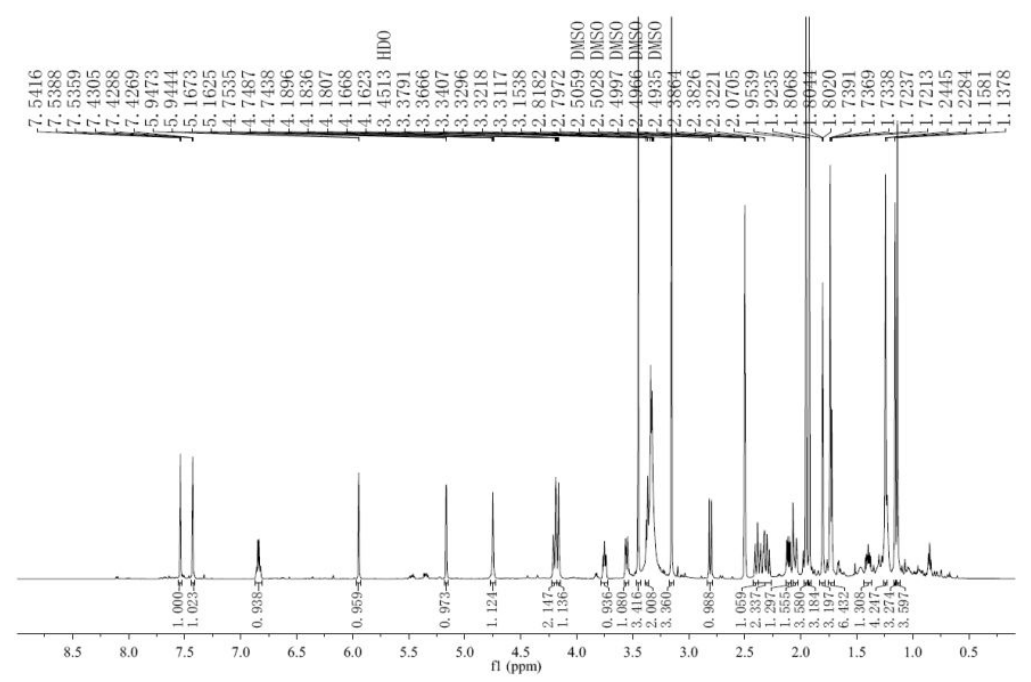

Figure S4. ${ }^{1} \mathrm{H}$ NMR spectrum of Meliazedarine A (1) in DMSO- $d_{6}$

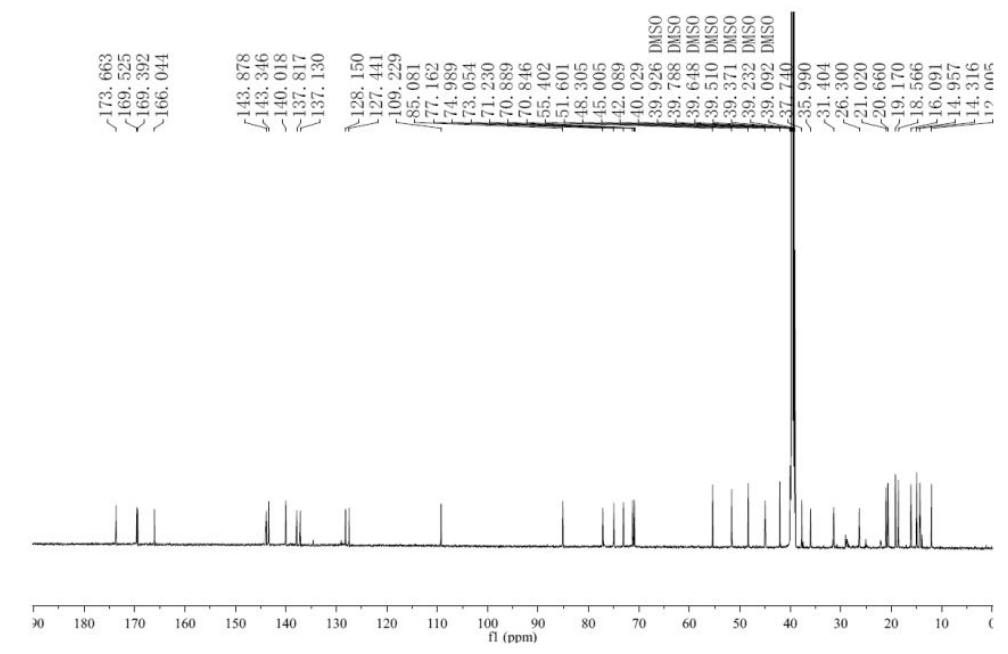

Figure S5. ${ }^{13} \mathrm{C}$ NMR spectrum of Meliazedarine A (1) in DMSO- $d_{6}$

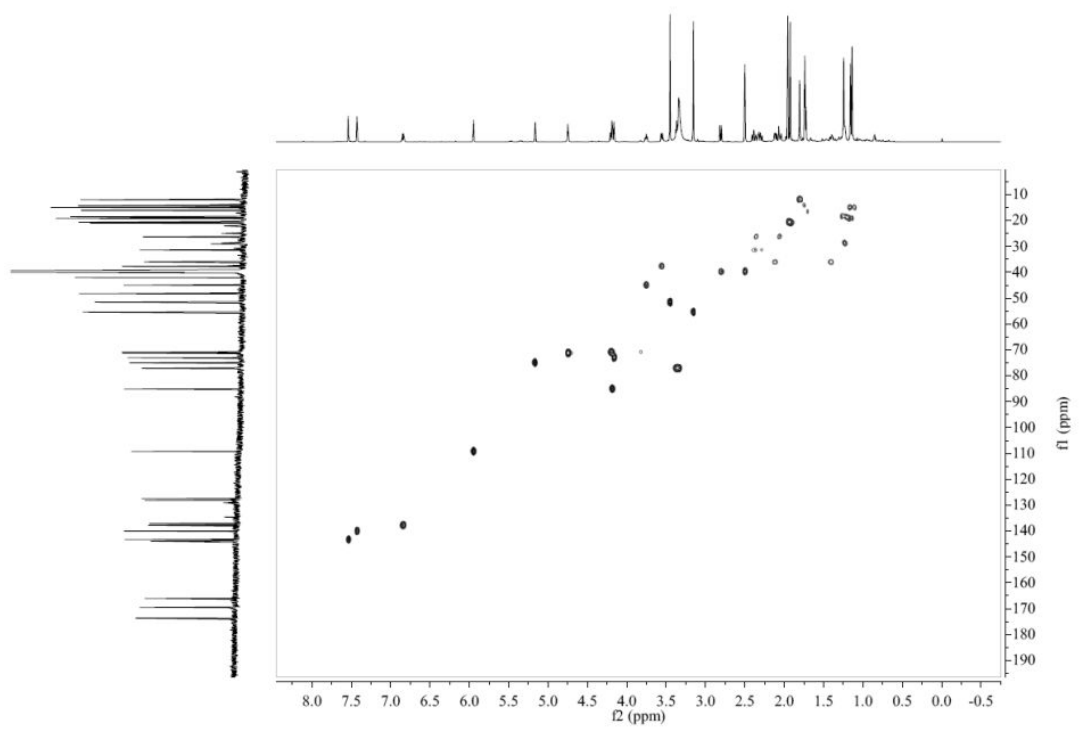

Figure S6. HSQC spectrum of Meliazedarine A (1) in DMSO- $d_{6}$ $10 / 36$ 


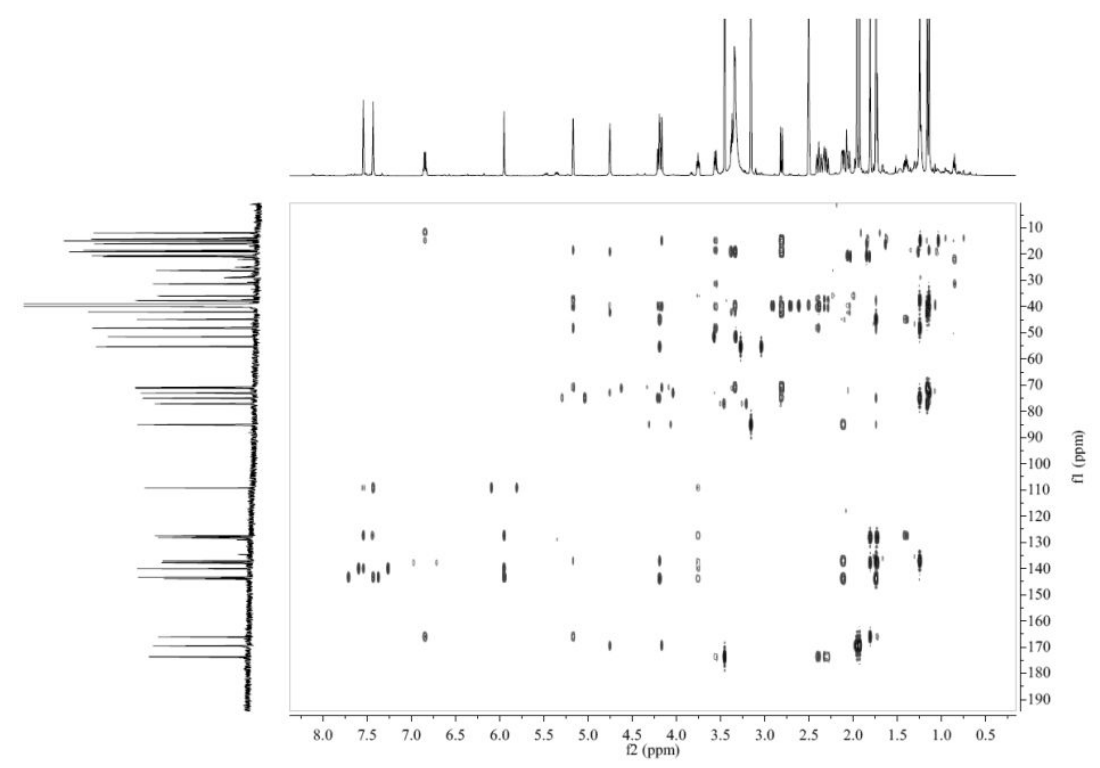

Figure S7. HMBC spectrum of Meliazedarine A (1) in DMSO- $d_{6}$

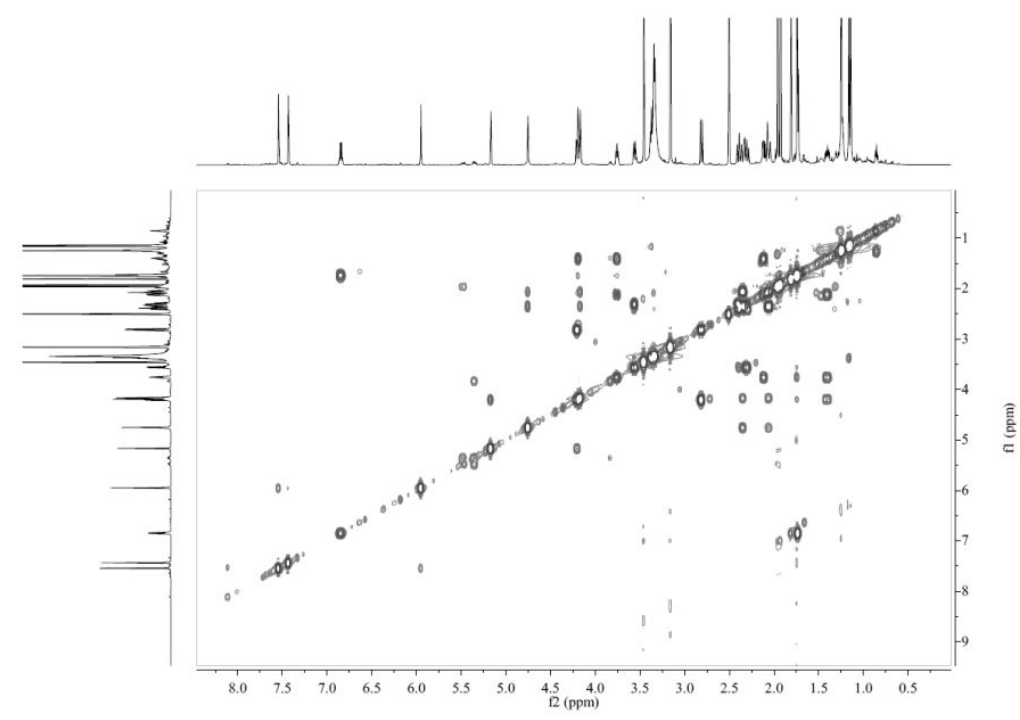

Figure S8. ${ }^{1} \mathrm{H}-{ }^{1} \mathrm{H}$ COSY spectrum of Meliazedarine A (1) in DMSO- $d_{6}$

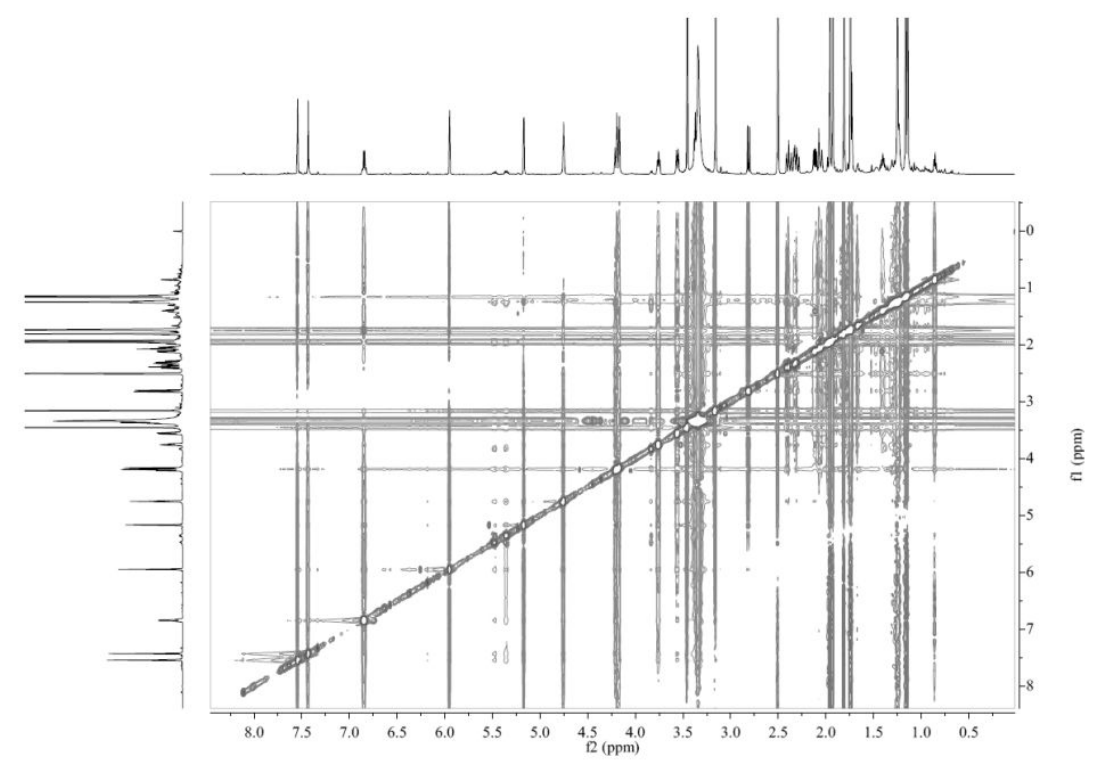

Figure S9. ROESY spectrum of Meliazedarine A (1) in DMSO- $d_{6}$ 


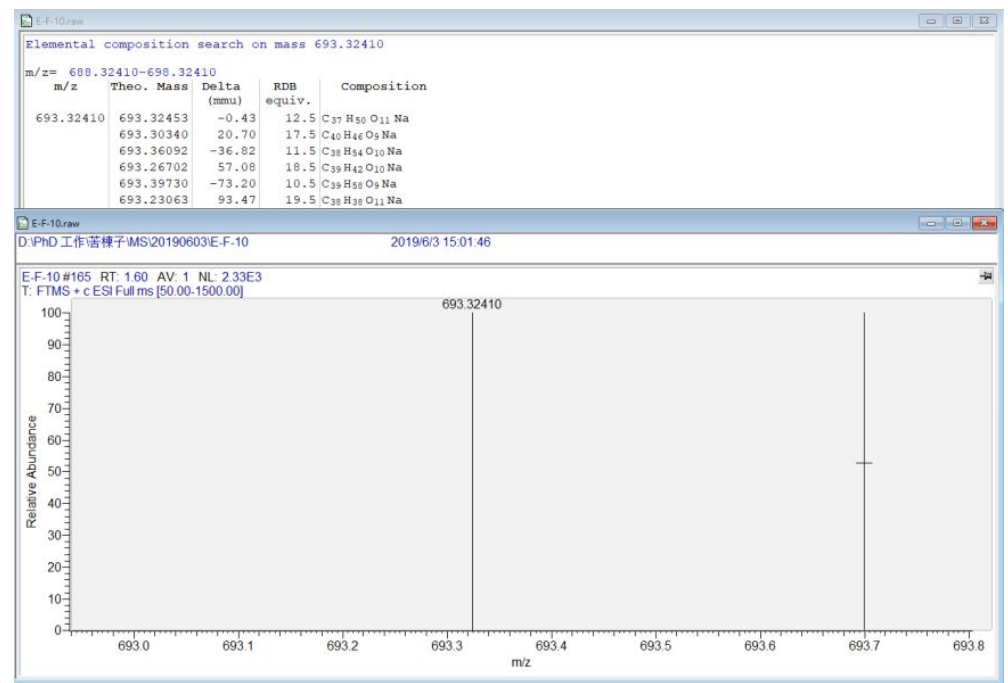

Figure S10. (+)-HRESIMS spectrum of Meliazedarine A (1)

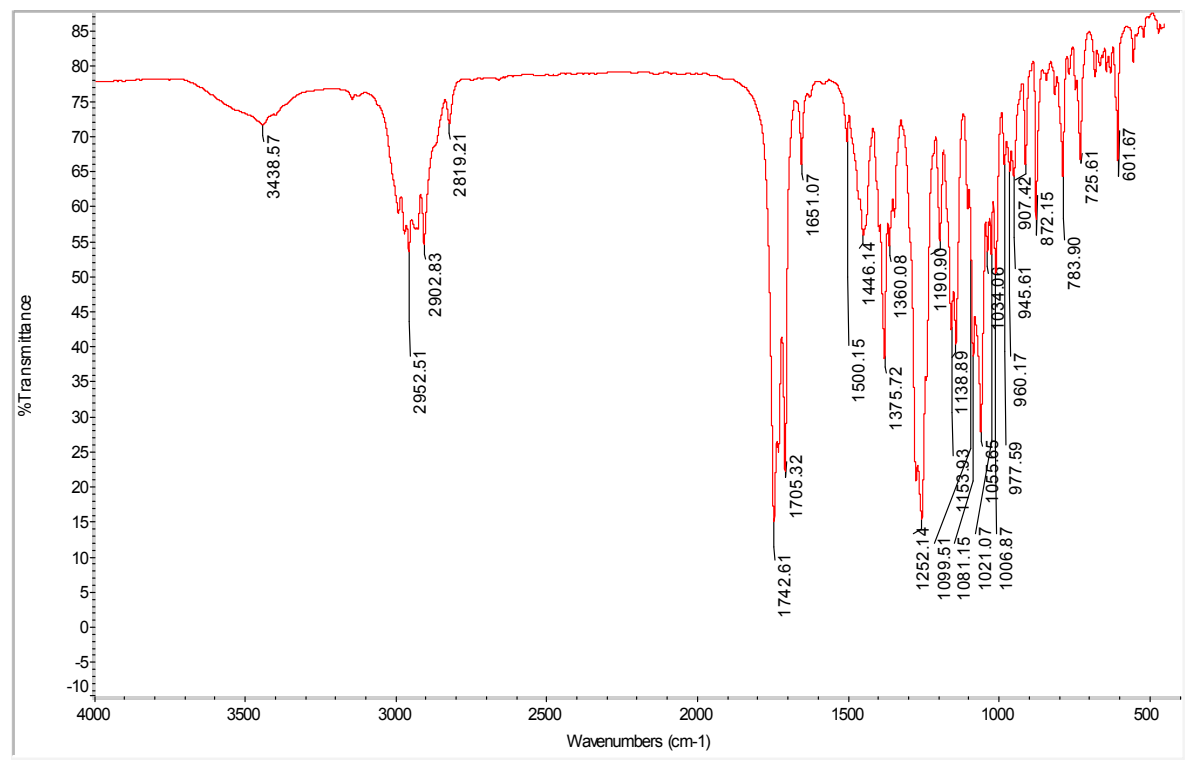

Figure S11. IR spectrum of Meliazedarine A (1)

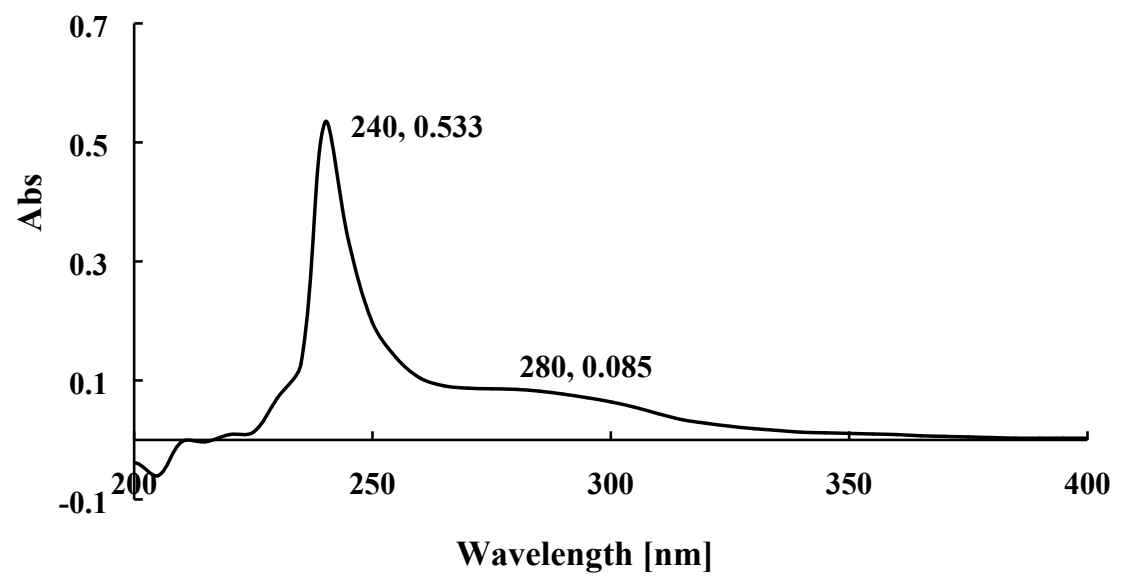

Figure S12. UV spectrum of Meliazedarine A (1) in $\mathrm{CHCl}_{3}$ 


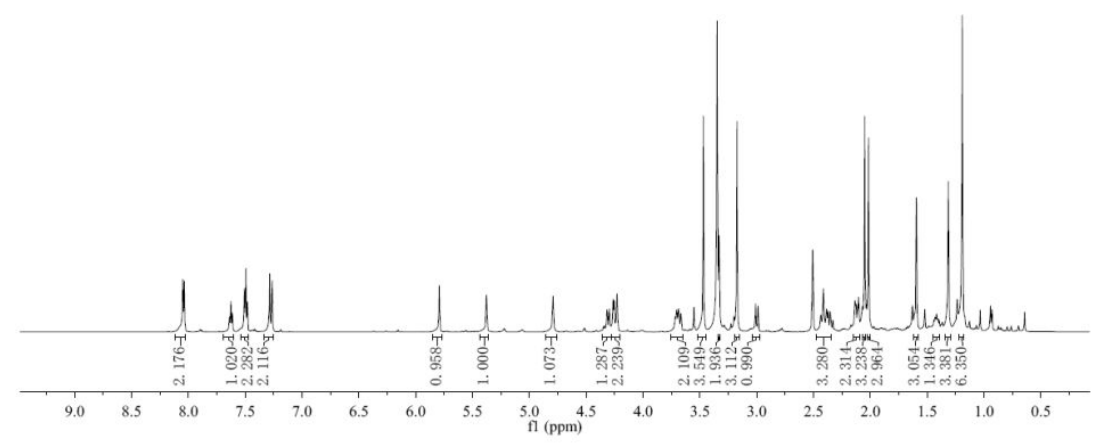

Figure S13. ${ }^{1} \mathrm{H}$ NMR spectrum of Meliazedarine B (2) in DMSO- $d_{6}$
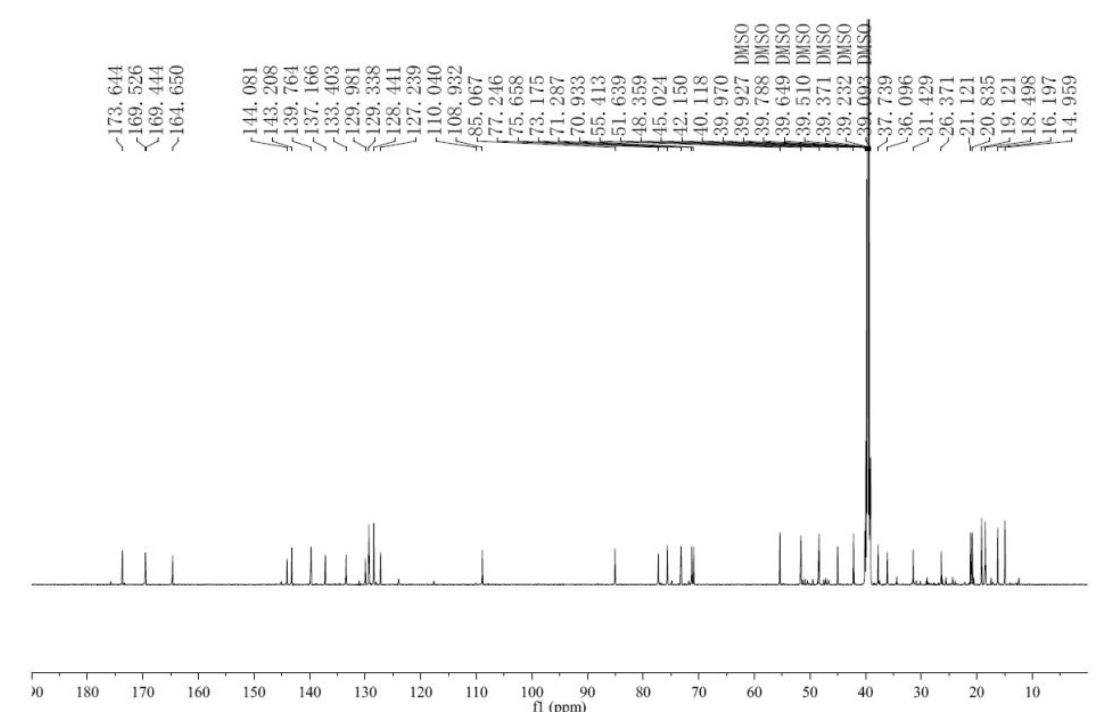

Figure S14. ${ }^{13} \mathrm{C}$ NMR spectrum of Meliazedarine B (2) in DMSO- $d_{6}$

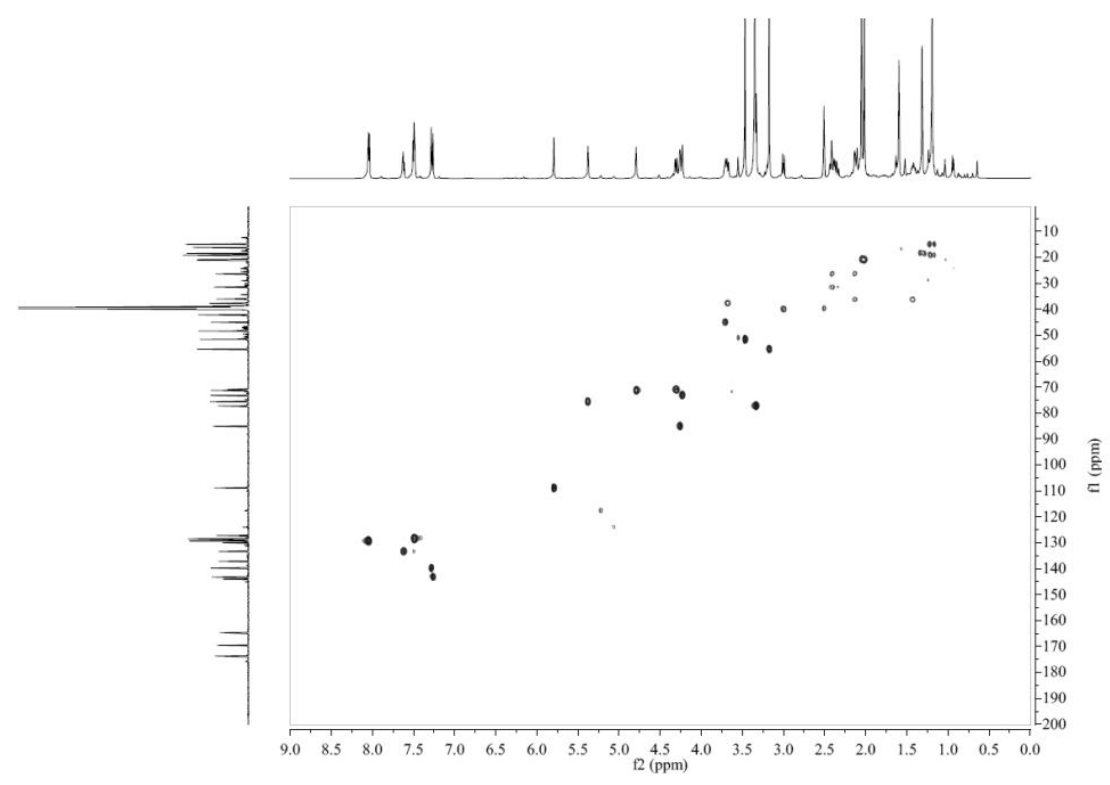

Figure S15. HSQC spectrum of Meliazedarine B (2) in DMSO- $d_{6}$ 


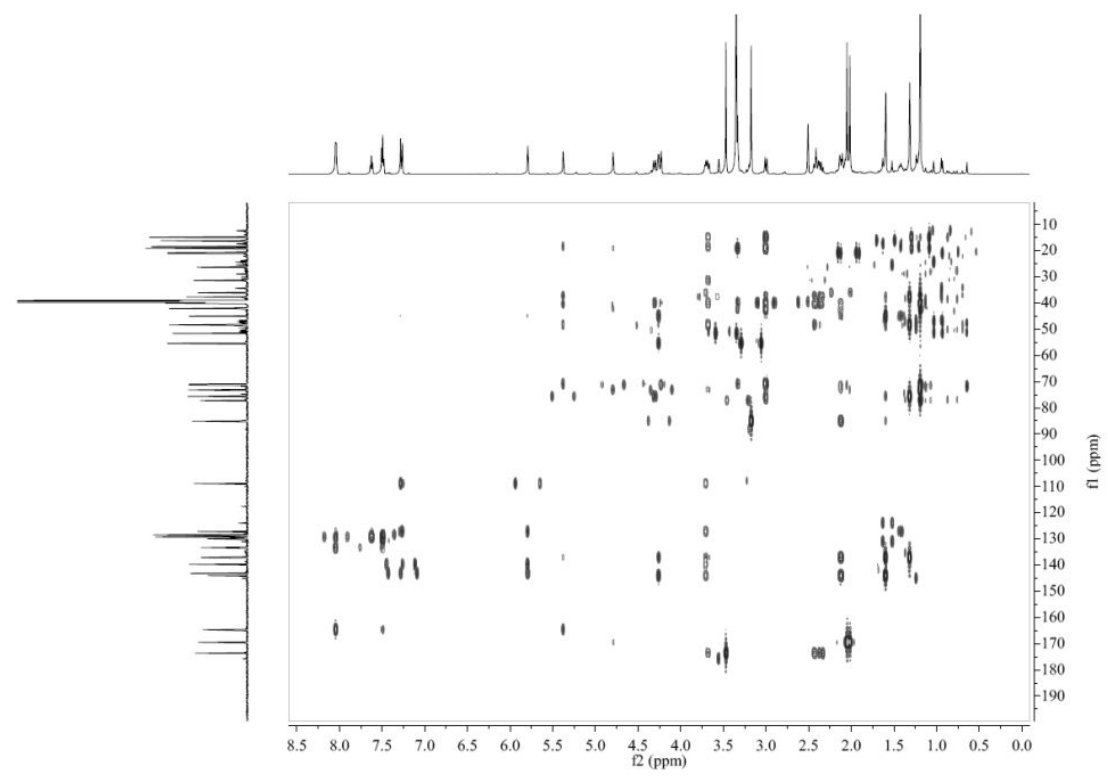

Figure S16. HMBC spectrum of Meliazedarine B (2) in DMSO- $d_{6}$

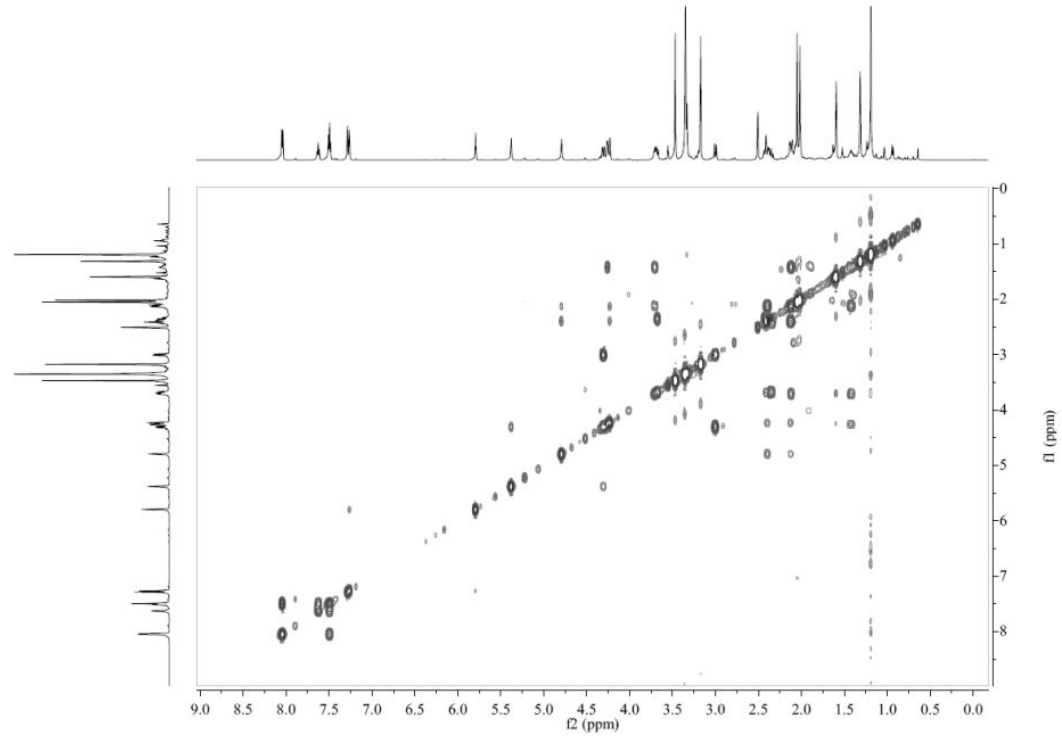

Figure S17. ${ }^{1} \mathrm{H}-{ }^{1} \mathrm{H}$ COSY spectrum of Meliazedarine B (2) in DMSO- $d_{6}$

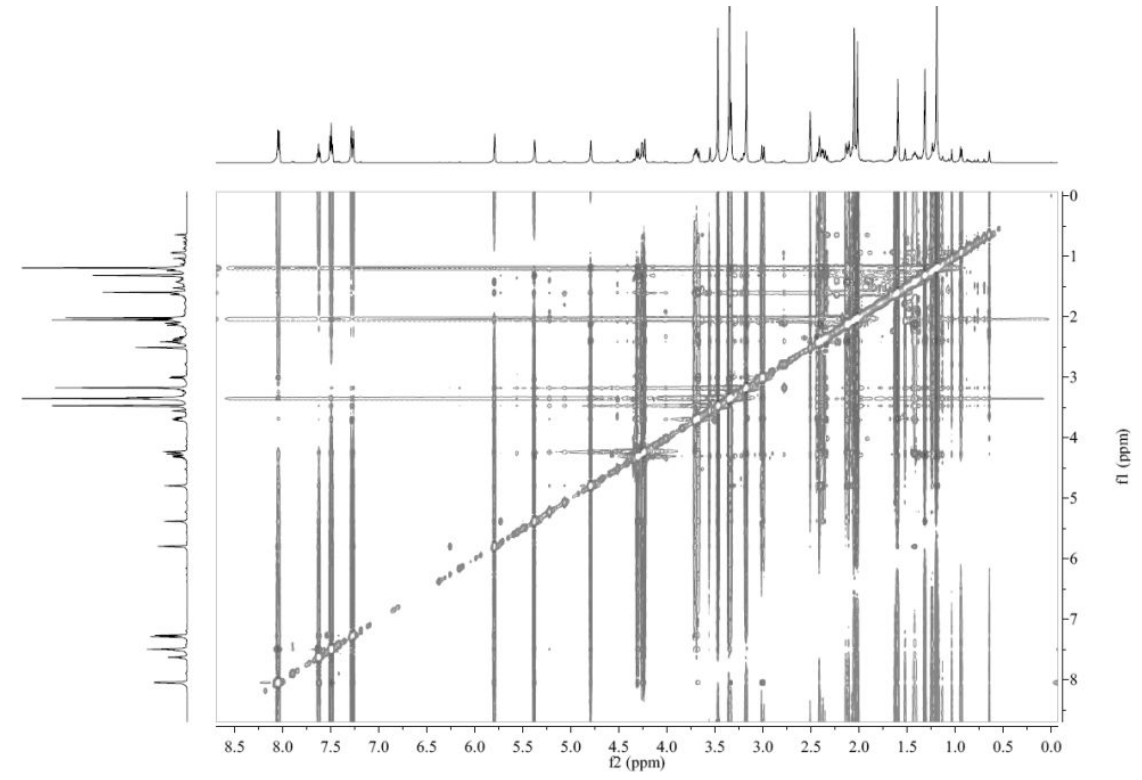

Figure S18. ROESY spectrum of Meliazedarine B (2) in DMSO- $d_{6}$ 

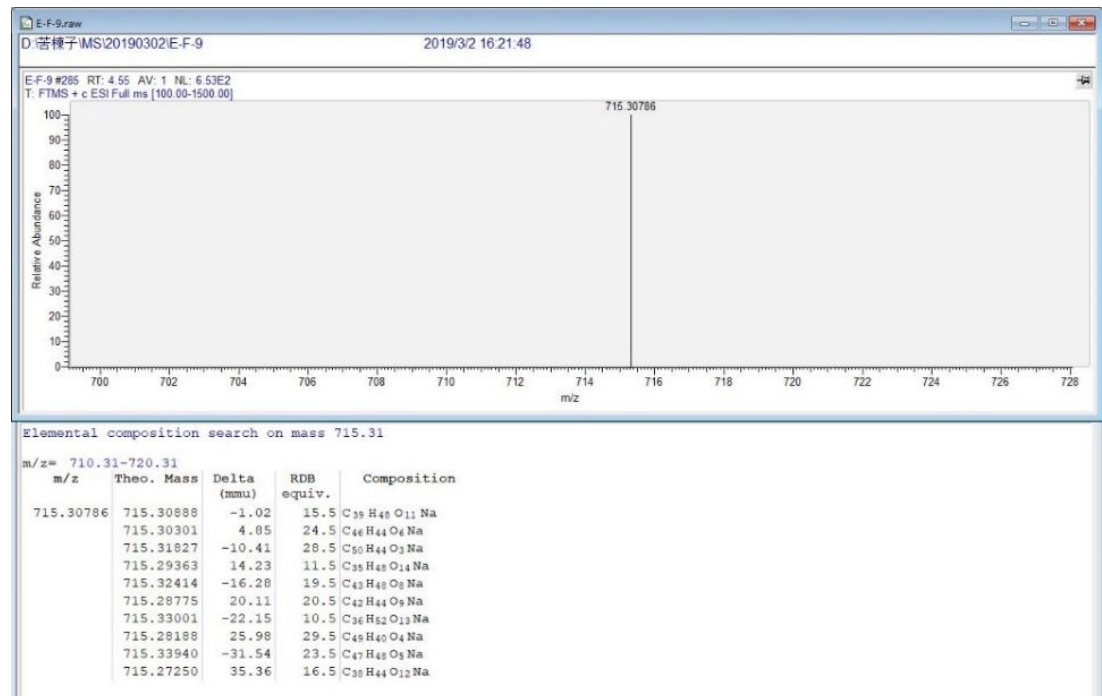

Figure S19. (+)-HRESIMS spectrum of Meliazedarine B (2)

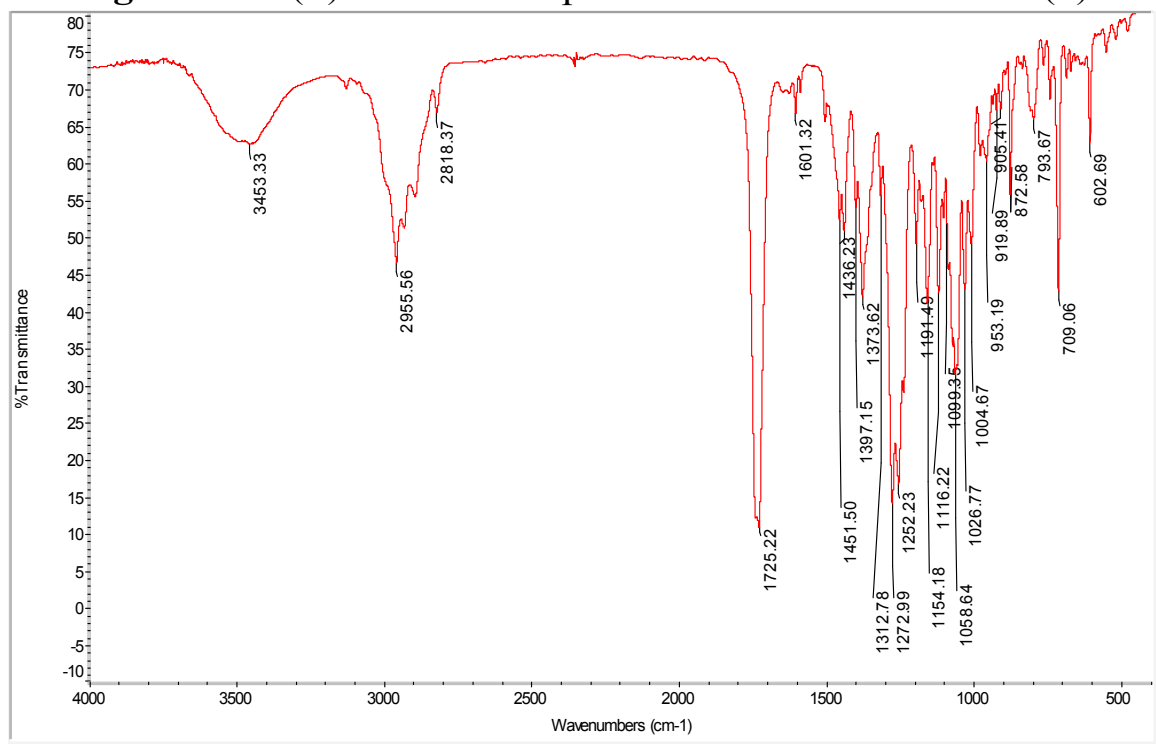

Figure S20. IR spectrum of Meliazedarine B (2)

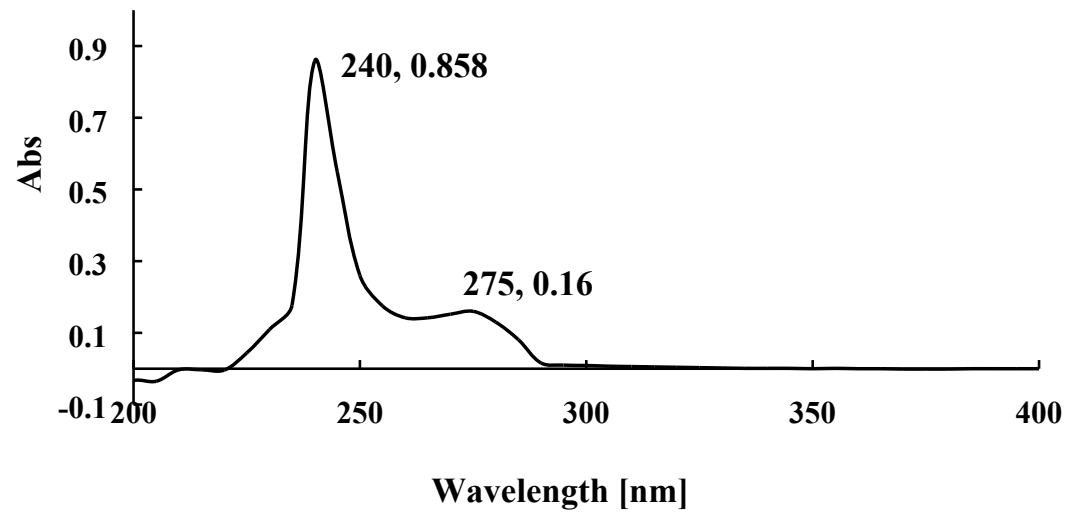

Figure S21. UV spectrum of Meliazedarine B (2) in $\mathrm{CHCl}_{3}$ 


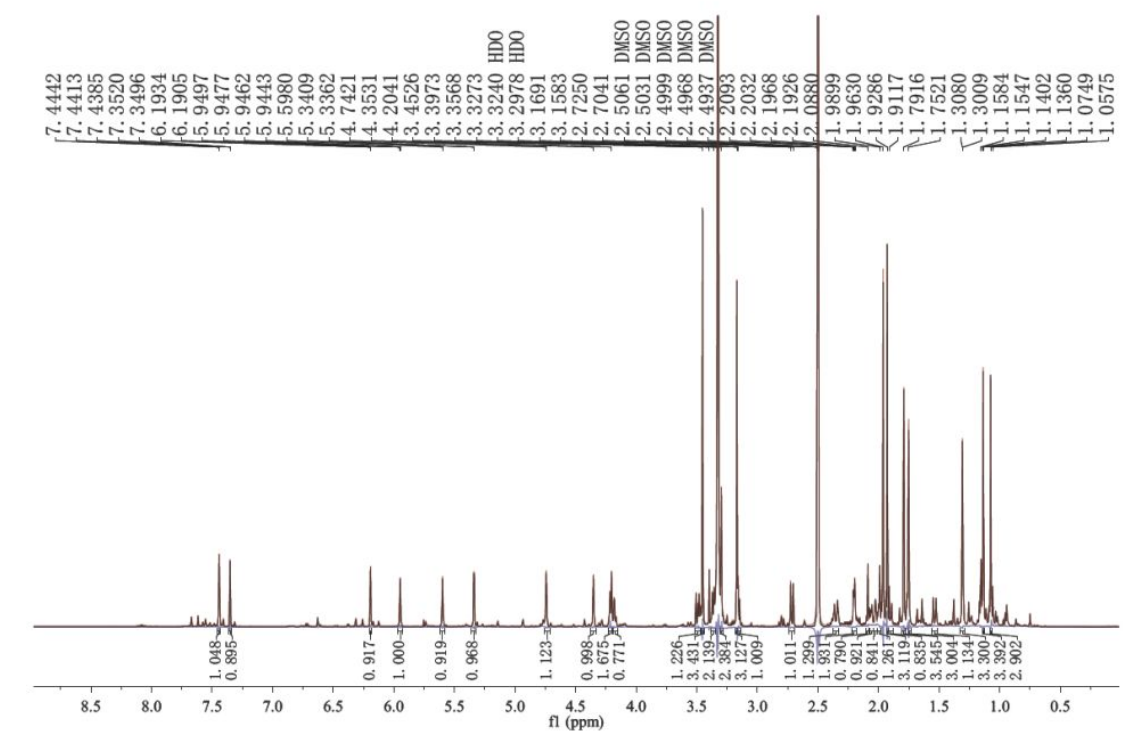

Figure S22. ${ }^{1} \mathrm{H}$ NMR spectrum of Meliazedarine C (3) in DMSO- $d_{6}$

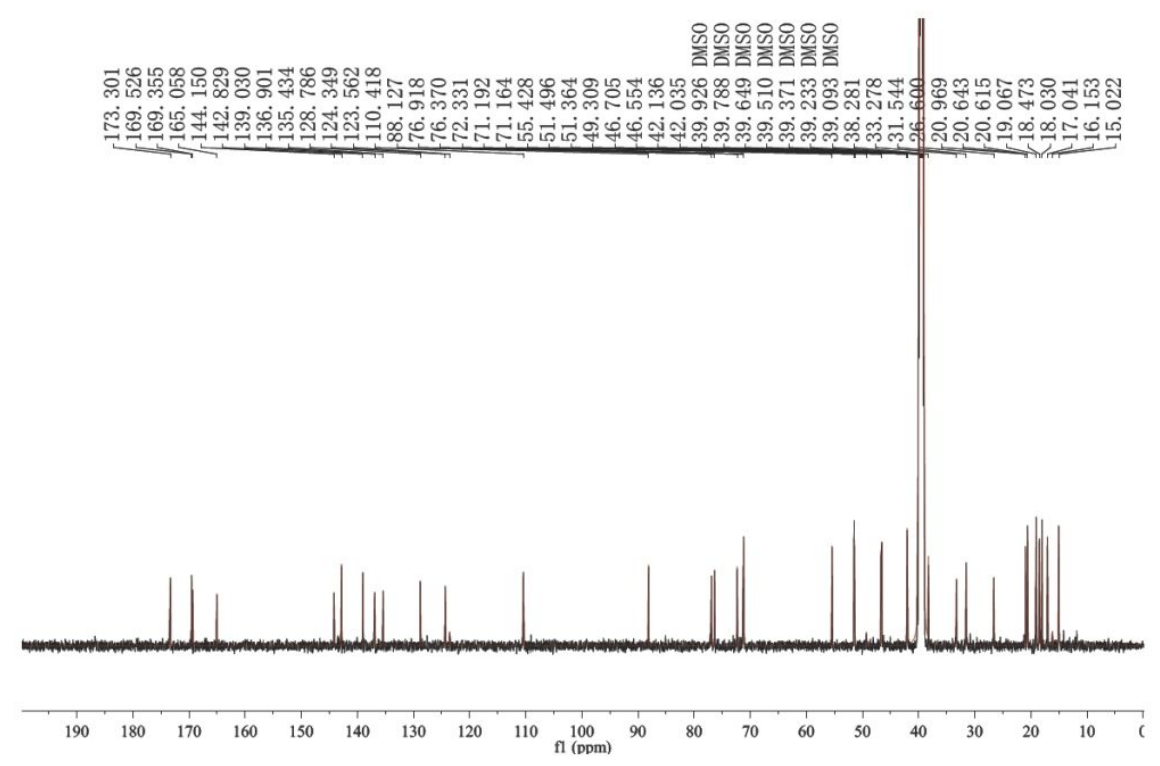

Figure S23. ${ }^{13} \mathrm{C}$ NMR spectrum of Meliazedarine C (3) in DMSO- $d_{6}$

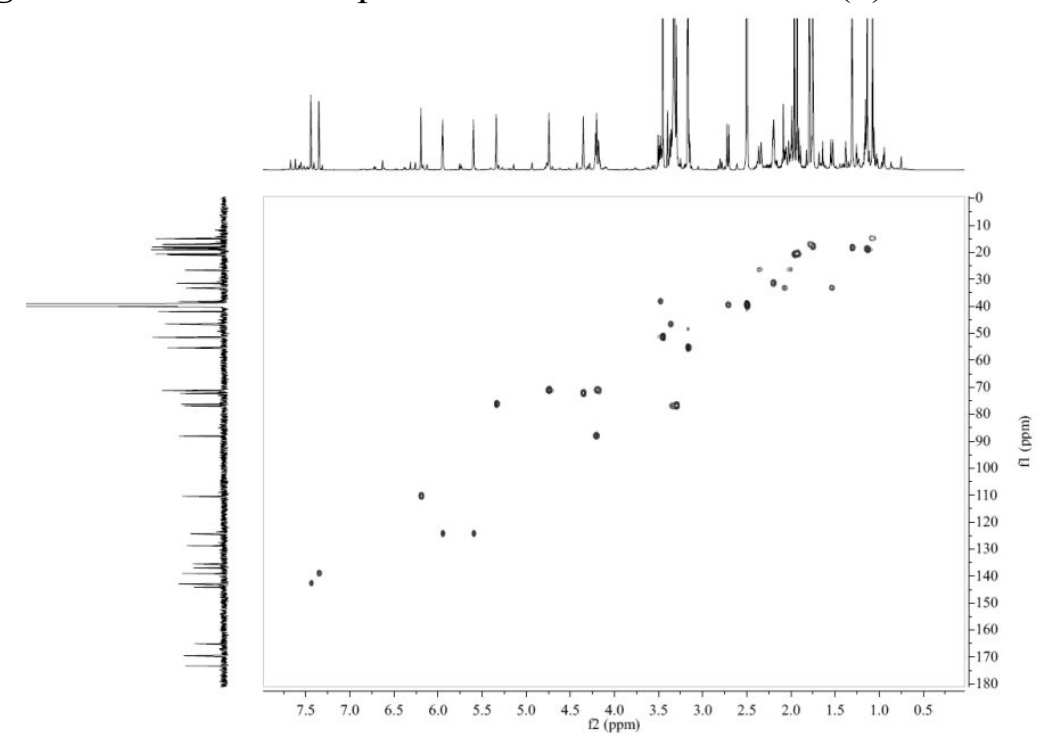

Figure S24. HSQC spectrum of Meliazedarine C (3) in DMSO- $d_{6}$ $16 / 36$ 


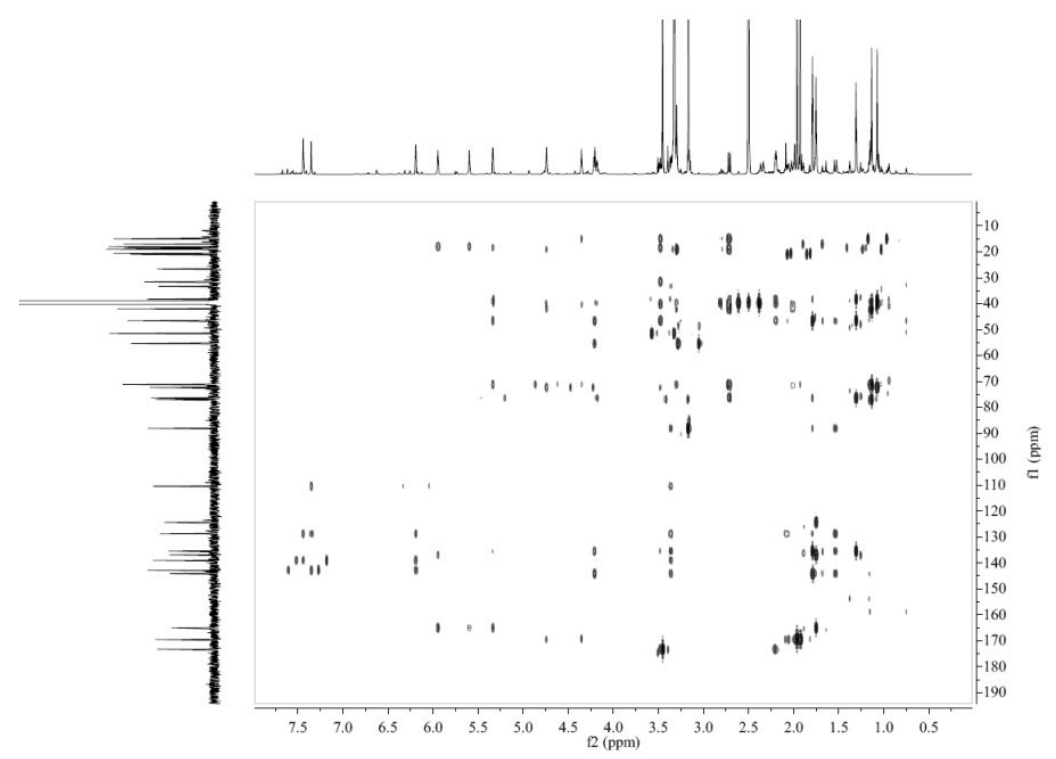

Figure S25. HMBC spectrum of Meliazedarine C (3) in DMSO- $d_{6}$

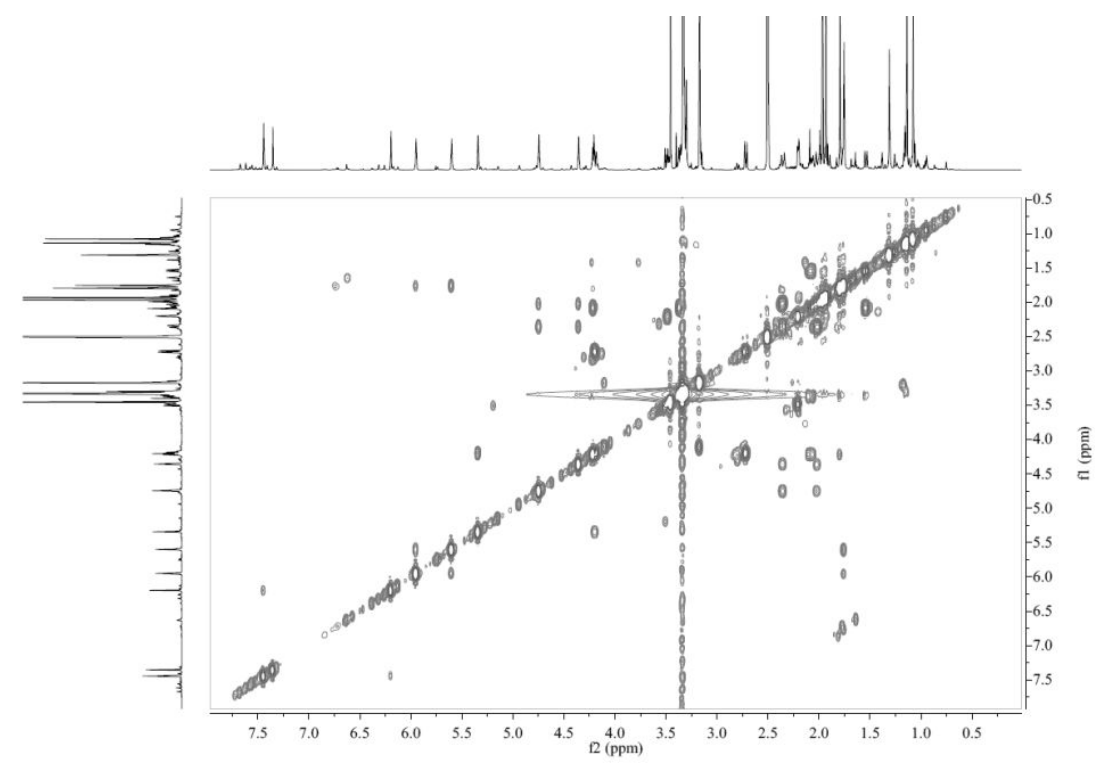

Figure S26. ${ }^{1} \mathrm{H}-{ }^{1} \mathrm{H}$ COSY spectrum of Meliazedarine C (3) in DMSO- $d_{6}$

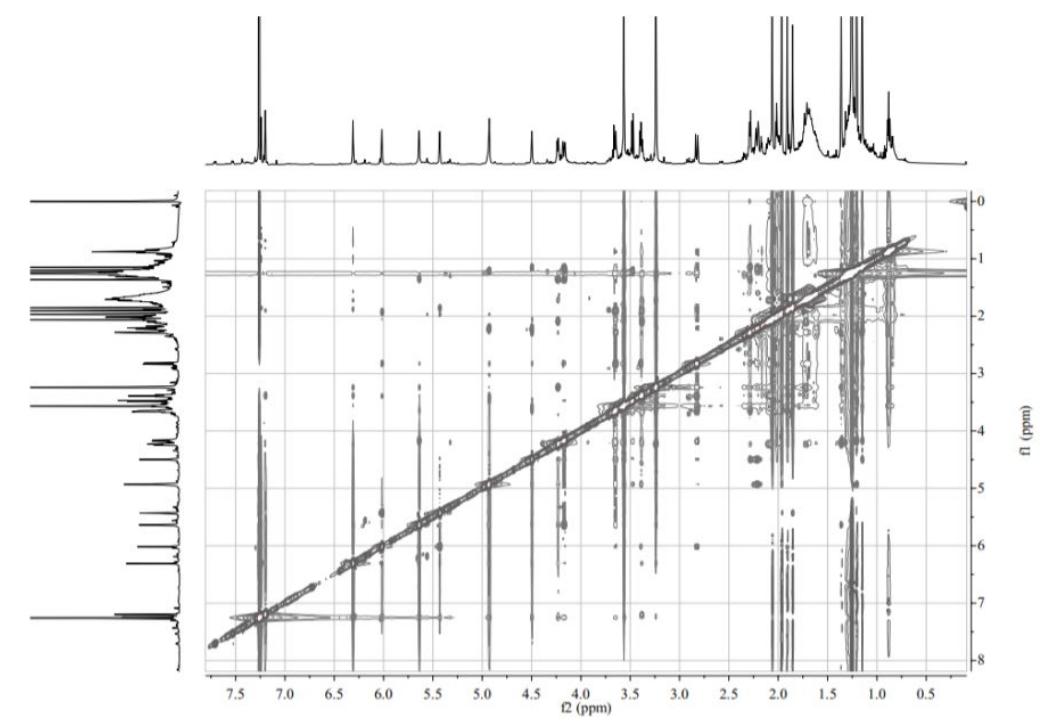

Figure S27. ROESY spectrum of Meliazedarine C (3) in $\mathrm{CDCl}_{3}$ 


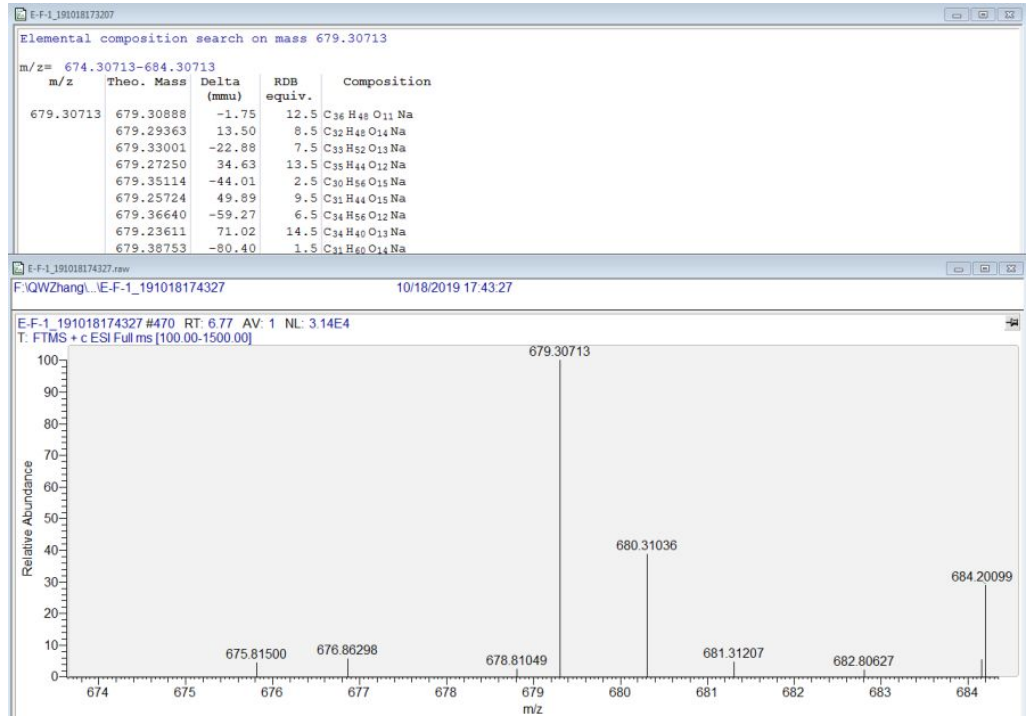

Figure S28. (+)-HRESIMS spectrum of Meliazedarine C (3)

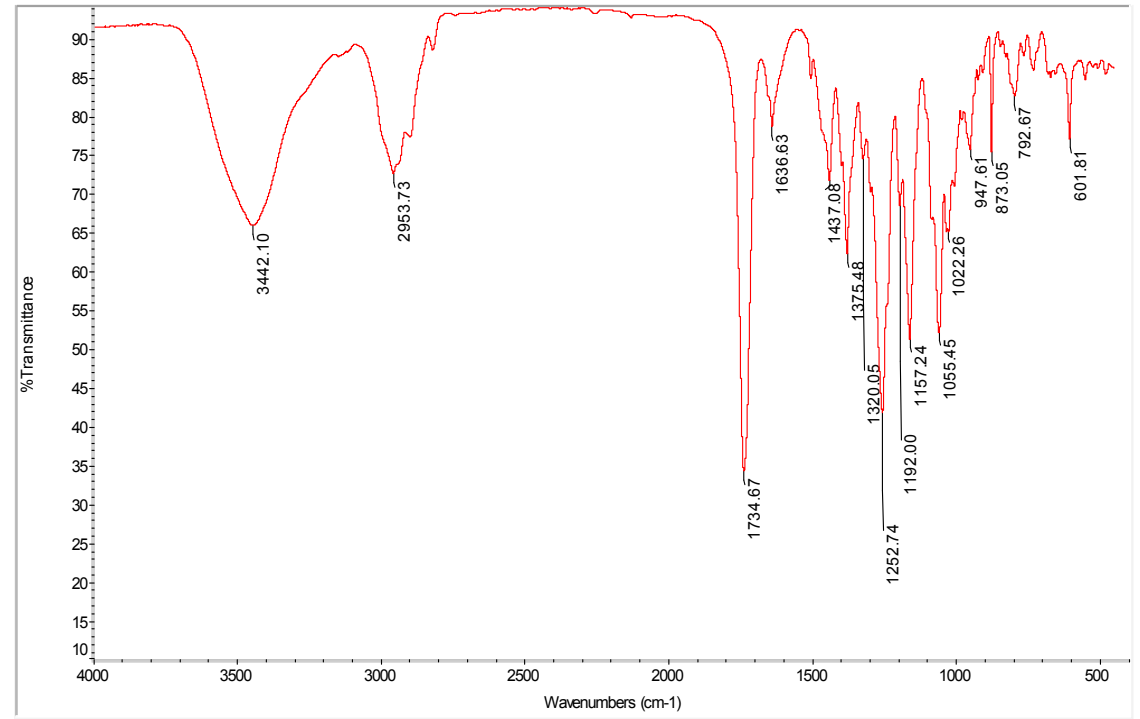

Figure S29. IR spectrum of Meliazedarine C (3)

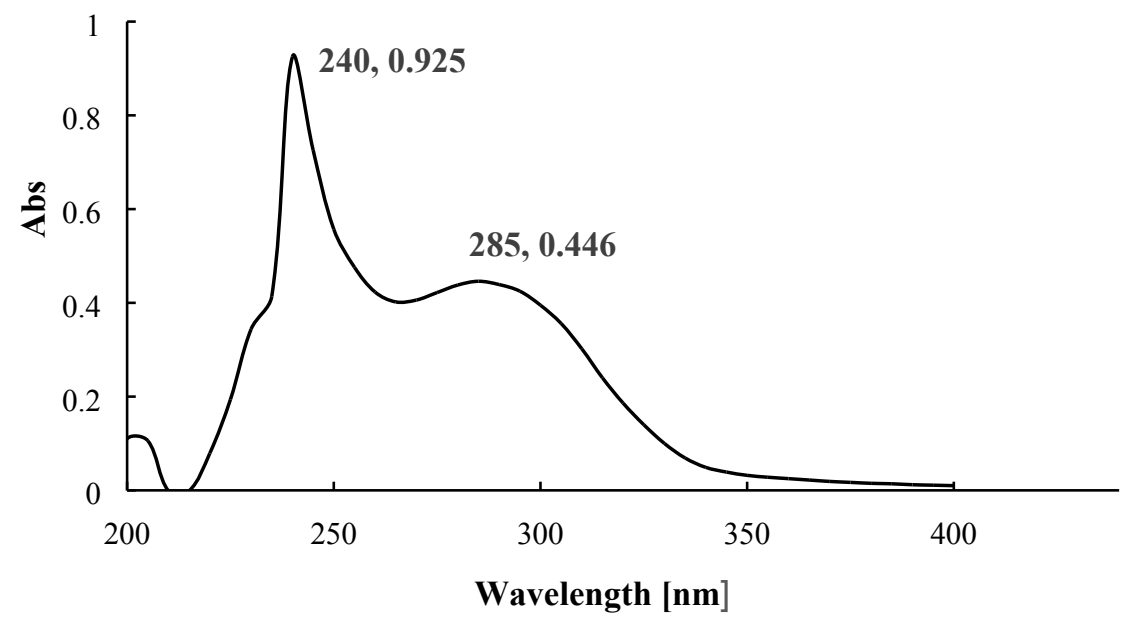

Figure S30. UV spectrum of Meliazedarine C (3) in $\mathrm{CHCl}_{3}$ 


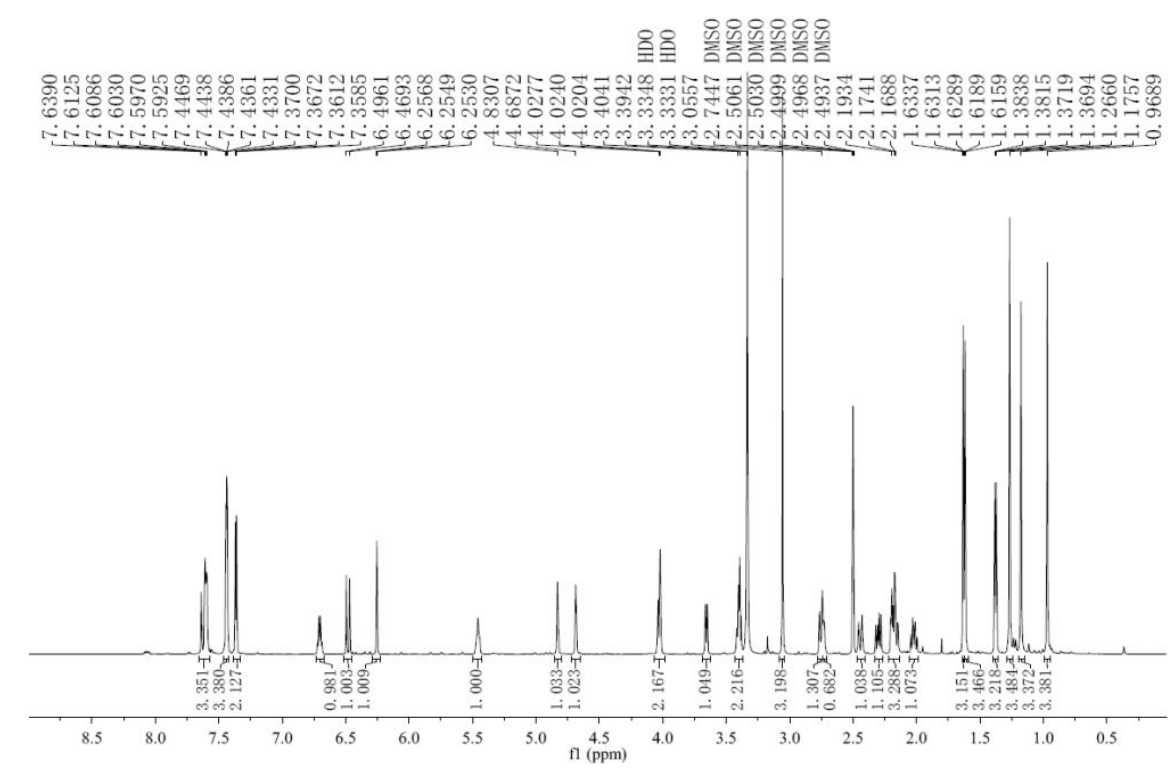

Figure S31. ${ }^{1} \mathrm{H}$ NMR spectrum of Meliazedarine D (4) in DMSO- $d_{6}$

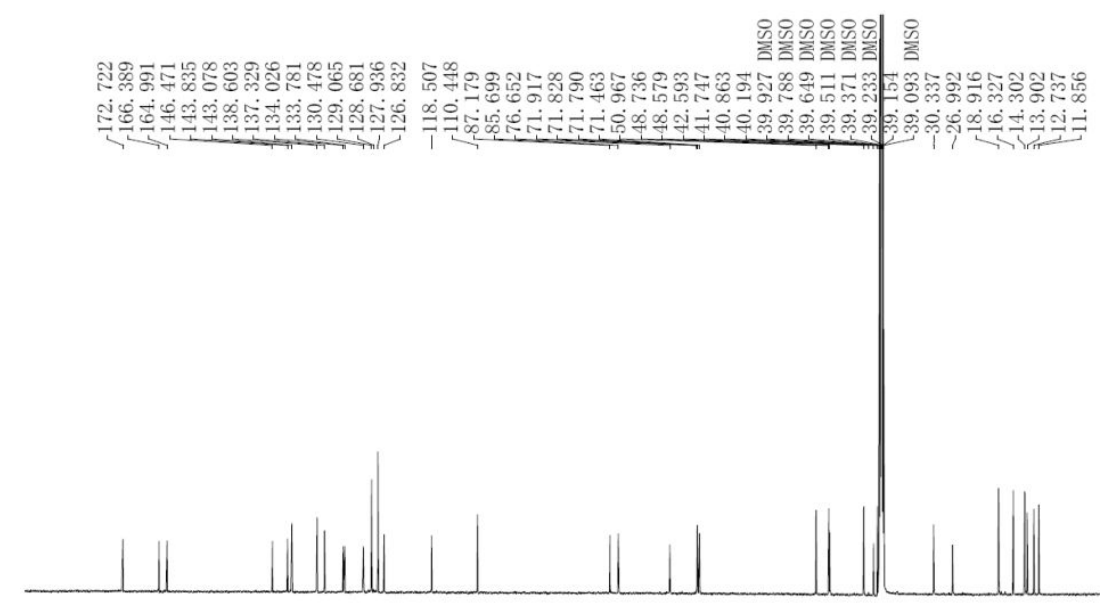

Figure S32. ${ }^{13} \mathrm{C}$ NMR spectrum of Meliazedarine D (4) in DMSO- $d_{6}$

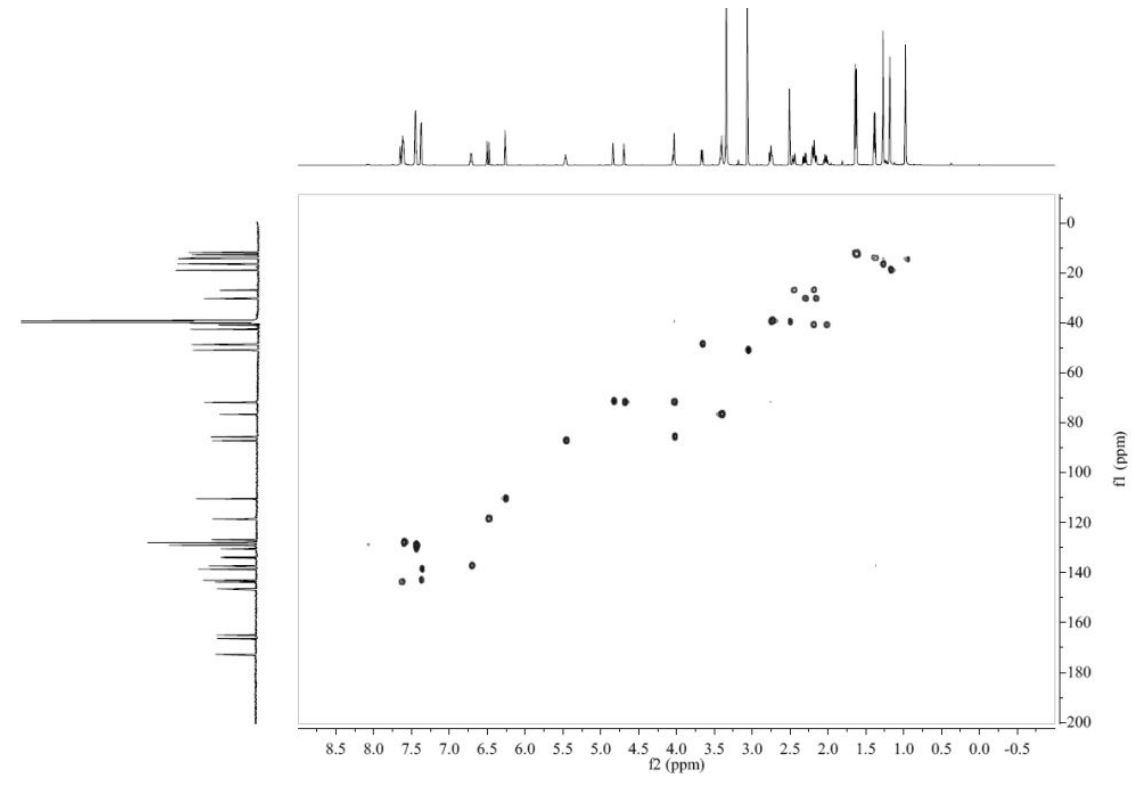

Figure S33. HSQC spectrum of Meliazedarine D (4) in DMSO- $d_{6}$ 


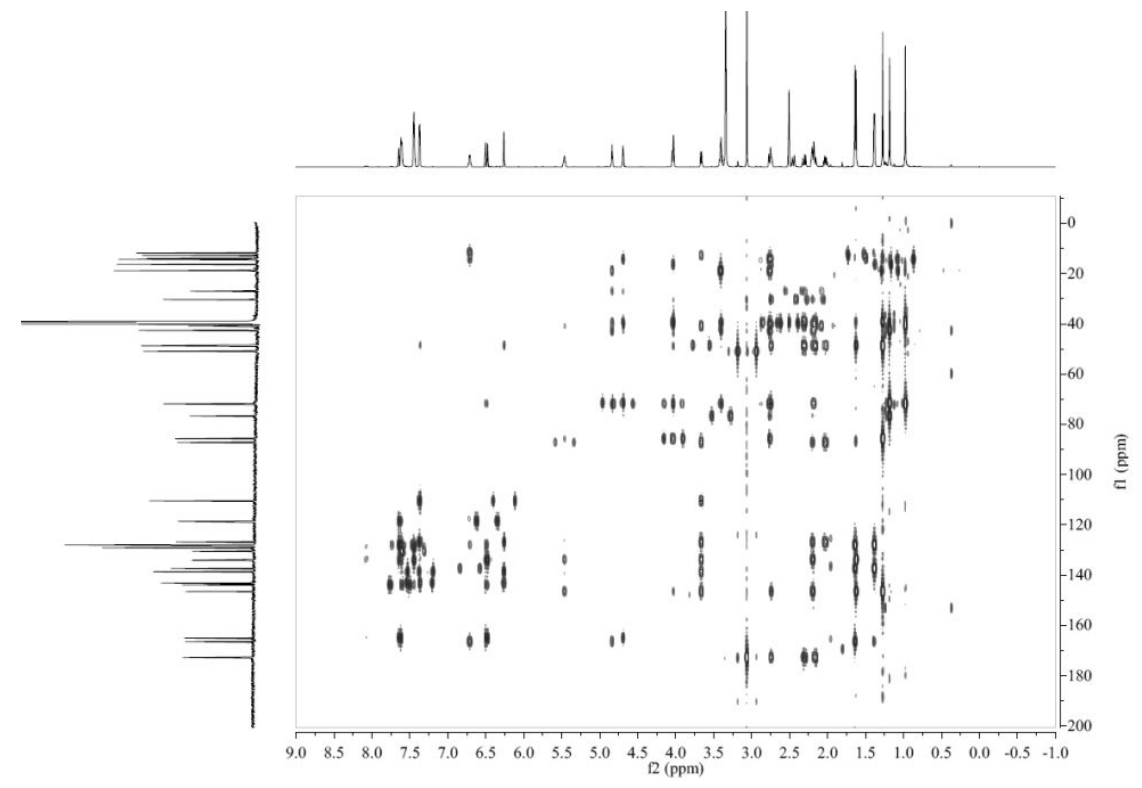

Figure S34. HMBC spectrum of Meliazedarine D (4) in DMSO- $d_{6}$

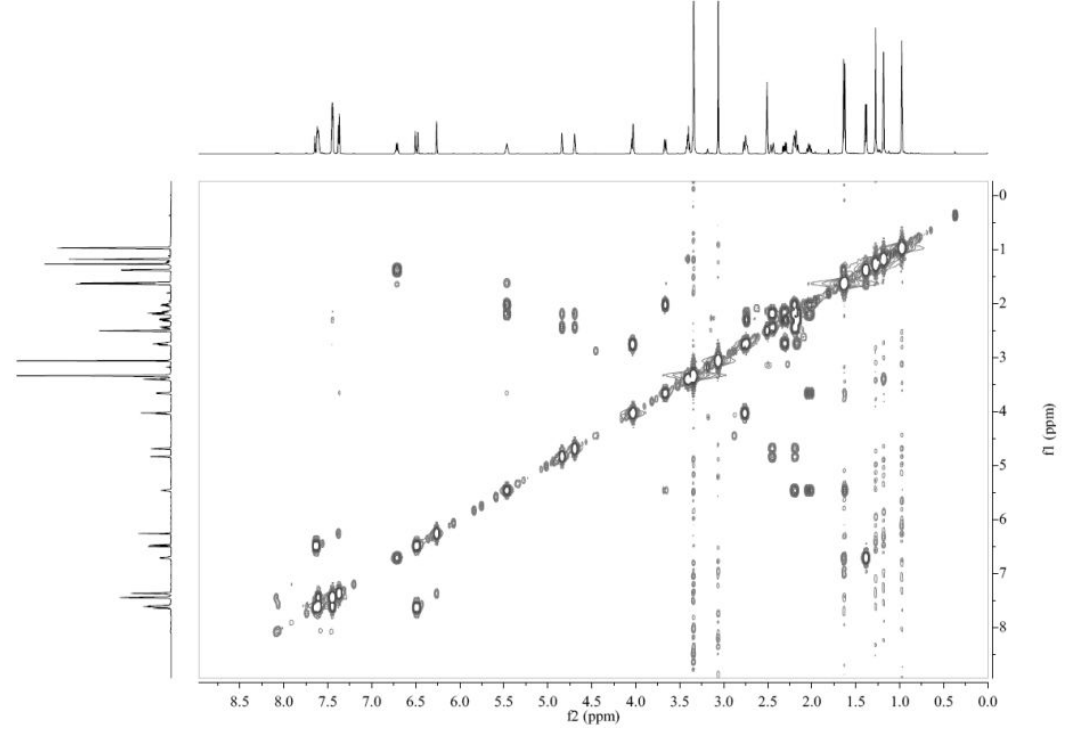

Figure S35. ${ }^{1} \mathrm{H}-{ }^{1} \mathrm{H}$ COSY spectrum of Meliazedarine D (4) in DMSO- $d_{6}$

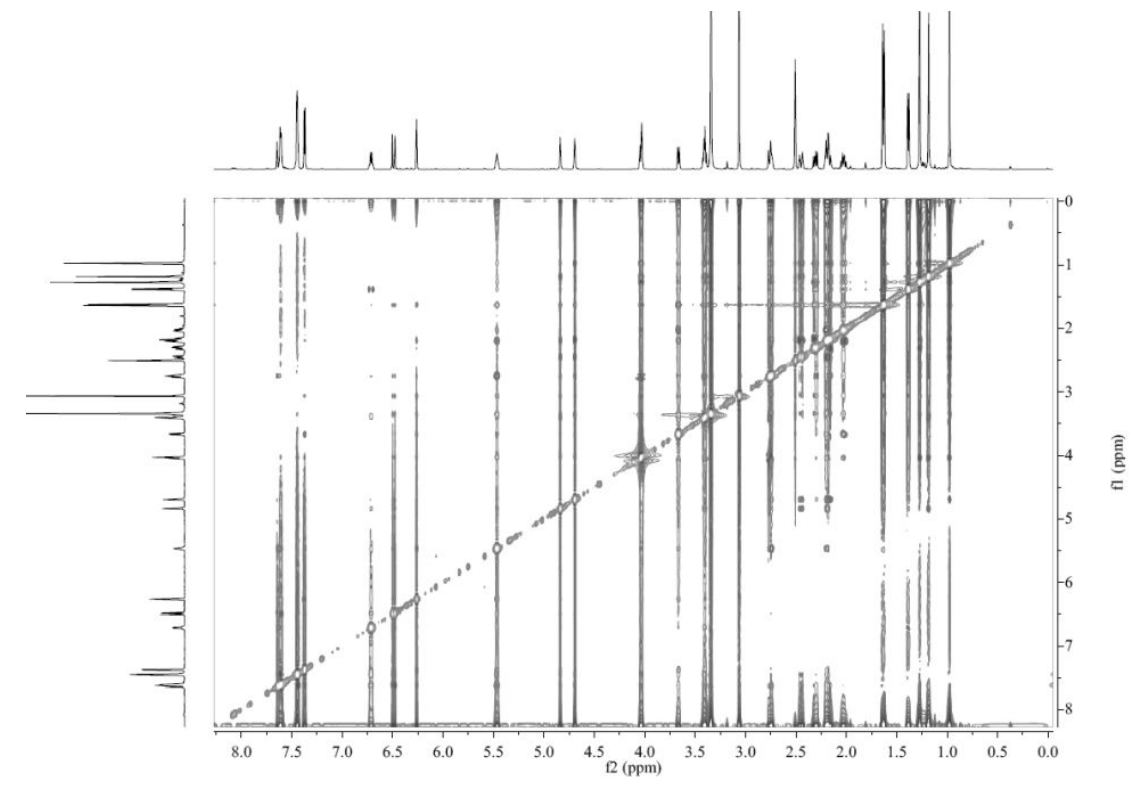

Figure S36. ROESY spectrum of Meliazedarine D (4) in DMSO- $d_{6}$ $20 / 36$ 


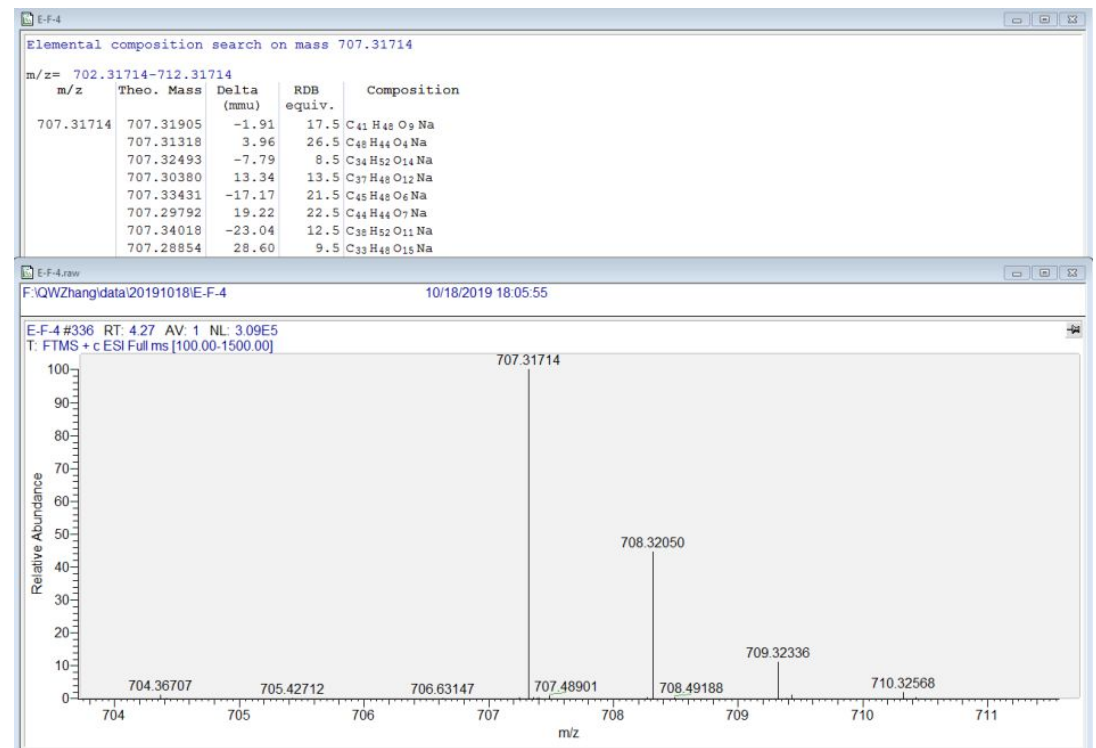

Figure S37. (+)-HRESIMS spectrum of Meliazedarine D (4)

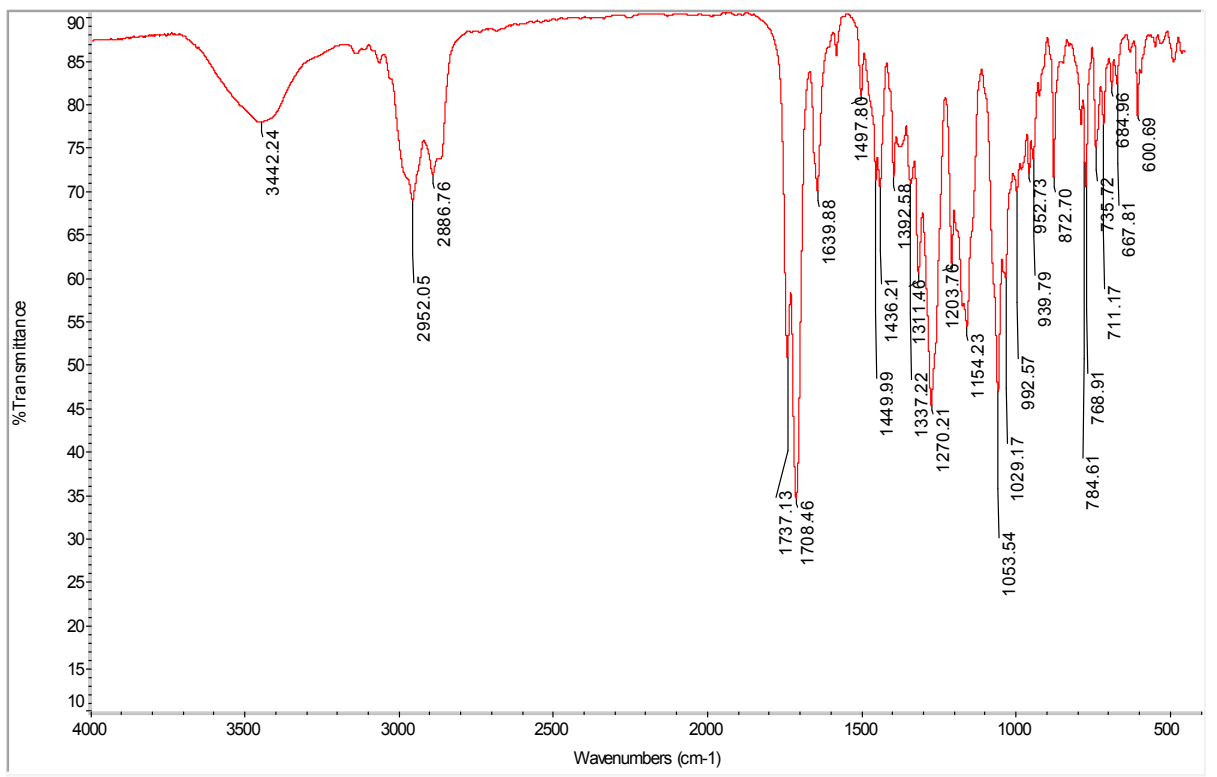

Figure S38. IR spectrum of Meliazedarine D (4)

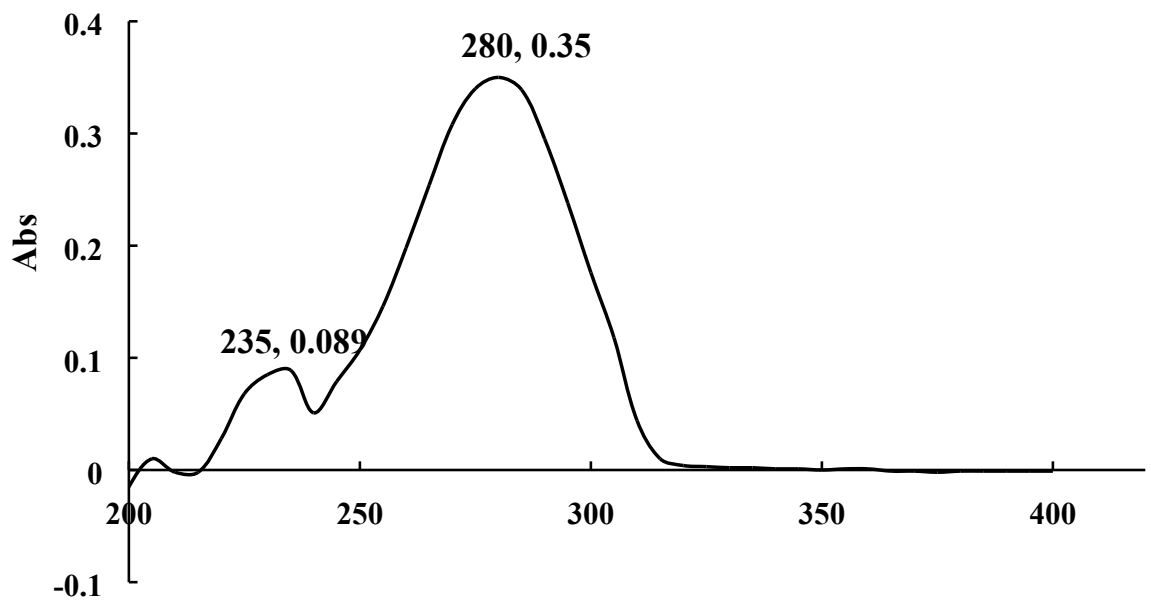

Wavelength $[\mathrm{nm}]$

Figure S39. UV spectrum of Meliazedarine D (4) in $\mathrm{CHCl}_{3}$ 

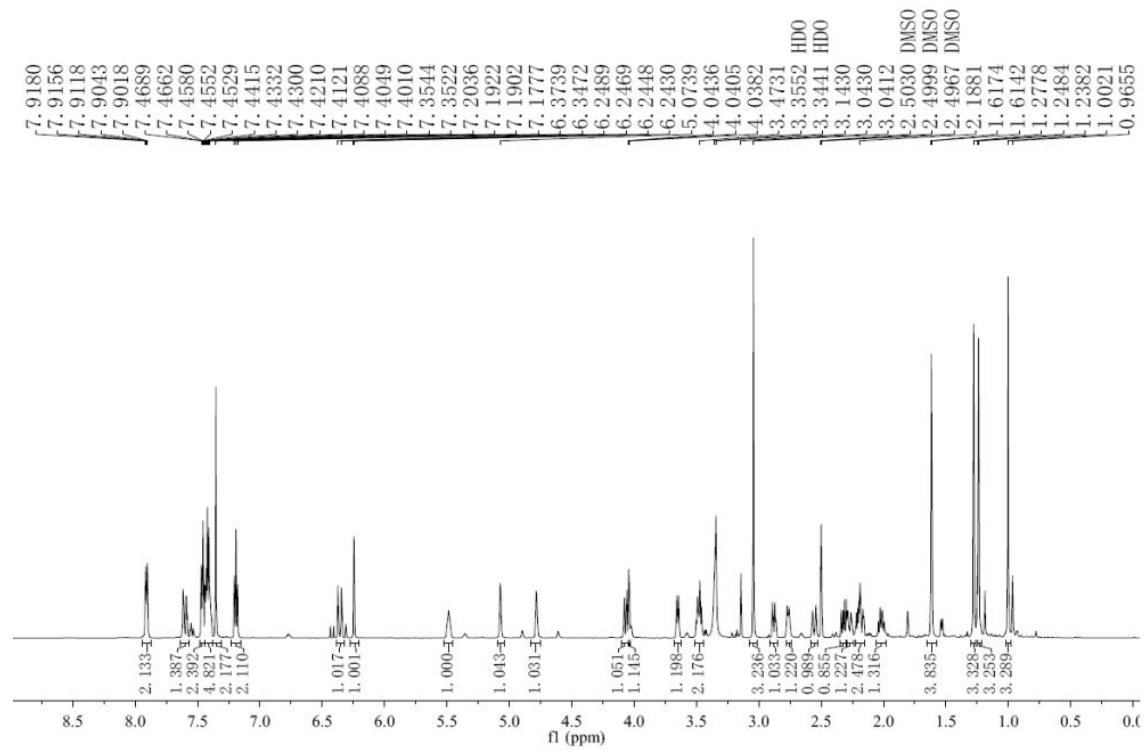

Figure S40. ${ }^{1} \mathrm{H}$ NMR spectrum of Meliazedarine E (5) in DMSO- $d_{6}$

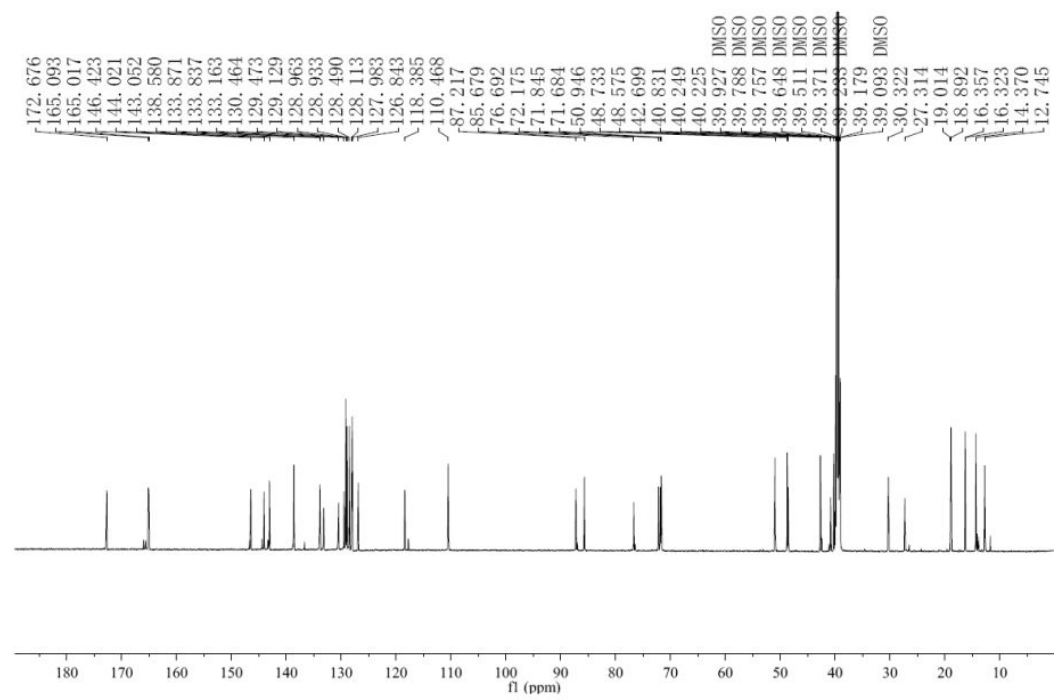

Figure S41. ${ }^{13} \mathrm{C}$ NMR spectrum of Meliazedarine E (5) in DMSO- $d_{6}$

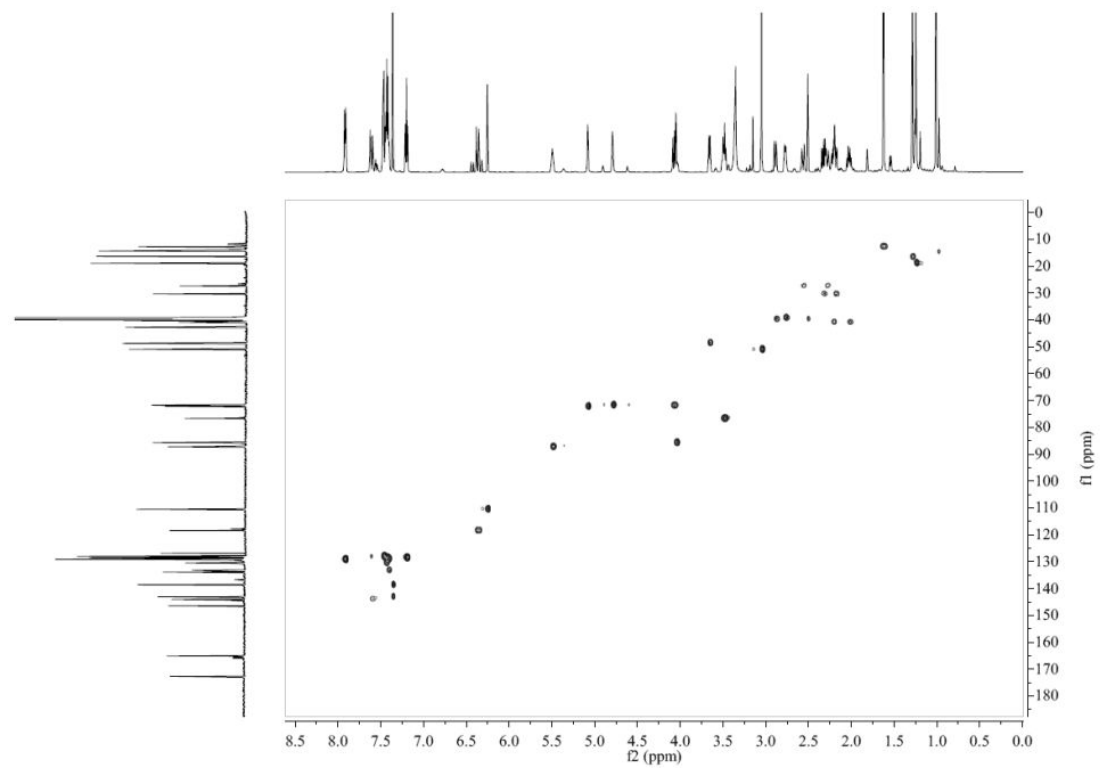

Figure S42. HSQC spectrum of Meliazedarine E (5) in DMSO- $d_{6}$ 


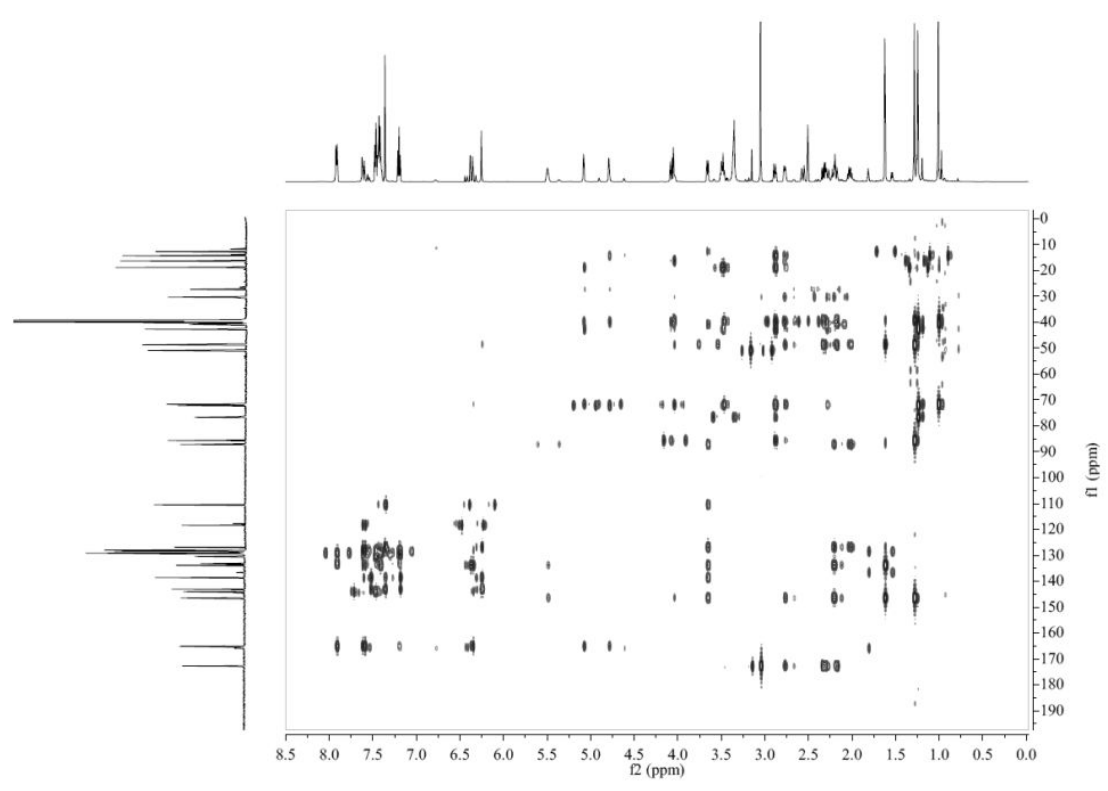

Figure S43. HMBC spectrum of Meliazedarine E (5) in DMSO- $d_{6}$

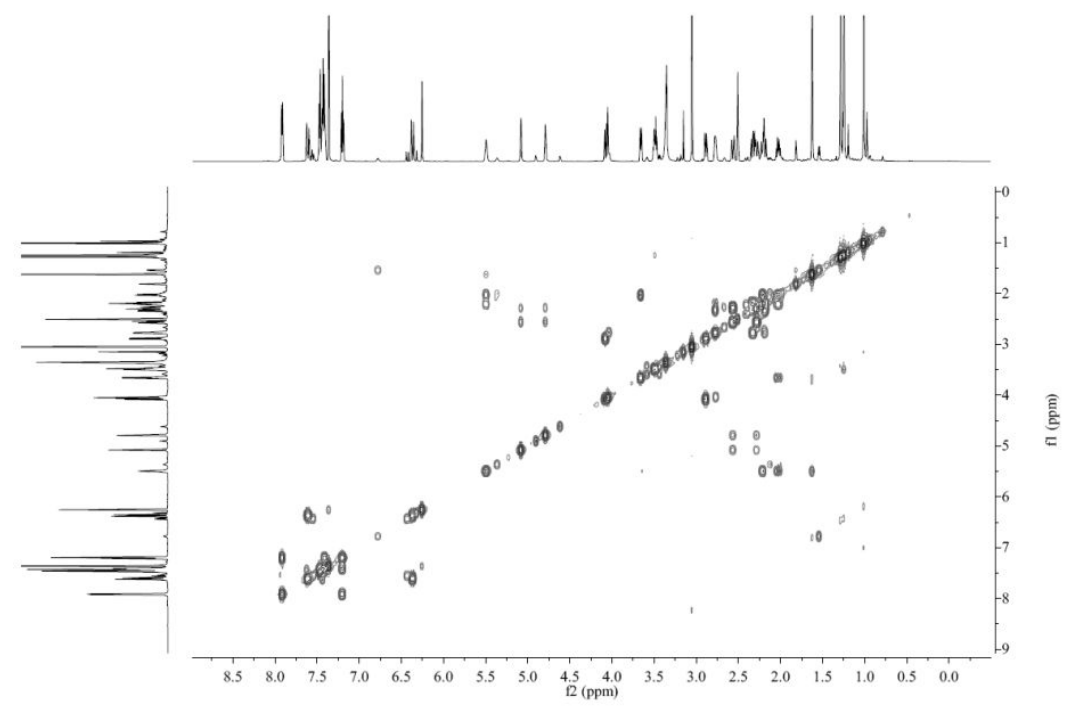

Figure S44. ${ }^{1} \mathrm{H}-{ }^{1} \mathrm{H}$ COSY spectrum of Meliazedarine E (5) in DMSO- $d_{6}$

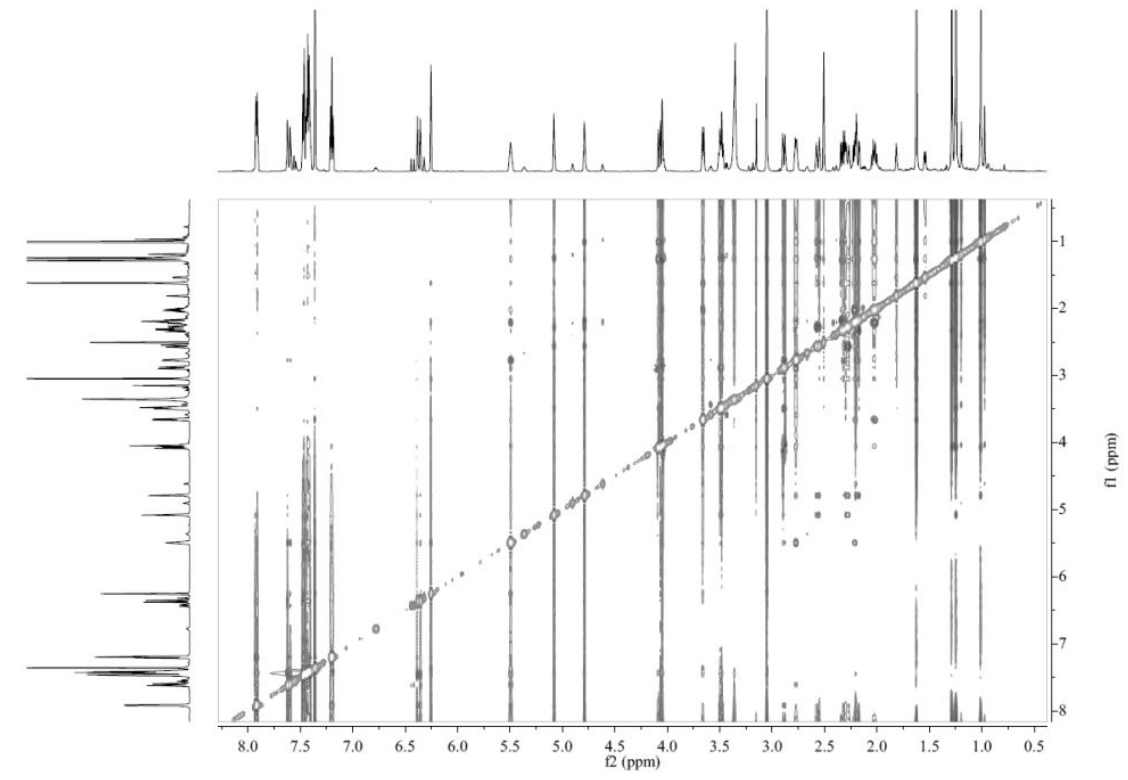

Figure S45. ROESY spectrum of Meliazedarine E (5) in DMSO- $d_{6}$ 


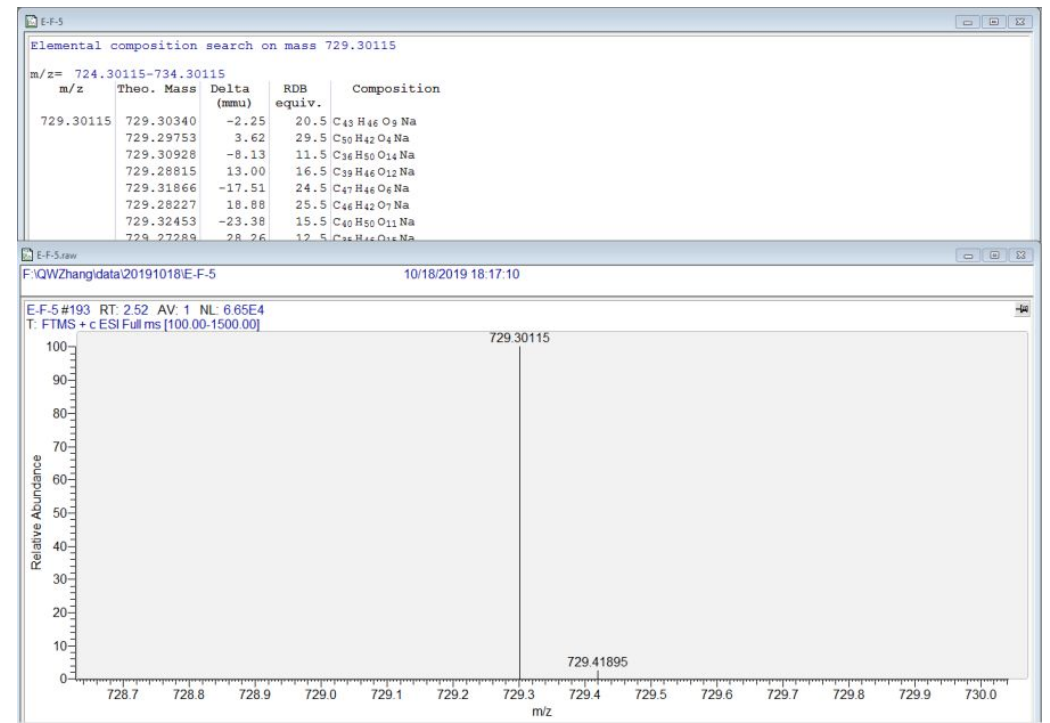

Figure S46. (+)-HRESIMS spectrum of Meliazedarine E (5)

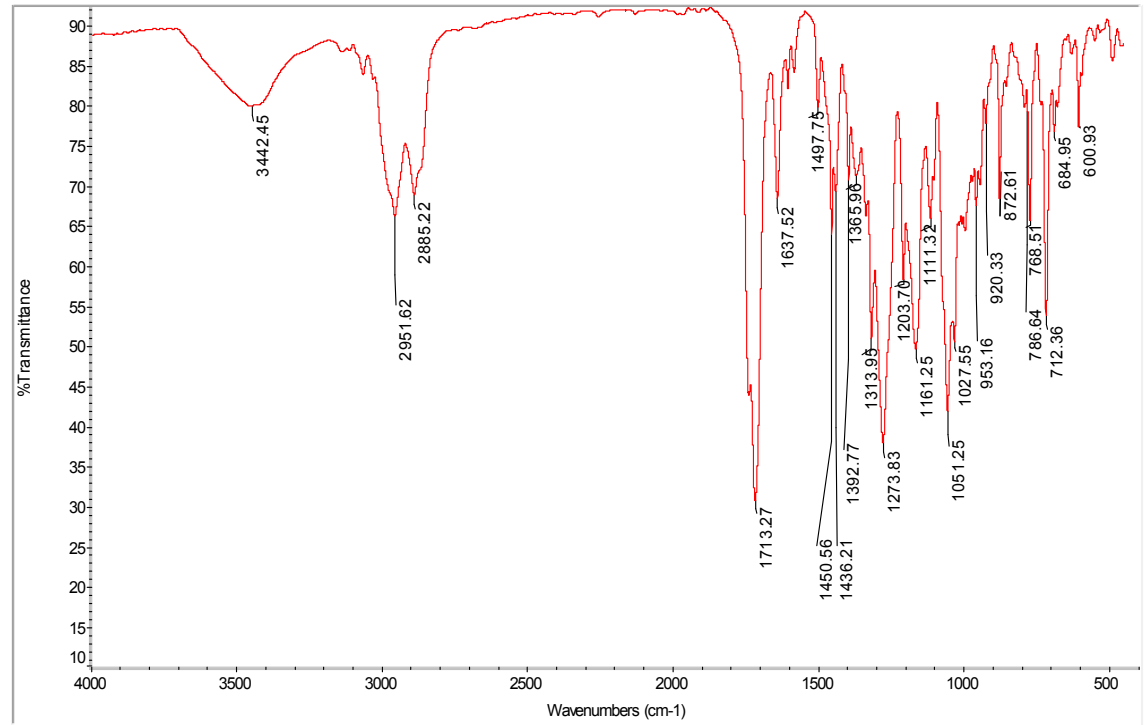

Figure S47. IR spectrum of Meliazedarine E (5)

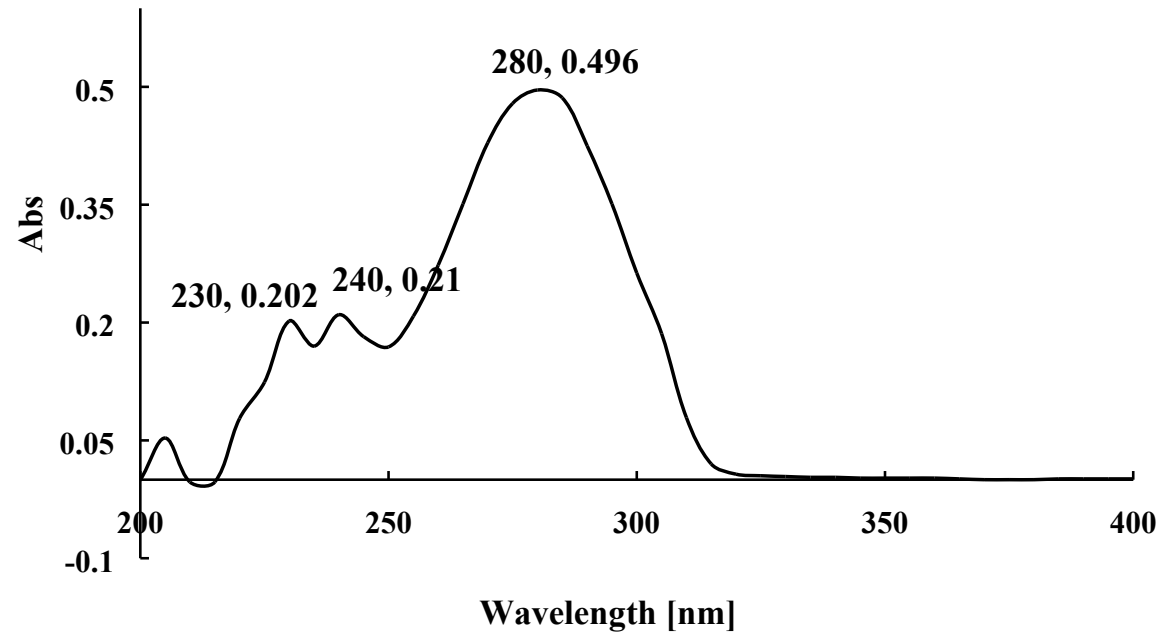

Figure S48. UV spectrum of Meliazedarine E (5) in $\mathrm{CHCl}_{3}$ 


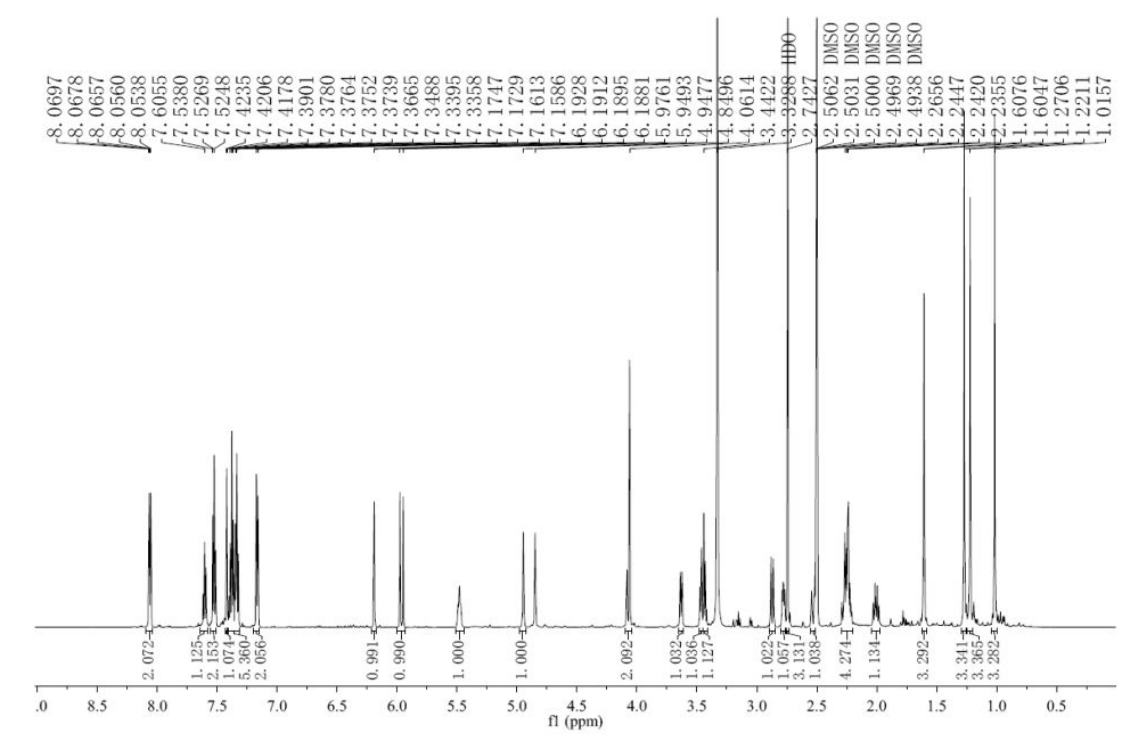

Figure S49. ${ }^{1} \mathrm{H}$ NMR spectrum of Meliazedarine F (6) in DMSO- $d_{6}$
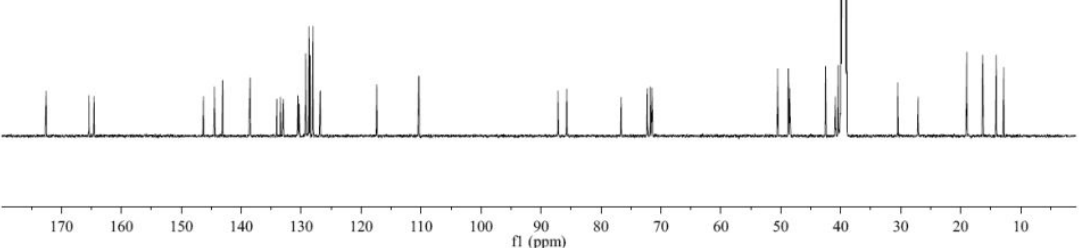

Figure S50. ${ }^{13} \mathrm{C}$ NMR spectrum of Meliazedarine F (6) in DMSO- $d_{6}$

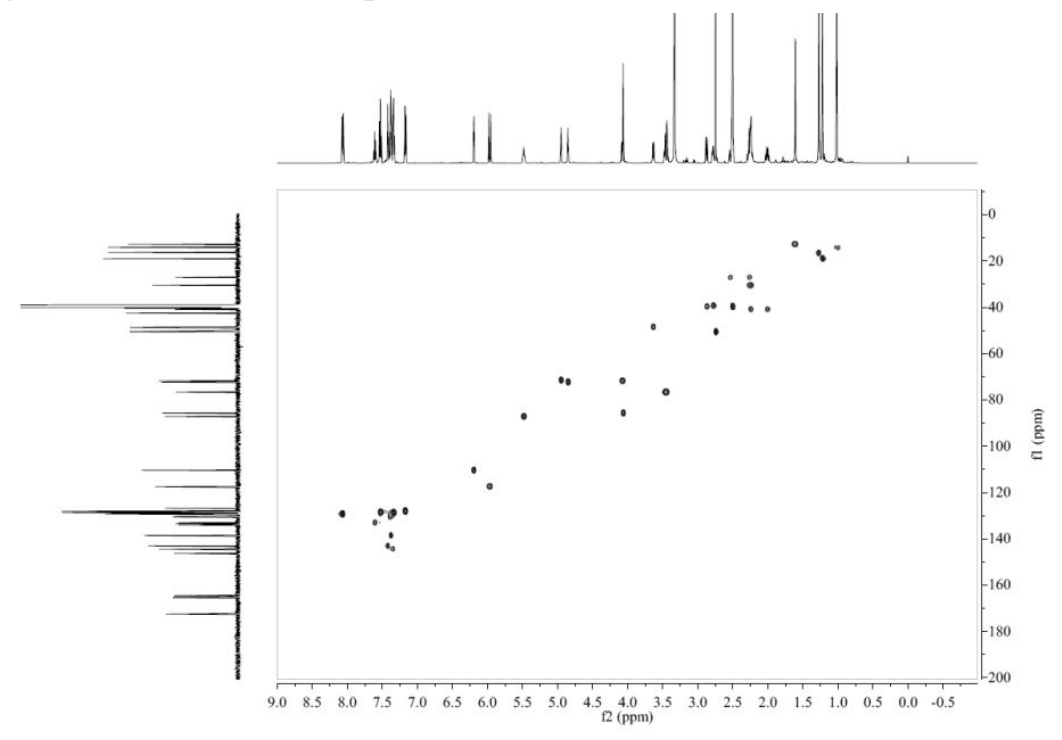

Figure S51. HSQC spectrum of Meliazedarine F (6) in DMSO- $d_{6}$ 


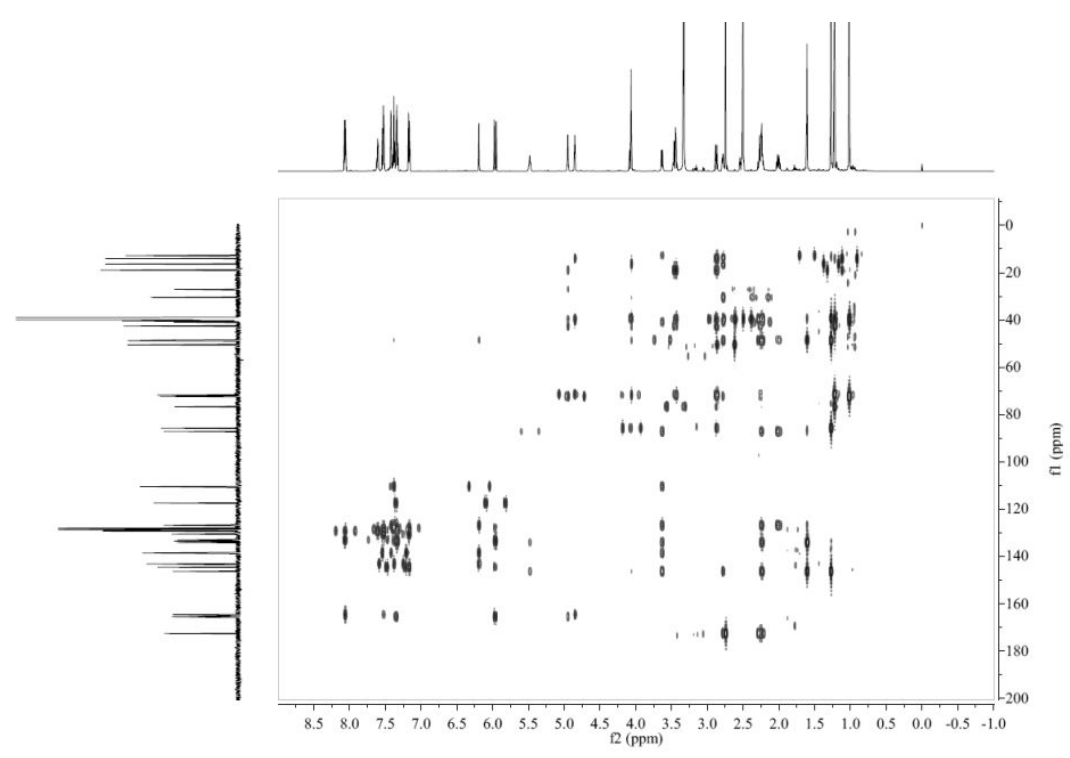

Figure S52. HMBC spectrum of Meliazedarine F (6) in DMSO- $d_{6}$

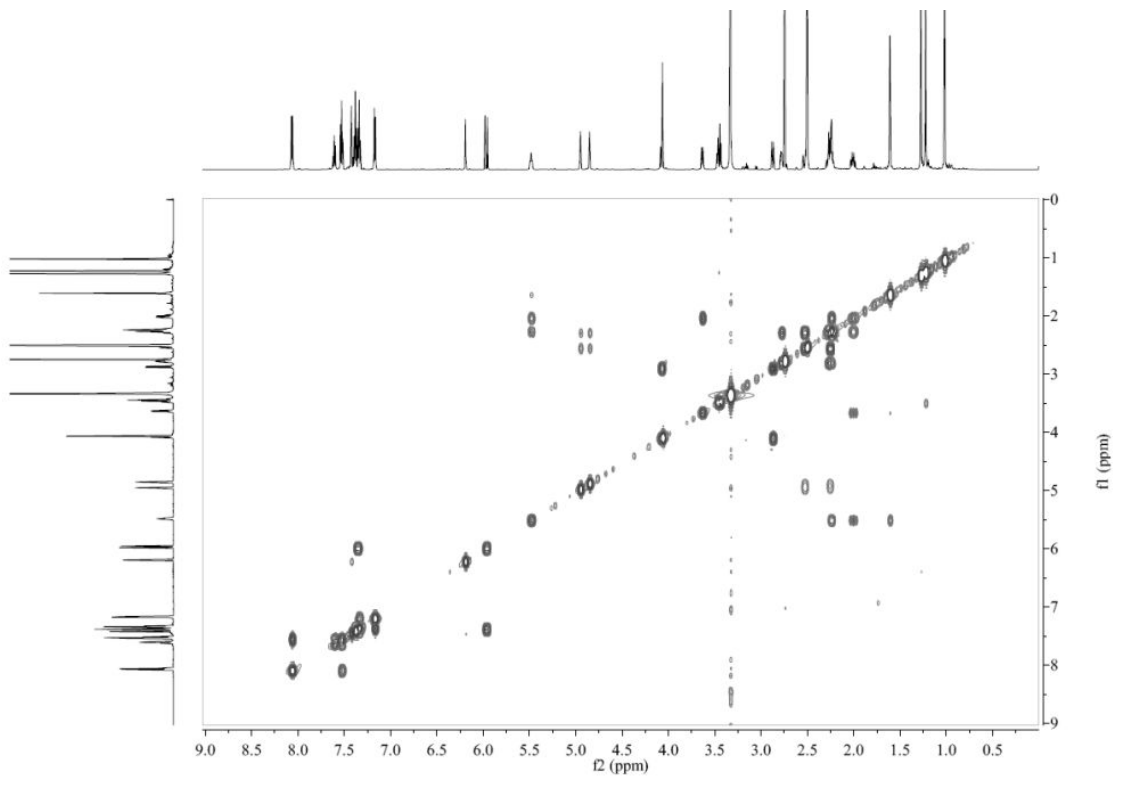

Figure S53. ${ }^{1} \mathrm{H}-{ }^{1} \mathrm{H}$ COSY spectrum of Meliazedarine F (6) in DMSO- $d_{6}$

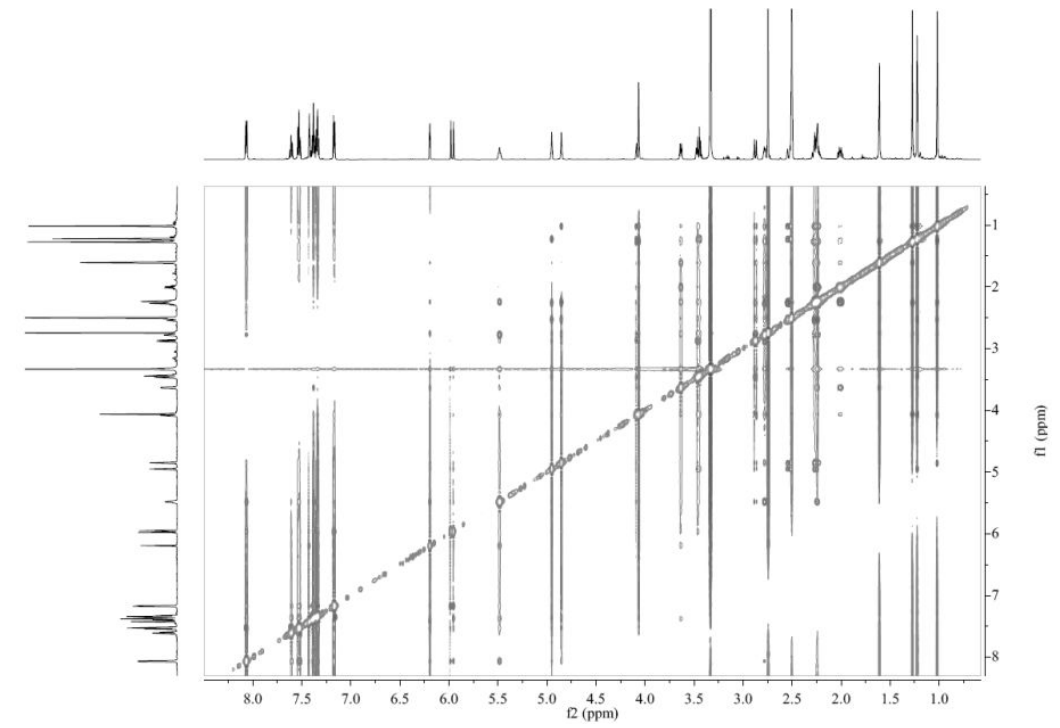

Figure S54. ROESY spectrum of Meliazedarine F (6) in DMSO- $d_{6}$ 


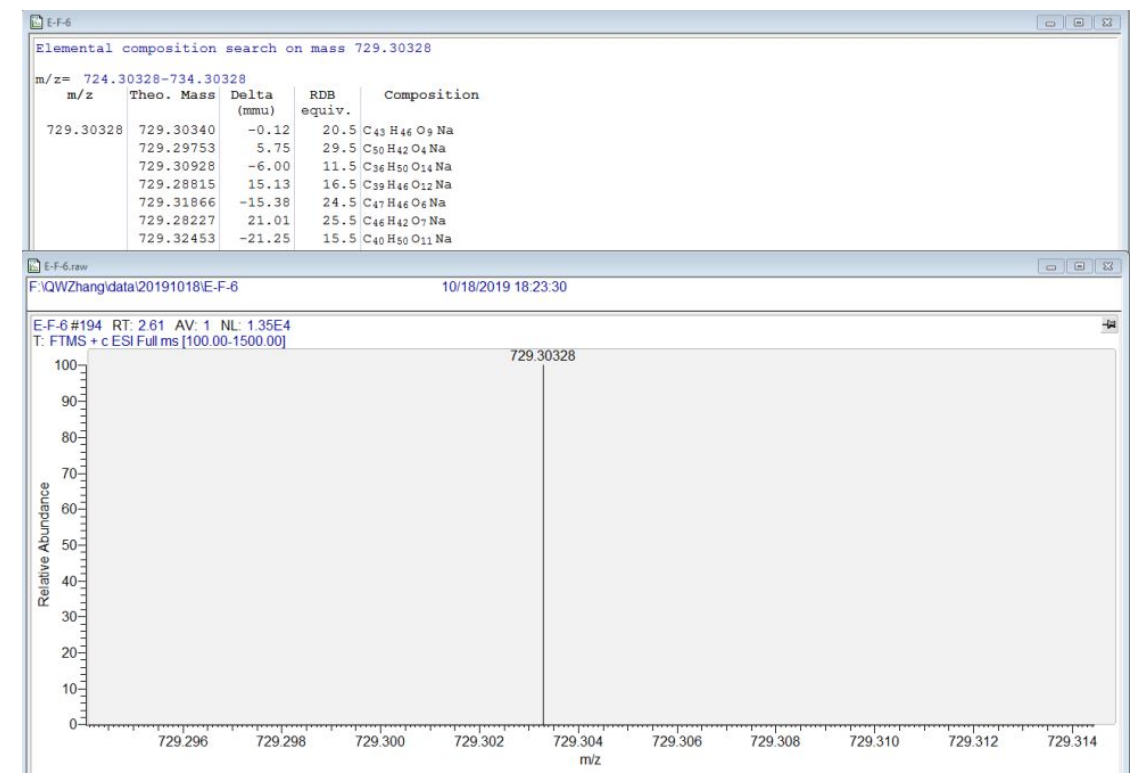

Figure S55. (+)-HRESIMS spectrum of Meliazedarine F (6)

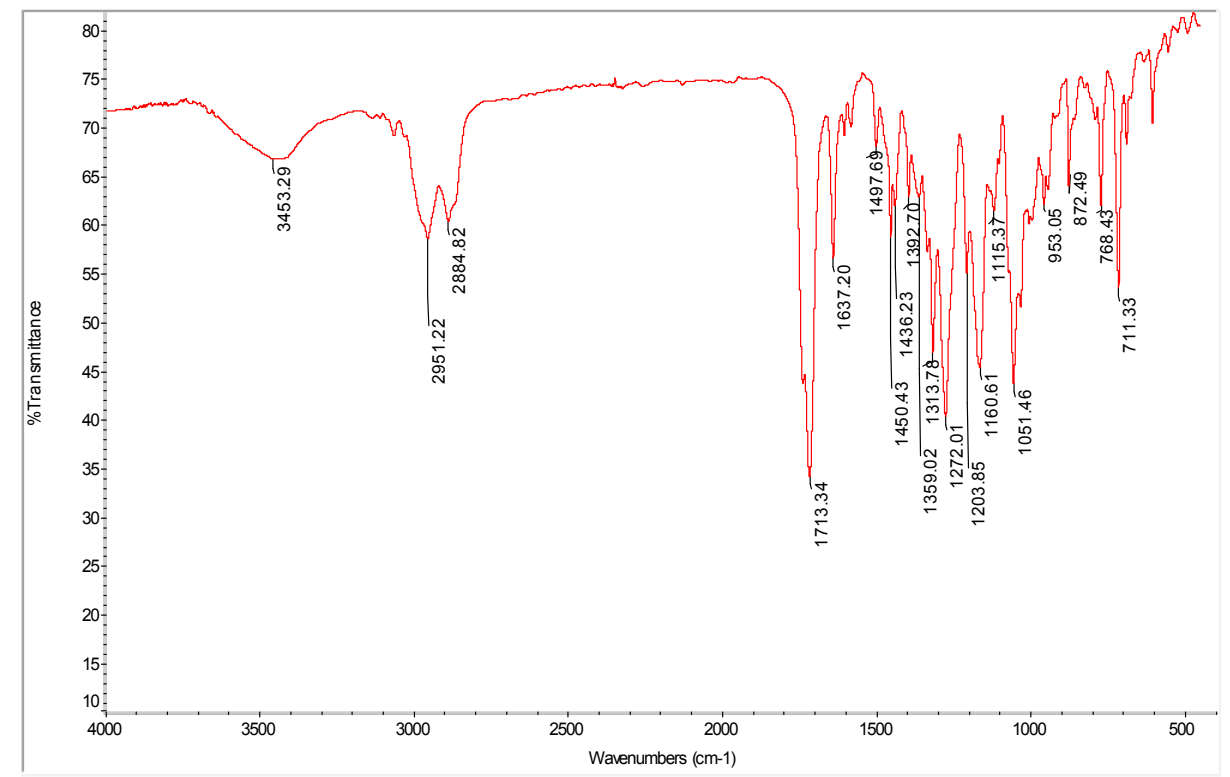

Figure S56. IR spectrum of Meliazedarine F (6)

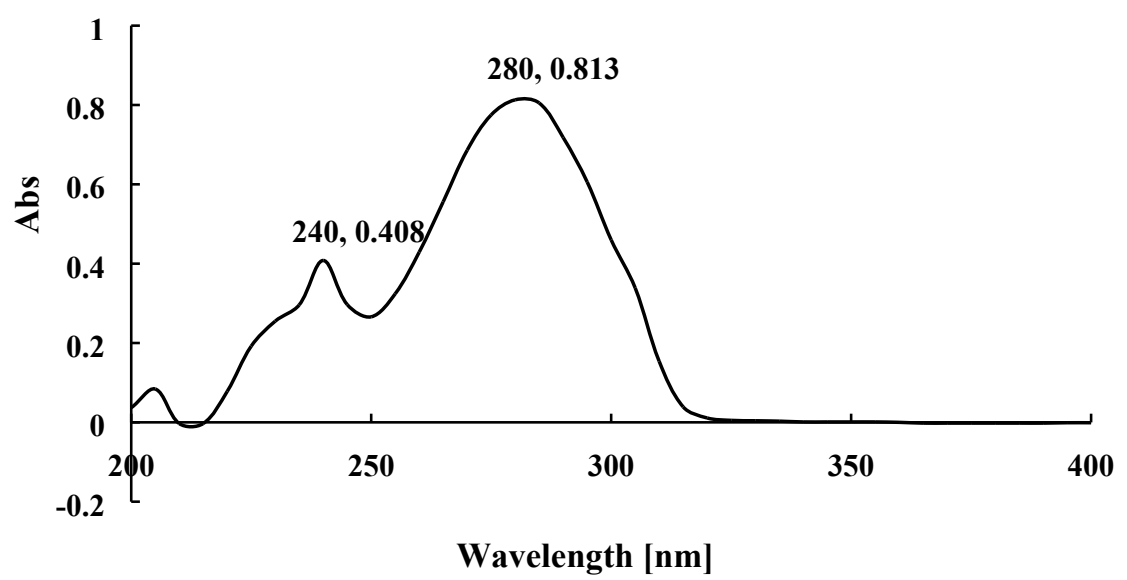

Figure S57. UV spectrum of Meliazedarine $\mathrm{F}(6)$ in $\mathrm{CHCl}_{3}$ 


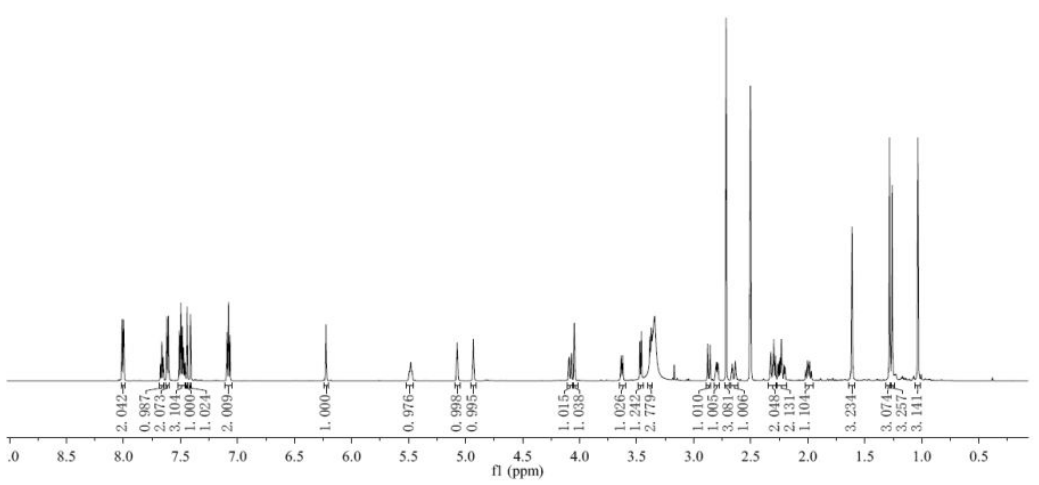

Figure S58. ${ }^{1} \mathrm{H}$ NMR spectrum of Meliazedarine G (7) in DMSO- $d_{6}$

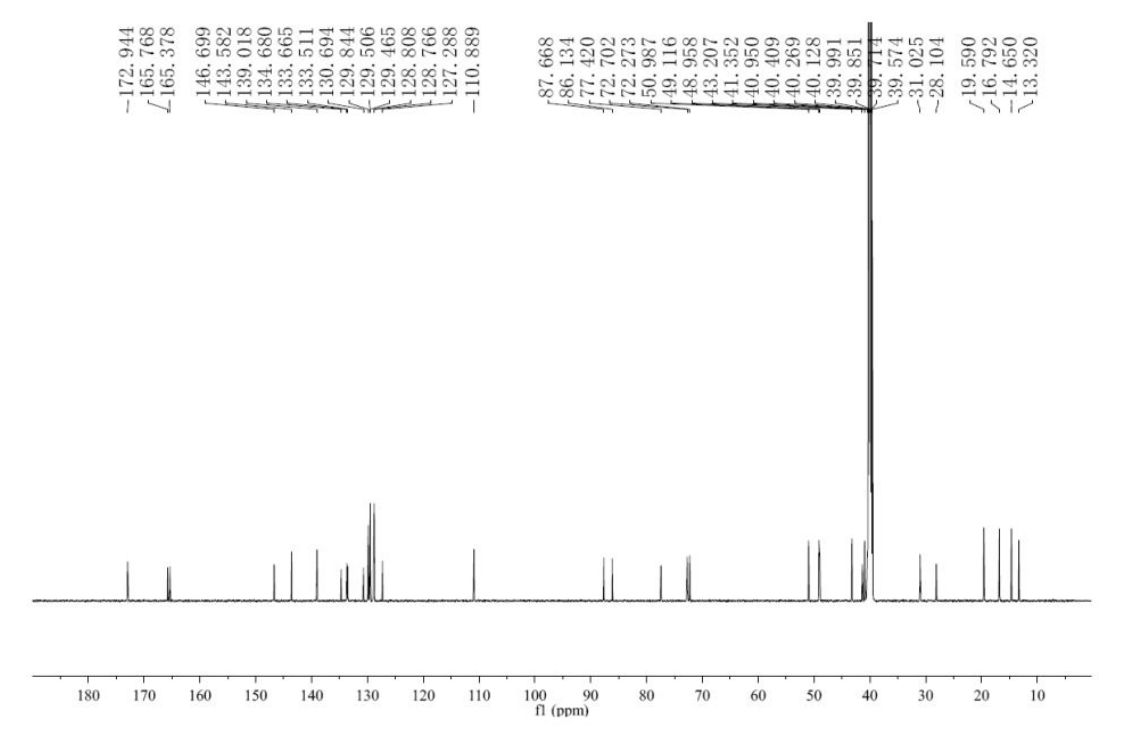

Figure S59. ${ }^{13} \mathrm{C}$ NMR spectrum of Meliazedarine G (7) in DMSO- $d_{6}$

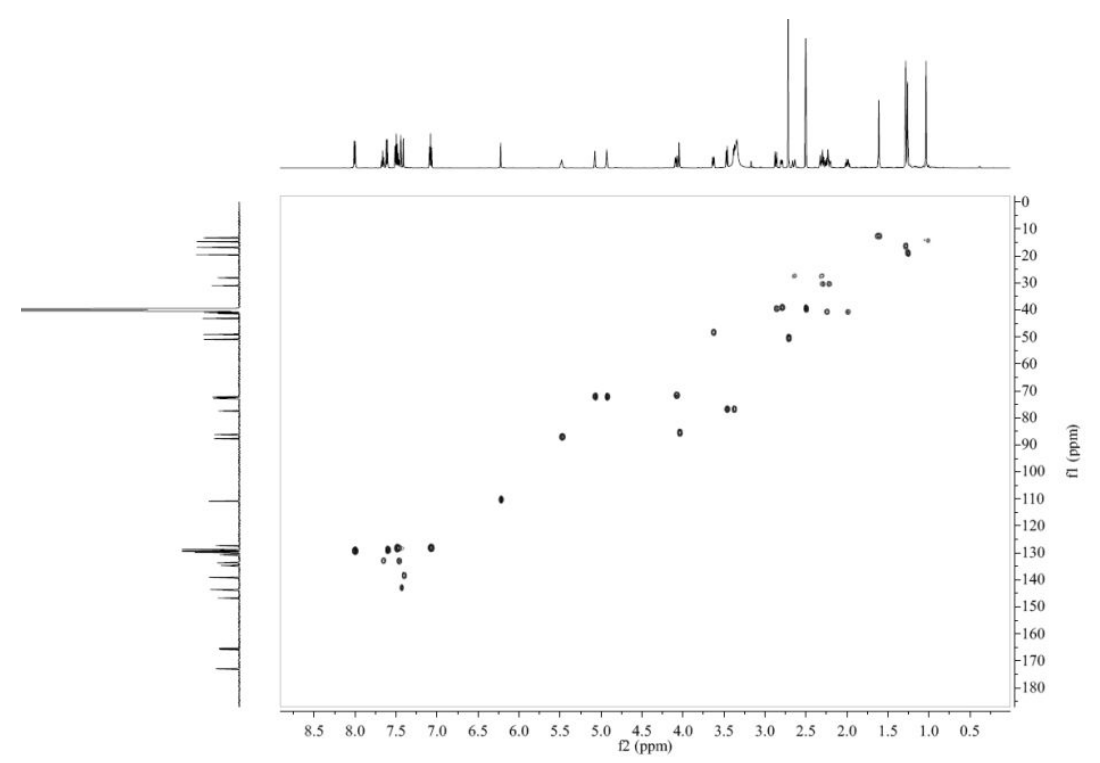

Figure S60. HSQC spectrum of Meliazedarine G (7) in DMSO- $d_{6}$ 


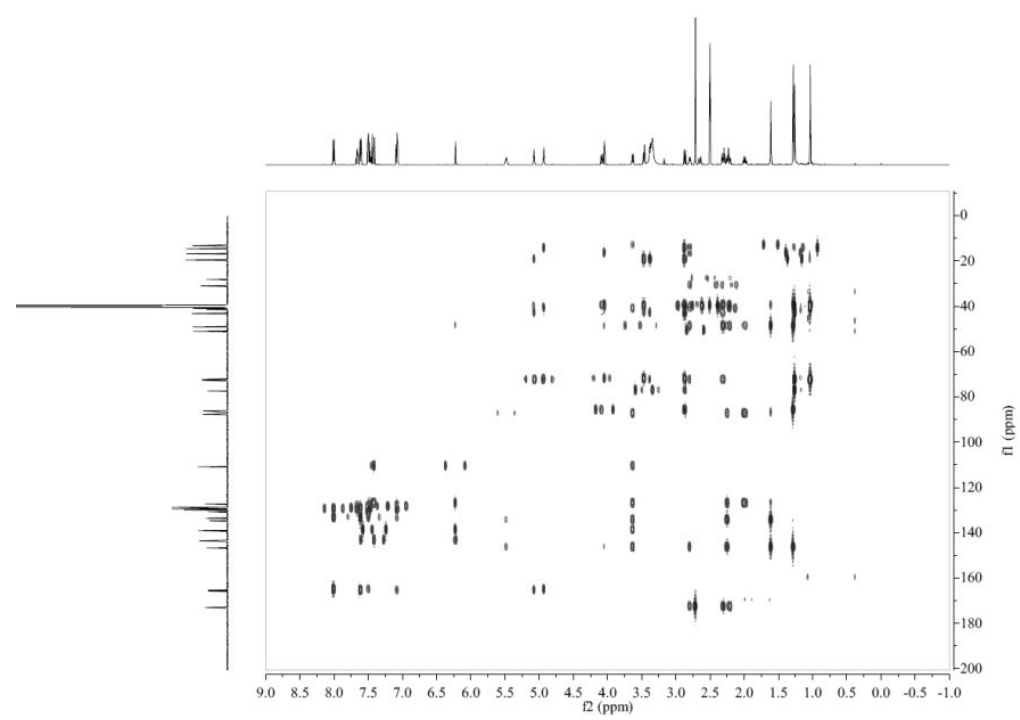

Figure S61. HMBC spectrum of Meliazedarine G (7) in DMSO- $d_{6}$

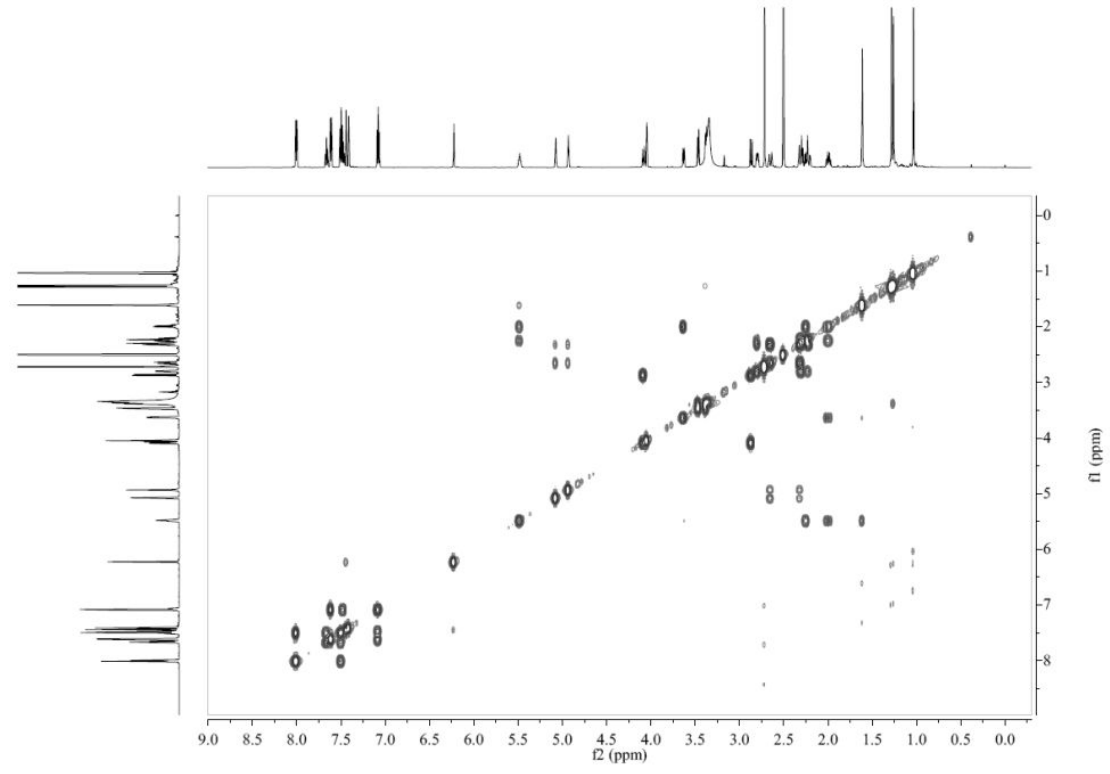

Figure S62. ${ }^{1} \mathrm{H}-{ }^{1} \mathrm{H}$ COSY spectrum of Meliazedarine G (7) in DMSO- $d_{6}$

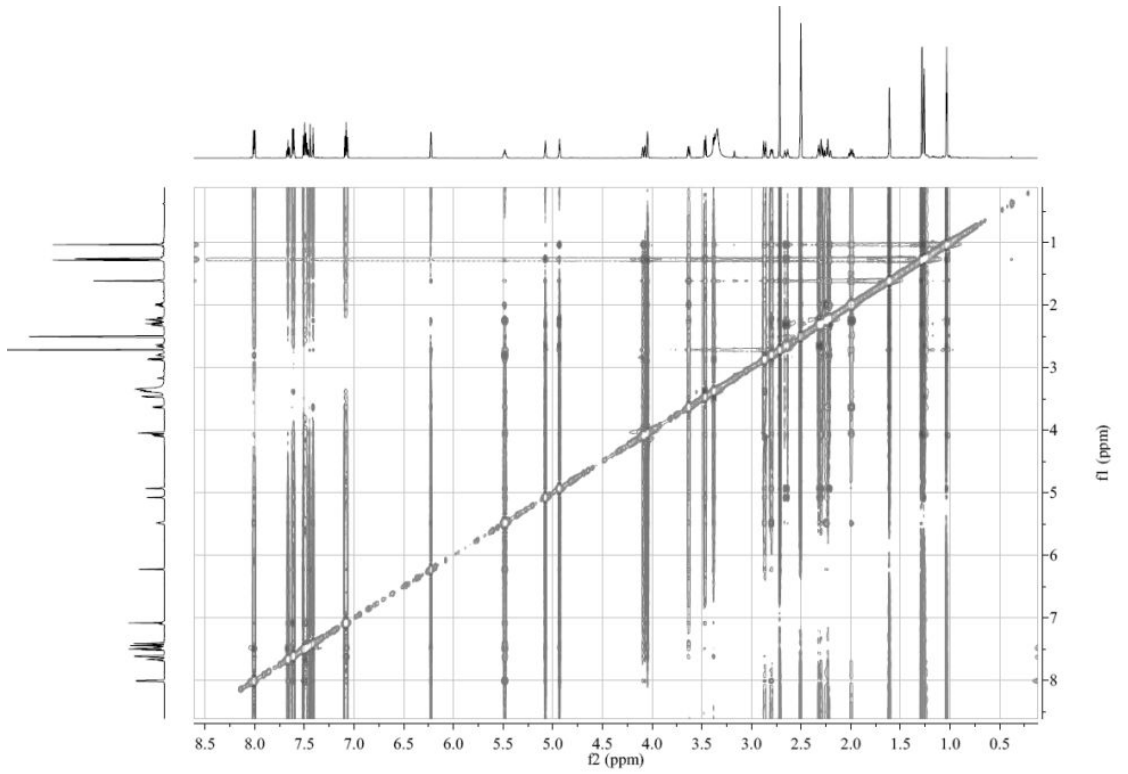

Figure S63. ROESY spectrum of Meliazedarine G (7) in DMSO- $d_{6}$ $29 / 36$ 


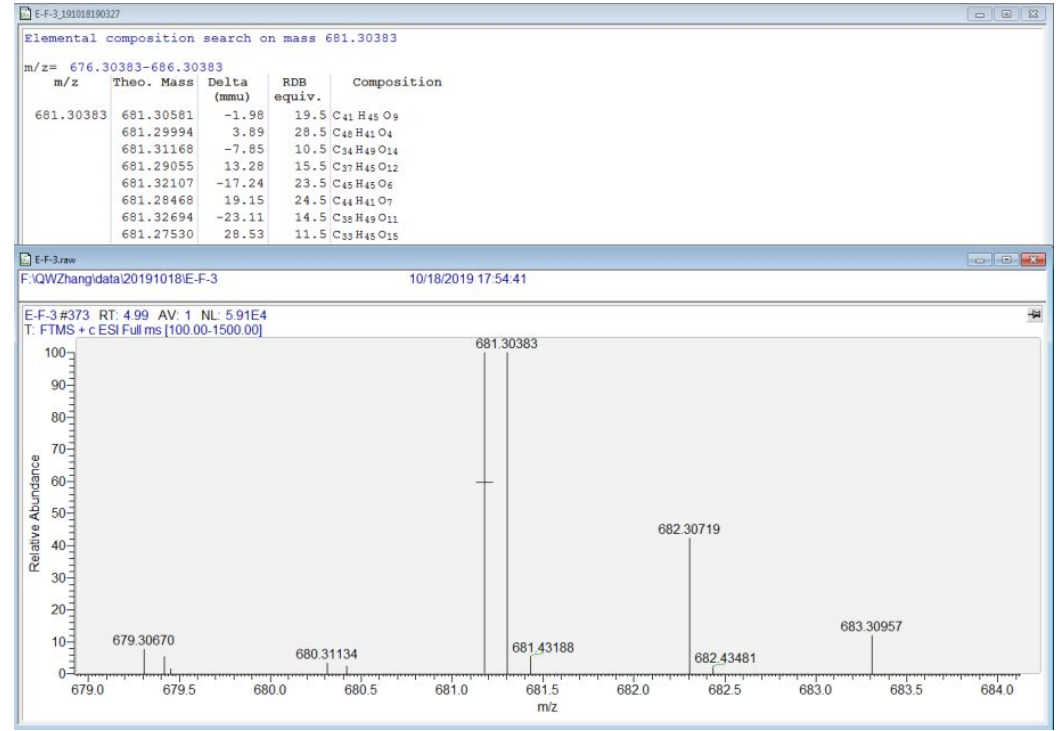

Figure S64. (+)-HRESIMS spectrum of Meliazedarine G (7)

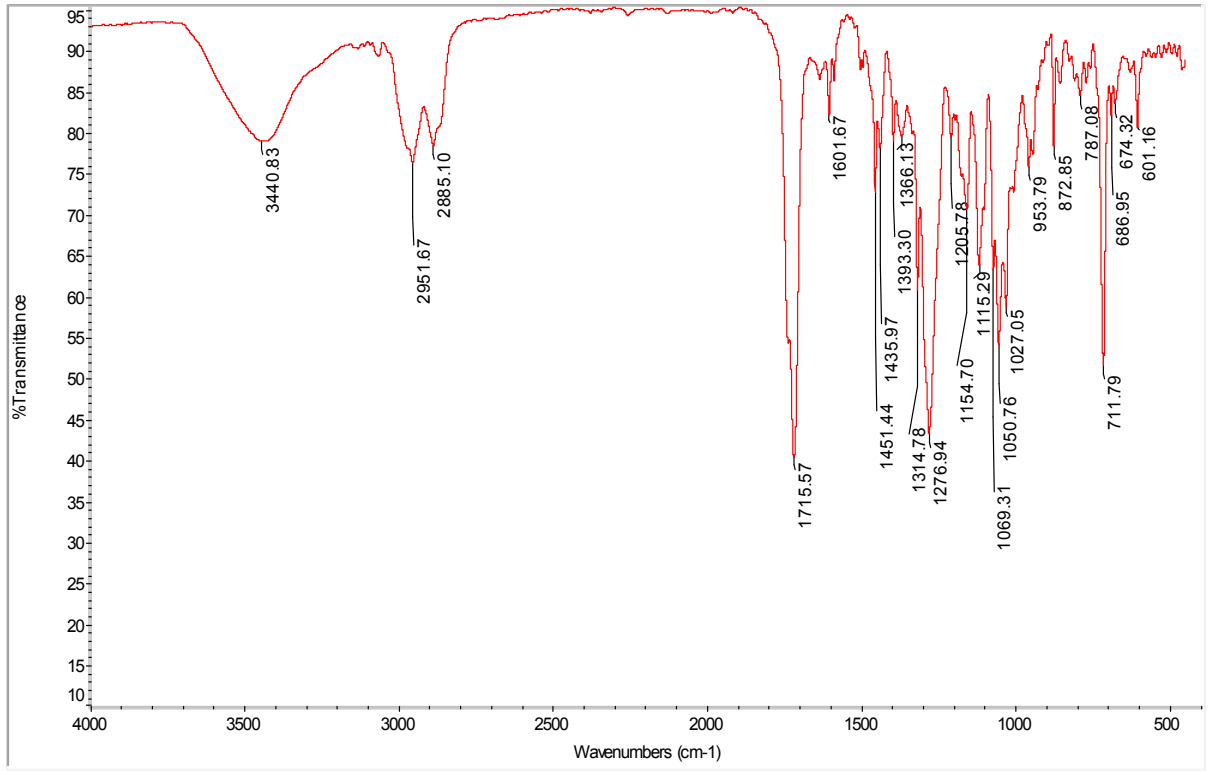

Figure S65. IR spectrum of Meliazedarine G (7)

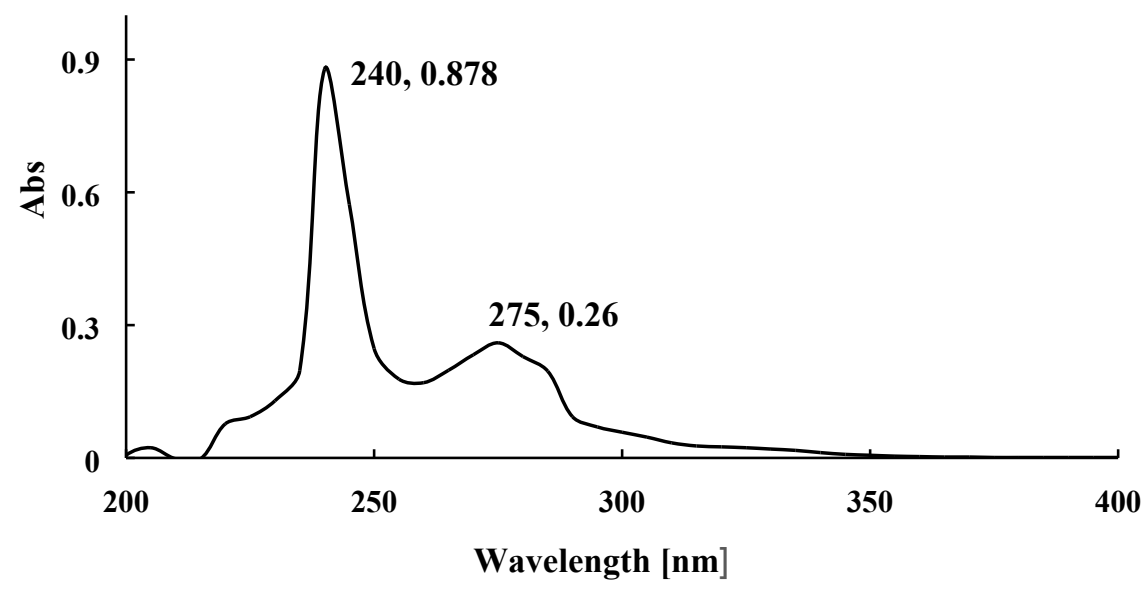

Figure S66. UV spectrum of Meliazedarine $\mathrm{G}(7)$ in $\mathrm{CHCl}_{3}$ 


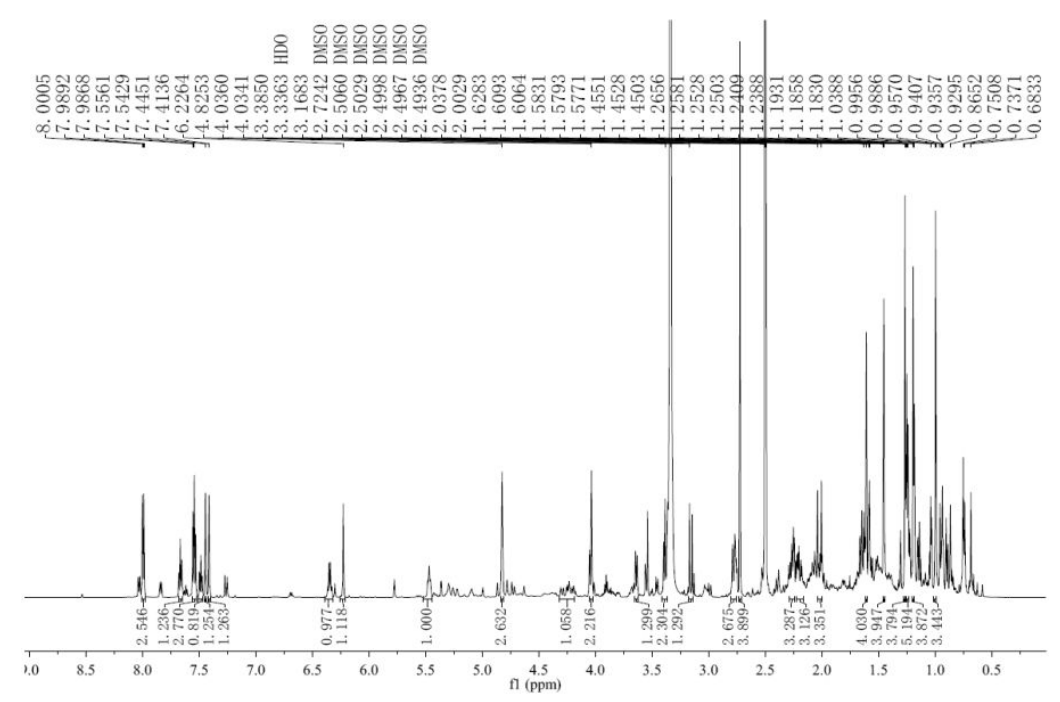

Figure S67. ${ }^{1} \mathrm{H}$ NMR spectrum of Meliazedarine H (8) in DMSO- $d_{6}$

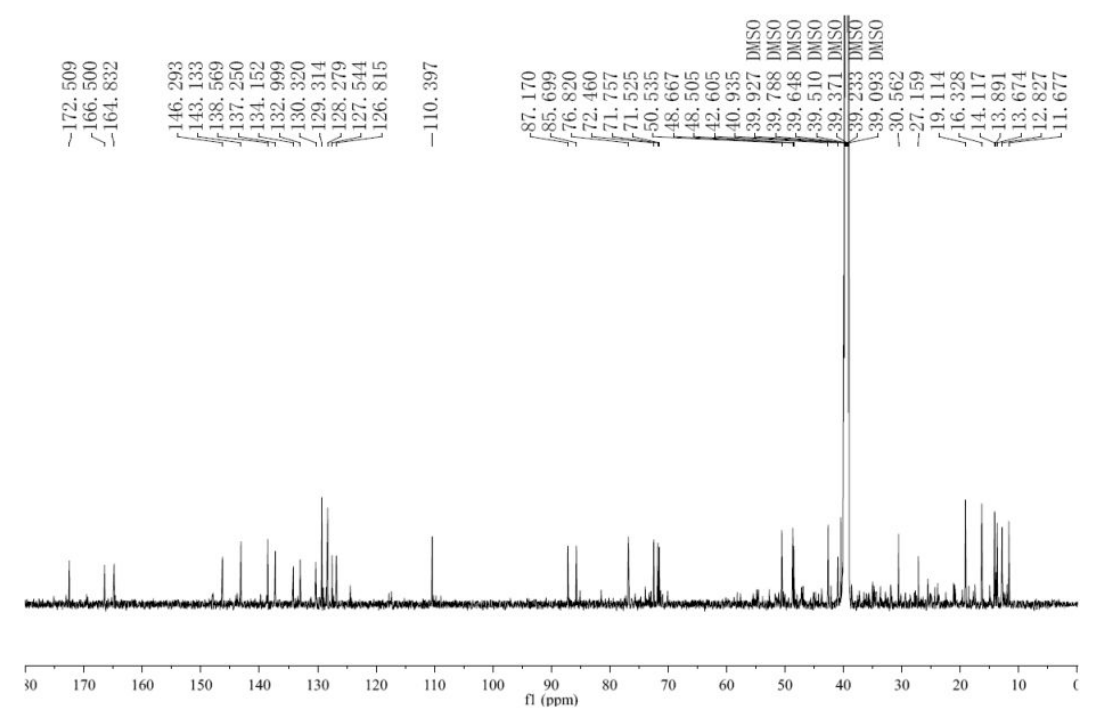

Figure S68. ${ }^{13} \mathrm{C}$ NMR spectrum of Meliazedarine H (8) in DMSO- $d_{6}$

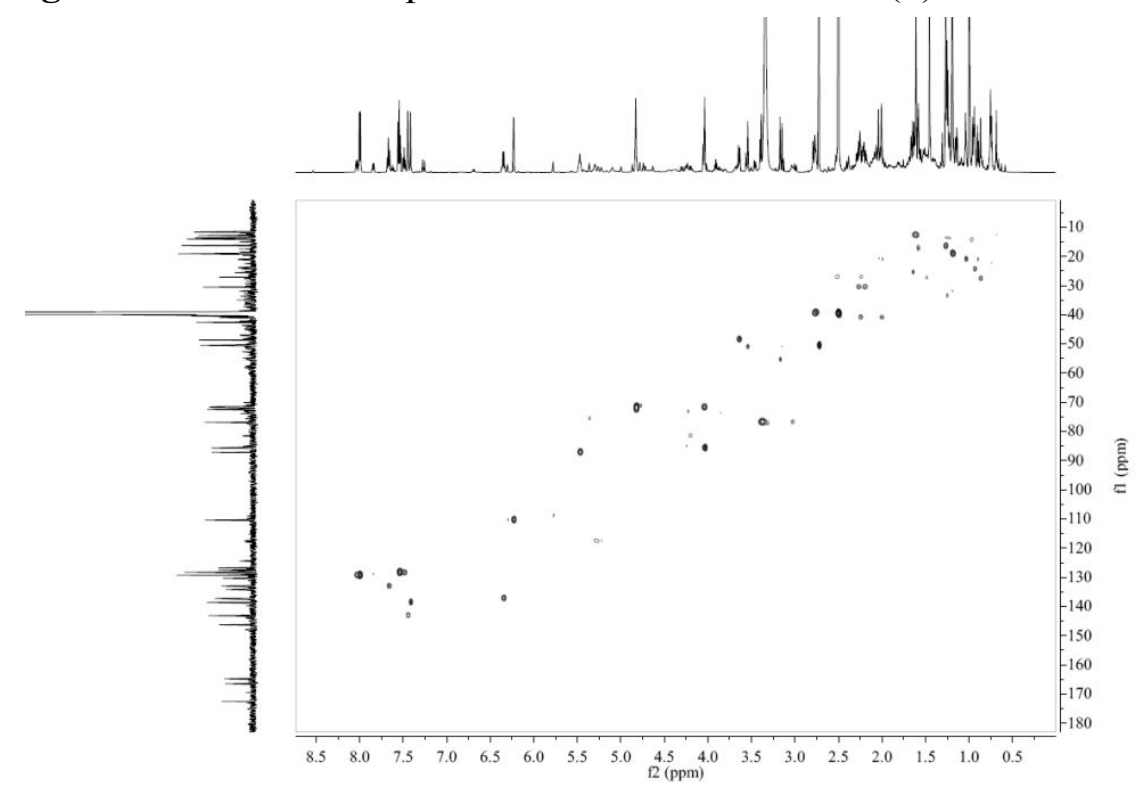

Figure S69. HSQC spectrum of Meliazedarine H (8) in DMSO- $d_{6}$ 


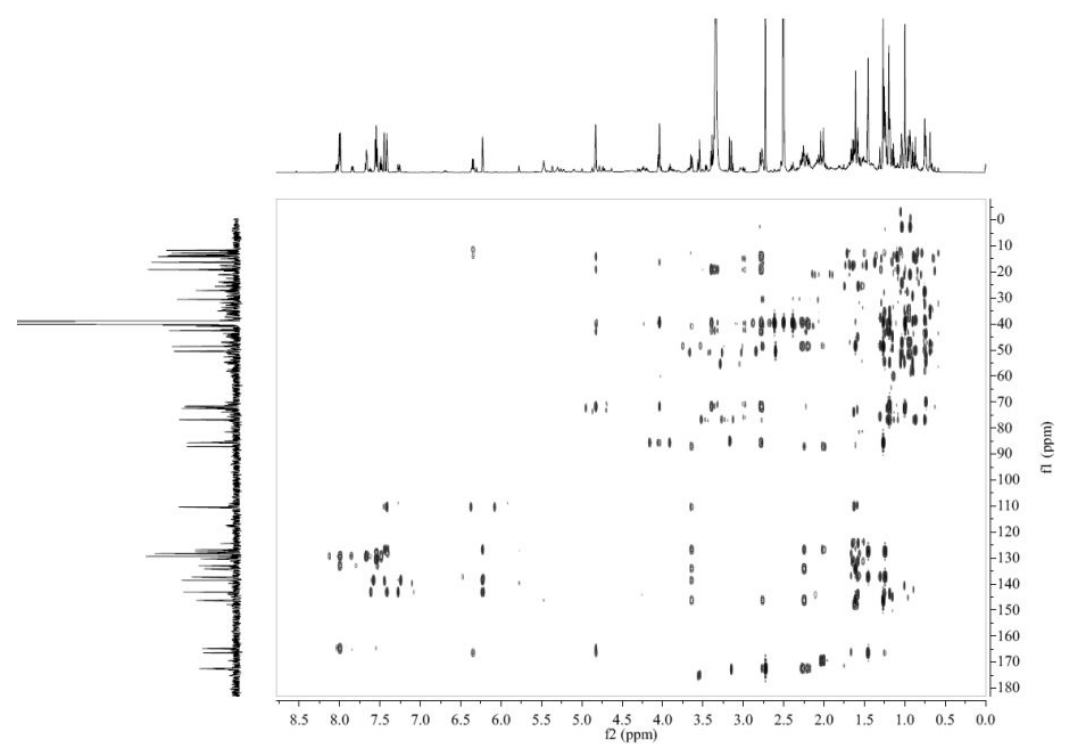

Figure S70. HMBC spectrum of Meliazedarine H (8) in DMSO- $d_{6}$

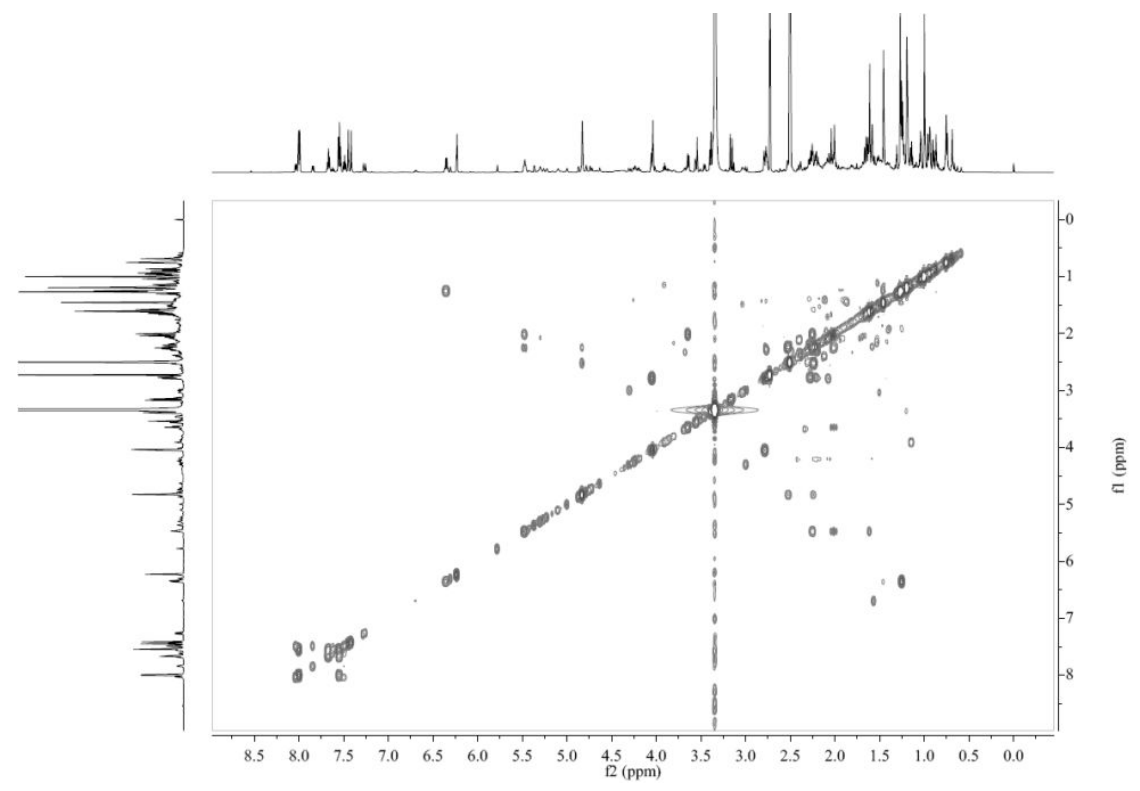

Figure S71. ${ }^{1} \mathrm{H}-{ }^{1} \mathrm{H}$ COSY spectrum of Meliazedarine H (8) in DMSO- $d_{6}$

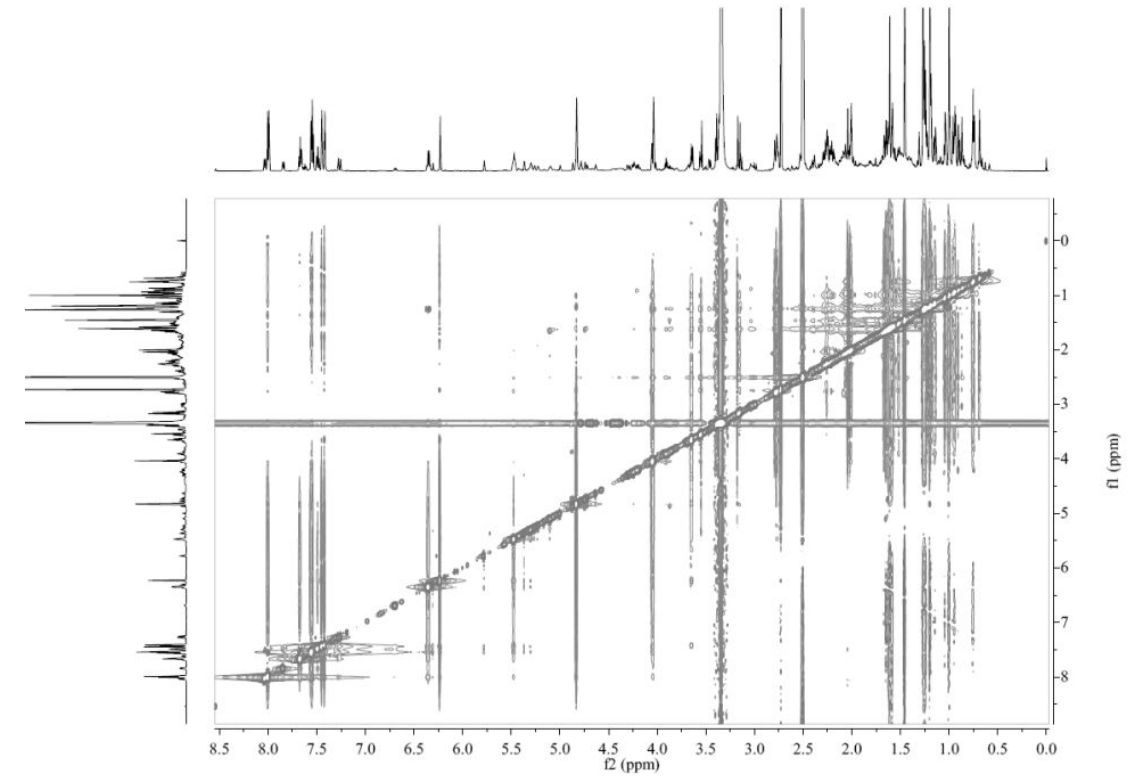

Figure S72. ROESY spectrum of Meliazedarine H (8) in DMSO- $d_{6}$ $32 / 36$ 


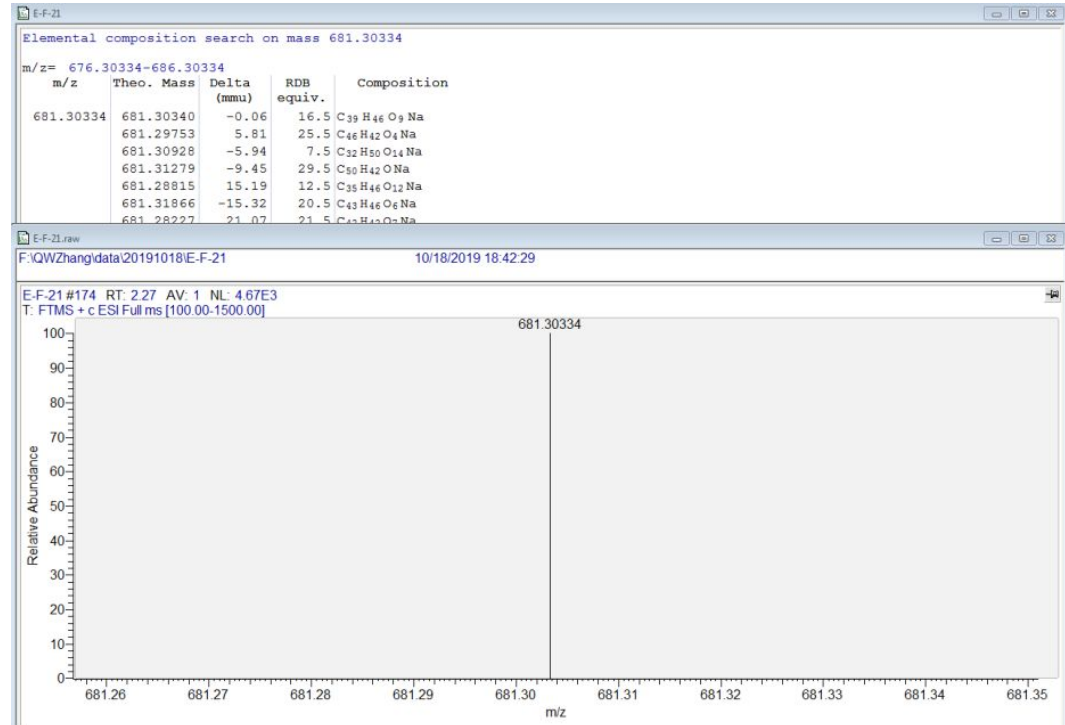

Figure S73. (+)-HRESIMS spectrum of Meliazedarine H (8)

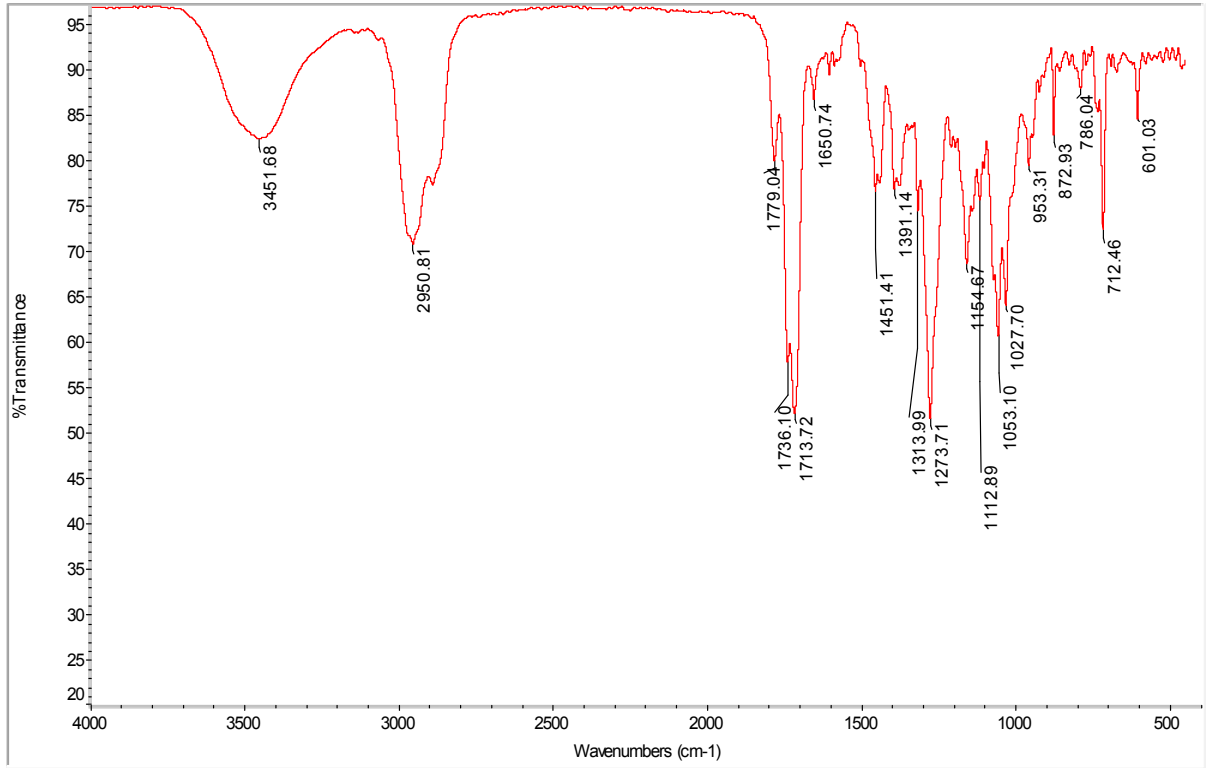

Figure S74. IR spectrum of Meliazedarine H (8)

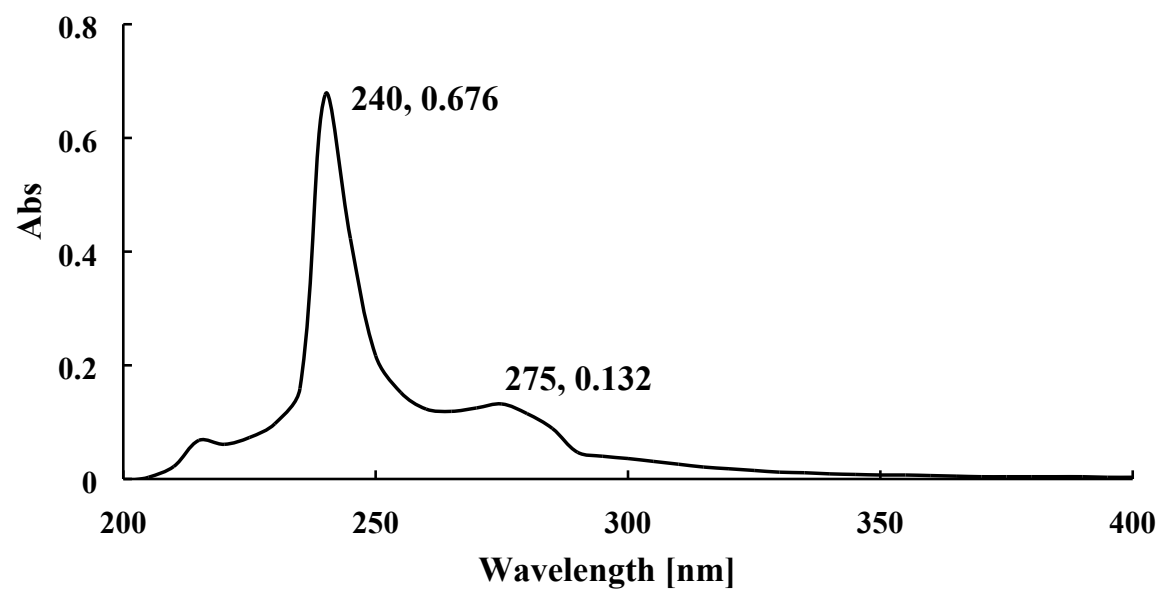

Figure S75. UV spectrum of Meliazedarine $\mathrm{H}(8)$ in $\mathrm{CHCl}_{3}$ 


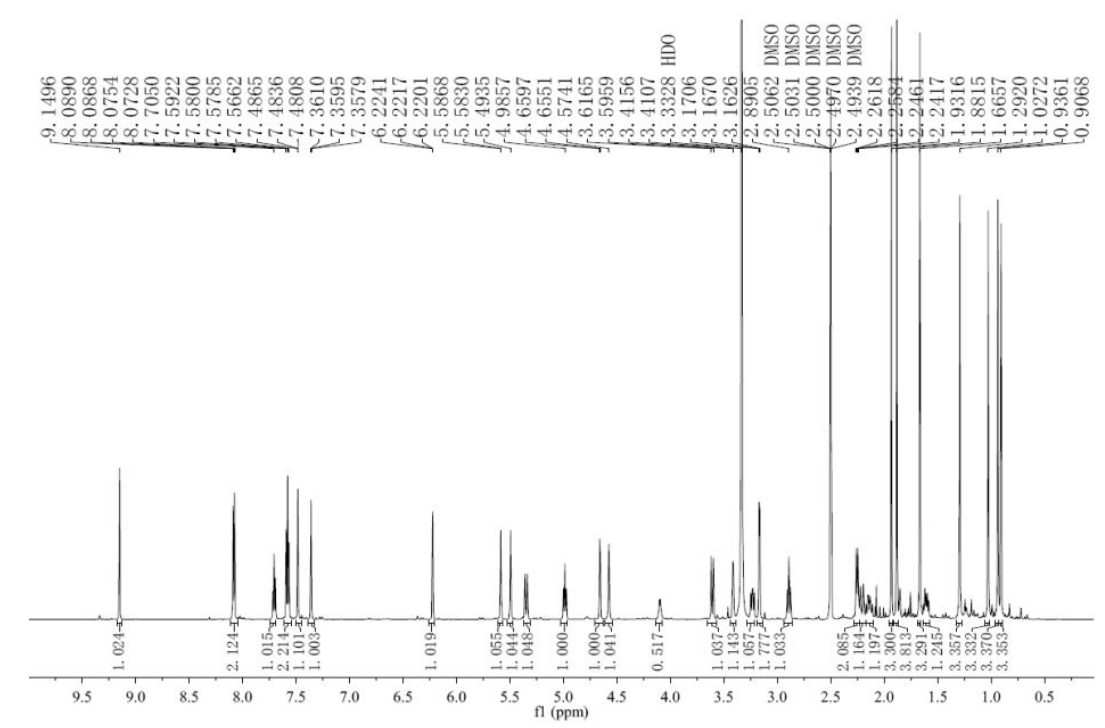

Figure S76. ${ }^{1} \mathrm{H}$ NMR spectrum of Meliazedarine I (9) in DMSO- $d_{6}$

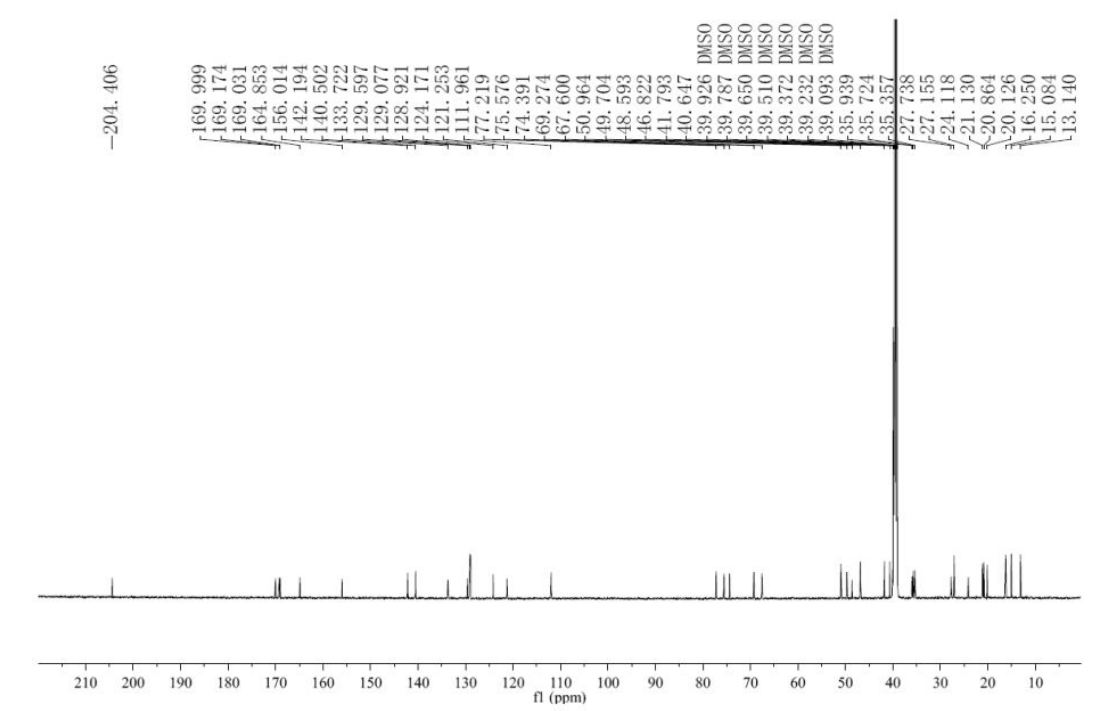

Figure S77. ${ }^{13} \mathrm{C}$ NMR spectrum of Meliazedarine I (9) in DMSO- $d_{6}$

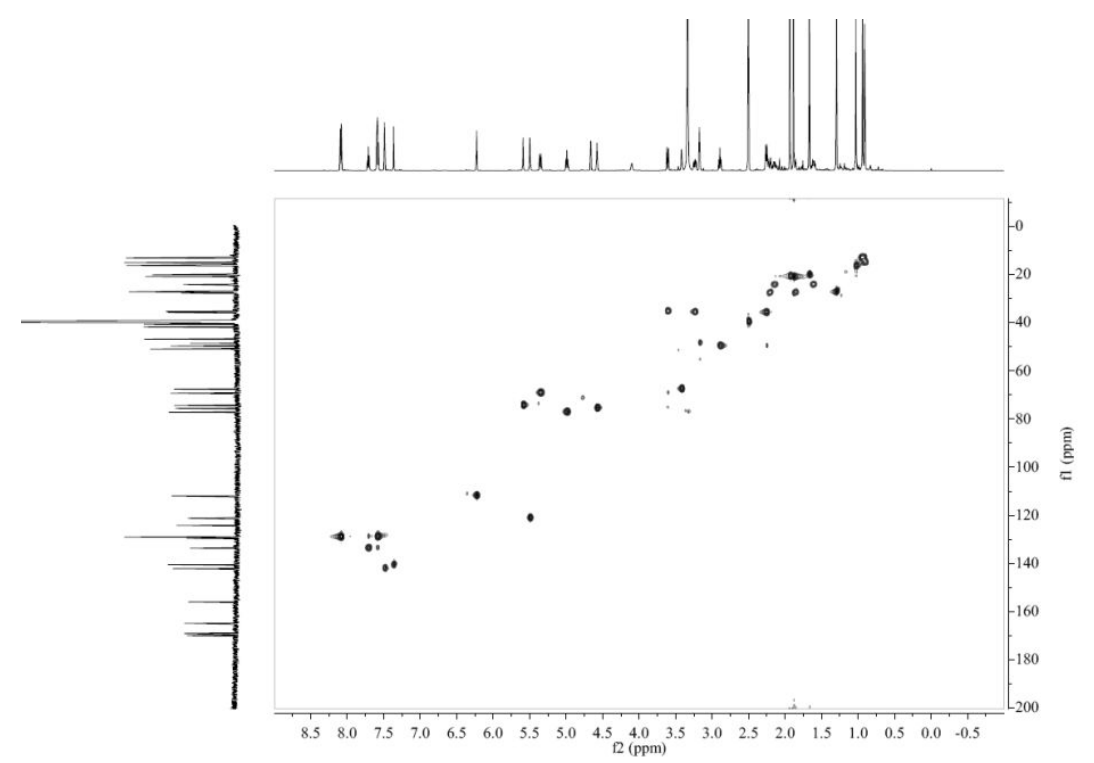

Figure S78. HSQC spectrum of Meliazedarine I (9) in DMSO- $d_{6}$ 


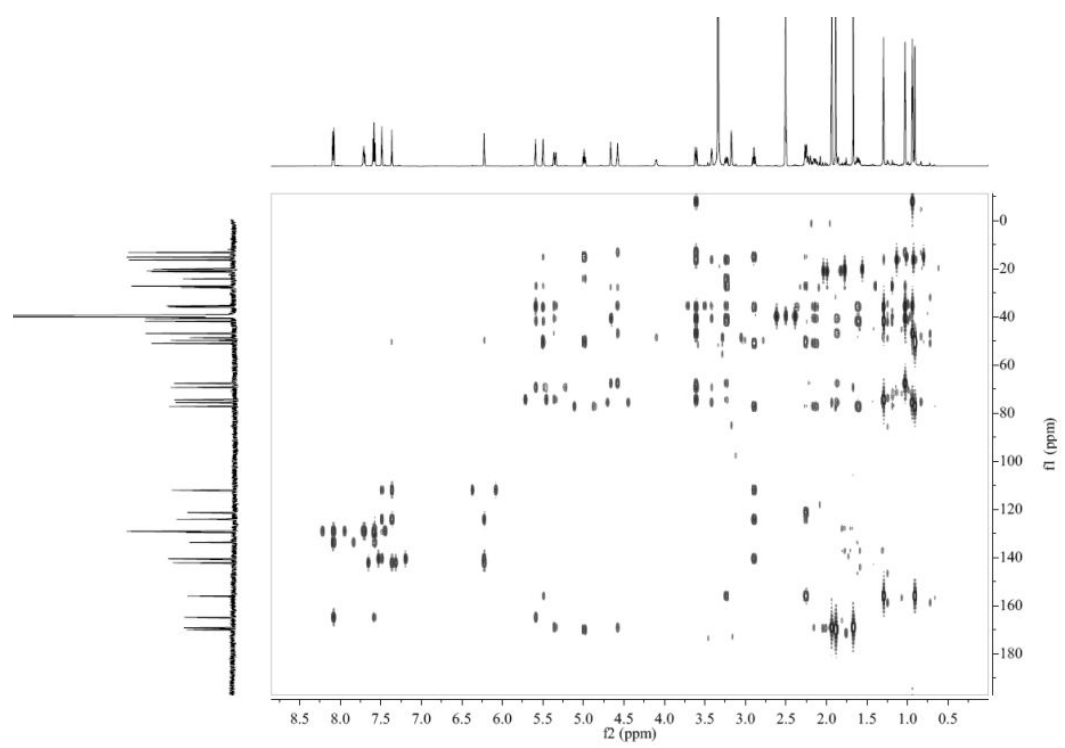

Figure S79. HMBC spectrum of Meliazedarine I (9) in DMSO- $d_{6}$

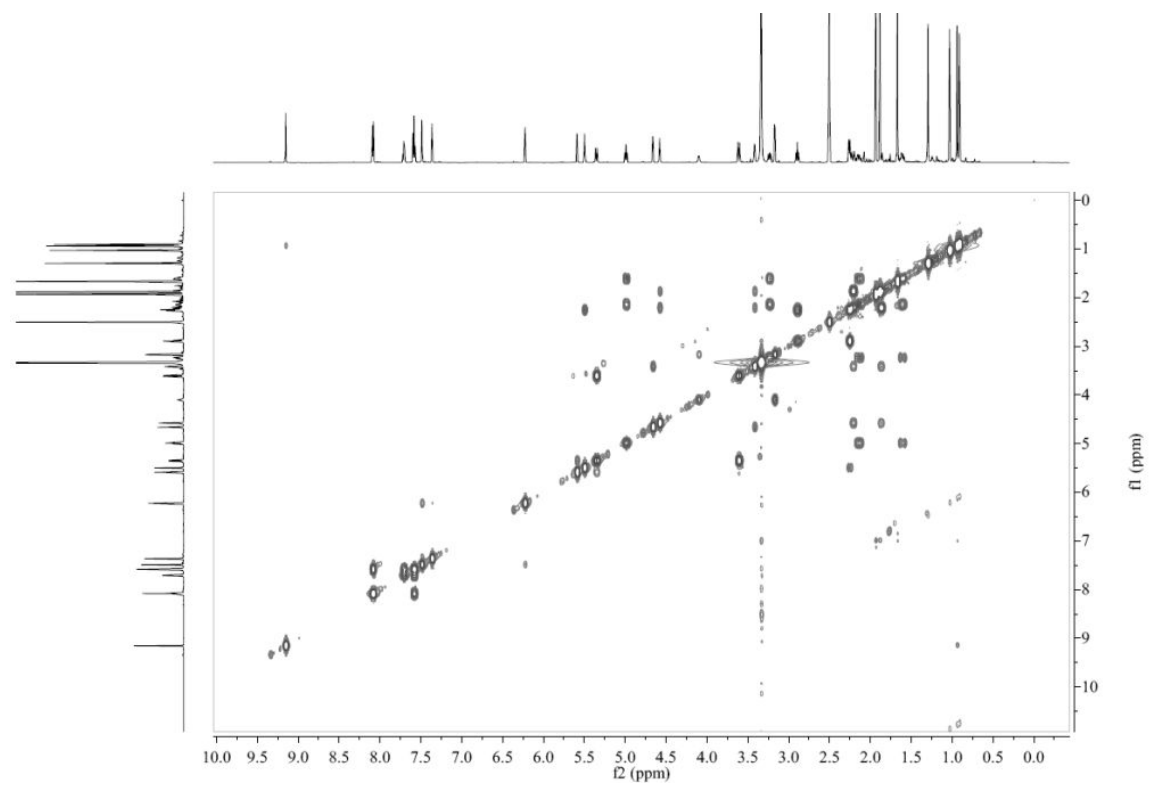

Figure S80. ${ }^{1} \mathrm{H}-{ }^{1} \mathrm{H}$ COSY spectrum of Meliazedarine I (9) in DMSO- $d_{6}$

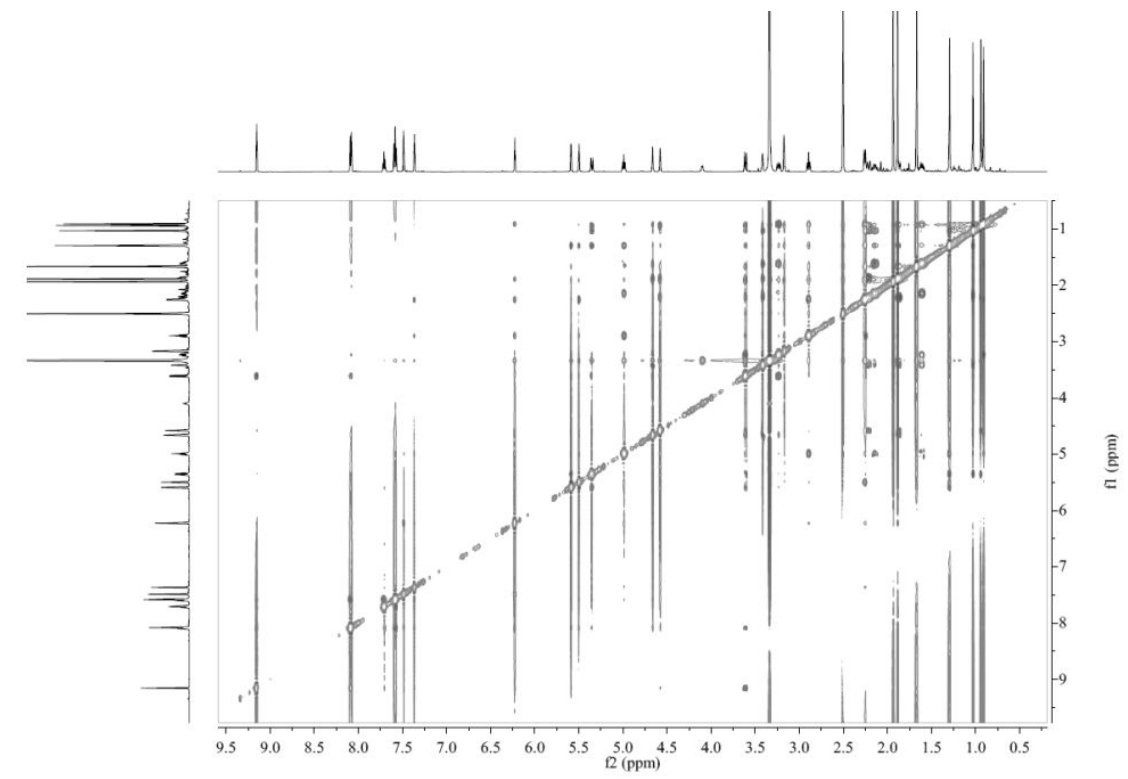

Figure S81. ROESY spectrum of Meliazedarine I (9) in DMSO- $d_{6}$ 


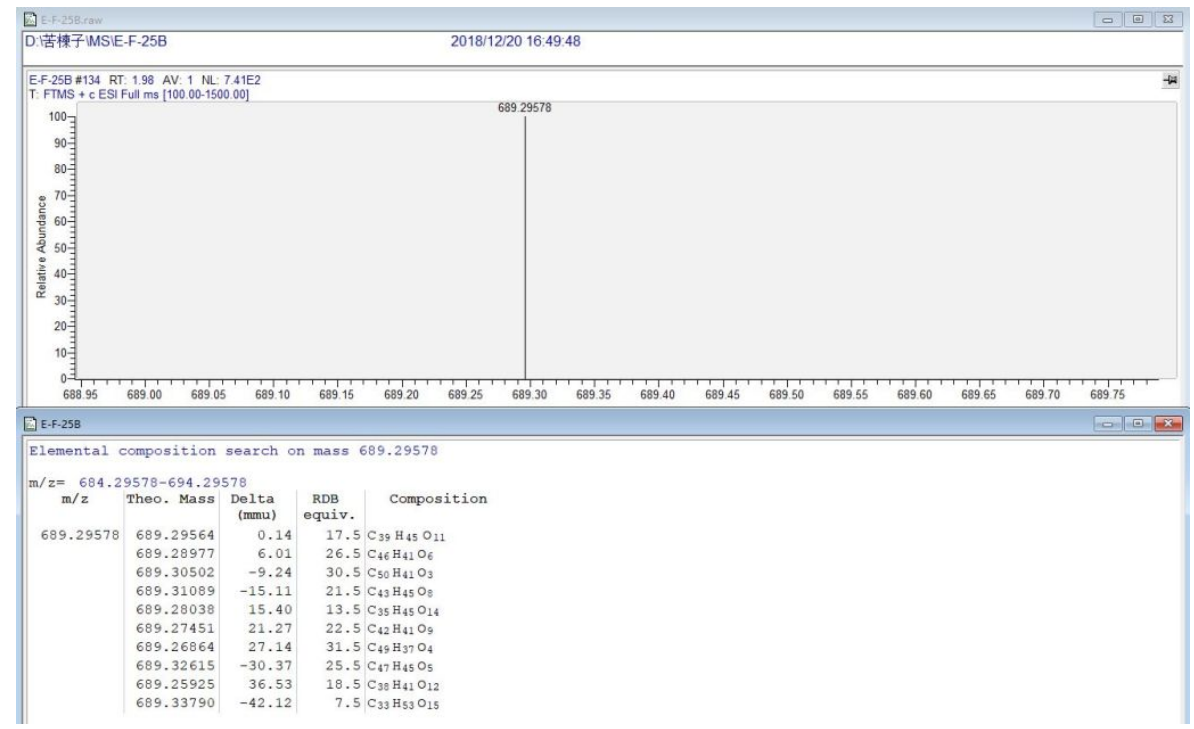

Figure S82. (+)-HRESIMS spectrum of Meliazedarine I (9)

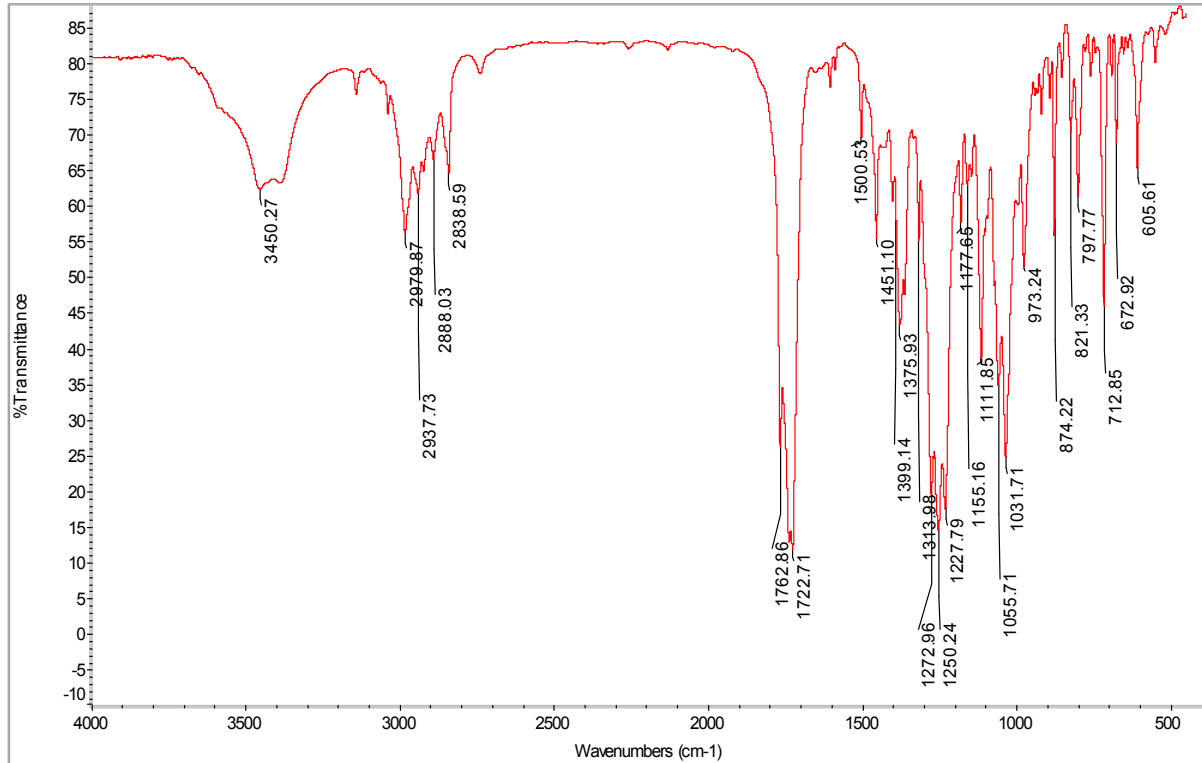

Figure S83. IR spectrum of Meliazedarine I (9)

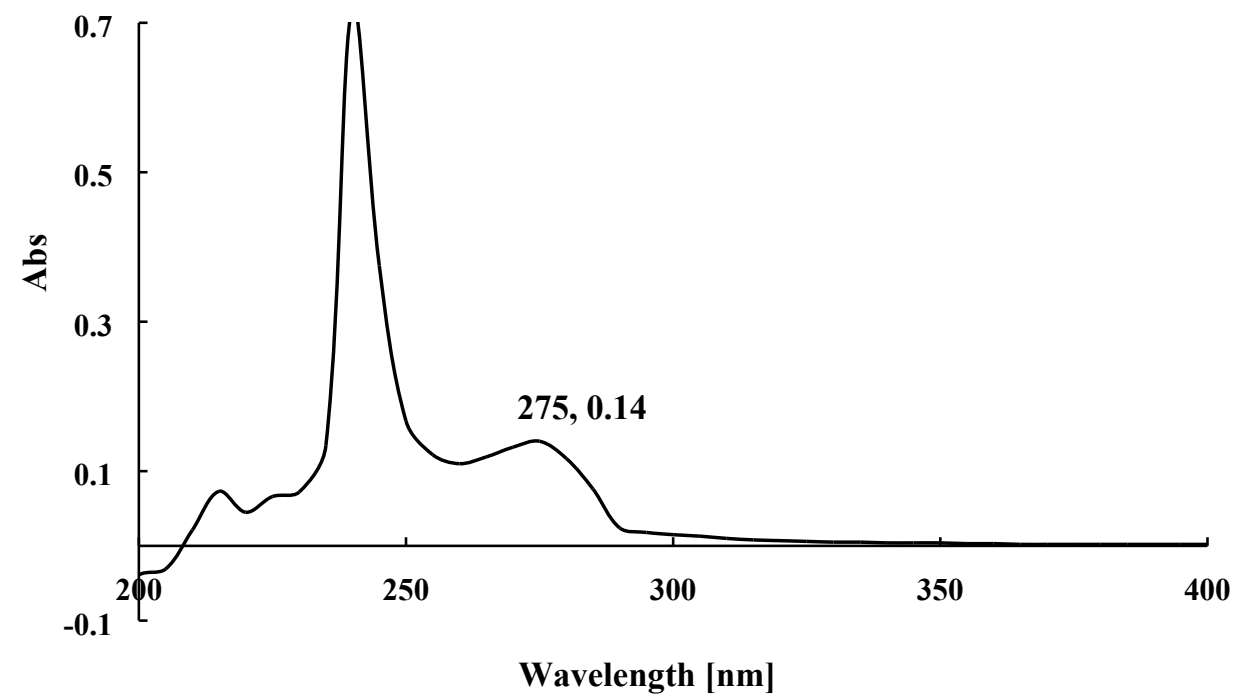

Figure S84. UV spectrum of Meliazedarine I (9) in $\mathrm{CHCl}_{3}$ 